University of Louisville

ThinkIR: The University of Louisville's Institutional Repository

Electronic Theses and Dissertations

$12-2010$

\title{
Cigarette smoke, DNA damage and repair in human cervical and vaginal cells in vitro and ex vivo.
}

Afsoon Moktar

University of Louisville

Follow this and additional works at: https://ir.library.louisville.edu/etd

\section{Recommended Citation}

Moktar, Afsoon, "Cigarette smoke, DNA damage and repair in human cervical and vaginal cells in vitro and ex vivo." (2010). Electronic Theses and Dissertations. Paper 999.

https://doi.org/10.18297/etd/999

This Doctoral Dissertation is brought to you for free and open access by ThinkIR: The University of Louisville's Institutional Repository. It has been accepted for inclusion in Electronic Theses and Dissertations by an authorized administrator of ThinkIR: The University of Louisville's Institutional Repository. This title appears here courtesy of the author, who has retained all other copyrights. For more information, please contact thinkir@louisville.edu. 


\title{
CIGARETTE SMOKE, DNA DAMAGE AND REPAIR IN HUMAN CERVICAL AND VAGINAL CELLS IN VITRO AND EX VIVO
}

\author{
By \\ Afsoon Moktar \\ B.S., University of Tehran \\ B.H.S., University of Louisville \\ M.B.A., Bellarmine University \\ M.S., University of Louisville

\begin{abstract}
A Dissertation
Submitted to the Faculty of the

Graduate School of Medicine of the University of Louisville

in Partial Fulfillment of the Requirements

for the Degree of
\end{abstract} \\ Doctor of Philosophy \\ Department of Pharmacology and Toxicology \\ University of Louisville \\ Louisville, Kentucky
}

December 2010 
Copyright 2010 by Afsoon Moktar

All Rights Reserved 



\title{
CIGARETTE SMOKE, DNA DAMAGE AND REPAIR IN HUMAN CERVICAL AND VAGINAL CELLS IN VITRO AND EX VIVO
}

By

\author{
Afsoon Moktar \\ B.S., University of Tehran \\ B.H.S., University of Louisville \\ M.B.A., Bellarmine University \\ M.S., University of Louisville
}

A Dissertation Approved on

September 17, 2010

By the following Dissertation Committee:

Ramesh C. Gupta, PhD (Dissertation Mentor)

David W. Hein, PhD

Alfred B. Jenson, M.D.

William G. McGregor, M.D.

Wolfgang Zacharias, PhD 


\section{DEDICATION}

This dissertation is dedicated to my parents, Ahmad and Ash Tabatabaie, for instilling in me the importance and power of hard work and higher education, for shaping me into the person I am today, and for all their love and kindness.

I would also like to dedicate this dissertation to my wonderful husband, Reza Moktar, for giving me the best chance for educational growth. With his love, support and patience he has opened my eyes to the world and allowed me to follow my dreams.

Moreover, this dissertation is dedicated to our amazing and lovely daughter, Melody A. Moktar, who gave me a new perspective on life. I hope I can make up for all the time that we spent apart.

Further gratitude goes to my two brothers, Afshin and Omid Tabatabaie, other family, friends, and loved ones who have encouraged and supported me in my journey. 


\section{ACKNOWLEDGEMENTS}

I would like to express deep appreciation to my dissertation advisor, Dr. Ramesh C. Gupta, for his invaluable assistance, advice, and for encouraging me to pursue excellence in regard to research and scholarship. I would also like to thank my committee members, Dr. David W. Hein for his kind consideration and generosity, Dr. Alfred B. Jenson for his unwavering interest in my project, encouragement and his invaluable guidance, Dr. William G. McGregor for believing in me, and Dr. Wolfgang Zacharias for his time and attention.

Special thanks go to Dr. Srivani Ravoori, who also served as my mentor, for her guidance, generous giving of time, patience and invaluable counsel during my entire research education. I am extremely obliged to Dr. Manicka Vadhanam, who as an amazing scientist and a friend was always willing to give his invaluable time and attention. I deeply appreciate his persistent help and great suggestions throughout the entire process. I would also like to thank Dr. Parker for her keen interest in my ex vivo study and her assistance in helping me to conduct the project. I am grateful to Betty Royce in the Gynecologic Oncology Clinic at the James

Graham Brown Cancer Center for her enthusiasm and immense assistance in patient recruitment. I am also greatly appreciative to Terry Campbell at the University of Louisville Ob/Gyn Colposcopy Clinic for her 
constant commitment and assistance in patient recruitment. I would also like to thank other physicians in the Gynecologic Oncology Clinic at the James Graham Brown Cancer Center and the University of Louisville Ob/Gyn Colposcopy Clinic for their assistance in sample collections.

I would like to thank Jeyaprakash Jeyabalan, as a brother, for his enormous support and encouragement. Additionally, I would like to acknowledge my laboratory colleagues for their kindness and encouragement.

I would like to thank Dr. Raina Fichorova of Brigham and Women's Hospital, Harvard Medical School, for providing HPV16-transformed cells (ECT1/E6 E7). I would also like to thank Dr. C. Gary Gairola at the University of Kentucky for kindly providing cigarette smoke condensate throughout the course of the study and statisticians at the James Graham Brown Cancer Center Statistical Core for their work on the ex vivo study. I would like to extend my appreciation to Dr. Rajesh Singh in Dr. Lillard's lab for his invaluable assistance in conducting the ImageStream experiment.

Much of this work was supported by the Agnes Brown Duggan Endowment and, in part, from NIEHS training grants T32-ES011564. 


\section{ABSTRACT \\ CIGARETTE SMOKE, DNA DAMAGE AND REPAIR IN HUMAN CERVICAL AND VAGINAL CELLS IN VITRO AND EX VIVO}

\section{Afsoon Moktar}

September 17, 2010

Among gynecological malignancies, carcinoma of the cervix is the leading cancer type worldwide. Conversely, vaginal tumors account for an incidence of approximately $1-2 \%$ of lower genital tract malignancies. Interestingly, the major shared risk factor among women with cervical and vaginal tumors is infection with cancer-associated human papillomaviruses (HPVs). In fact, HPV infection is the necessary causative factor in the development and progression of cervical and vaginal neoplasia in the majority of cases. Epidemiological studies support that cervical and vaginal pre-cancerous lesions that are initiated by HPV infection generally regress in the absence of known risk factors such as cigarette smoking. Further, female smokers have two times higher risk of developing cervical cancer from premalignant lesions than non-smokers, although the association between cigarette smoking and vaginal tumors has been controversial. Cigarette smoking exerts its cytogenetic effects in 
various forms such as DNA strand breaks and oxidative DNA damage. However, previous studies on cervical and vaginal abnormalities failed to investigate the effects of cigarette smoking on cervical and vaginal cells from a biological standpoint.

Therefore, the goal of this work was to investigate cigarette smokeinduced DNA strand breaks, oxidative damage and DNA repair in human cervical cancer cells (in vitro studies, Chapters II and III); we also examined DNA strand breaks in human vaginal cells in light of cigarette smoking and HPV status (an ex vivo study, Chapter IV). It was determined that cigarette smoke induces both DNA single- (SSBs) and double-strand breaks (DSBs) that are highly persistent, in addition to oxidative DNA damage, which is more pronounced in HPV infected human cervical cancer cells. Though, CSC-induced oxidative DNA damage was eventually removed in the cells, the possibility of error-prone DNA repair, however, cannot be ruled out. Lastly, our data derived from the ex-vivo study clearly showed an inverse relationship between the interaction of cigarette smoking and HPV infection in the induction of DNA strand breaks in vaginal cells of the studied population, regardless of age. Further, we have clearly showed that the extent of DNA DSBs increases as a function of age, which corroborates with the fact that vaginal cancers occur at a much older age, as compared to cervical cancers. In summary, the findings of this research project shed light on the role of cigarette smoke in cervical/vaginal carcinogenesis. Moreover, comet assay might serve as an 
early biomarker in identifying susceptible populations that are at risk for developing cervical/vaginal abnormalities. 


\section{TABLE OF CONTENTS}

PAGE

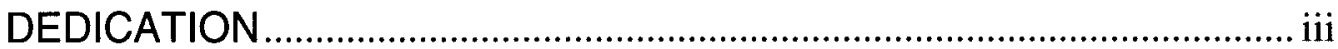

ACKNOWLEDGEMENTS ................................................................ iv

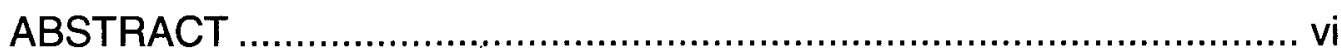

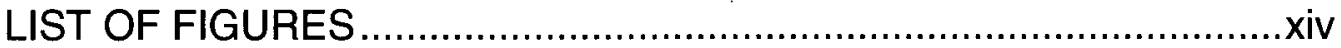

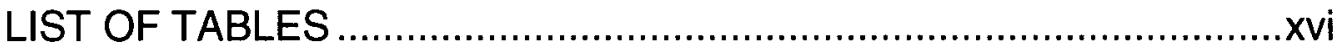

CHAPTER

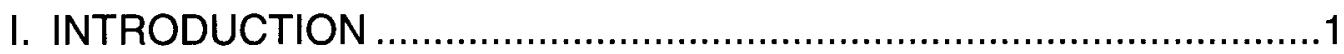

1. Cervical/Vaginal Cancer Statistics .............................................2

2. Cervical/Vaginal Cancer Histopathology ....................................

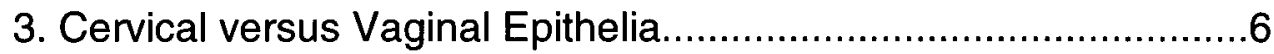

4. Cervical/Vaginal Cancer Etiology and Risk Factors......................7

5. Cigarette Smoke Constituents ................................................10

6. Role of Smoking as a Cofactor in Cervical/Vaginal Cancer .........11

7. Oxidative Stress, Cigarette Smoke and Cervical Cancer.............14

8. Cigarette Smoke, DNA Repair and Cervical Cancer....................15

9. p53 and Cervical Cancer …....................................................16

10. Rationale/Importance of the Current Studies ............................18

11. Rationale for Selecting Vaginal Cells for Ex Vivo Study ............20 
II. CIGARETTE SMOKE-INDUCED DNA DAMAGE AND REPAIR DETECTED BY THE COMET ASSAY IN HPV-TRANSFORMED

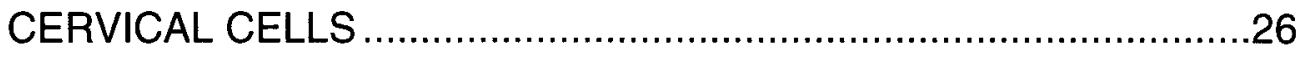

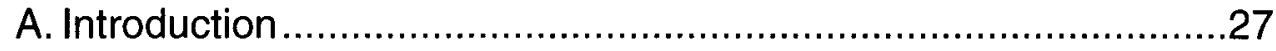

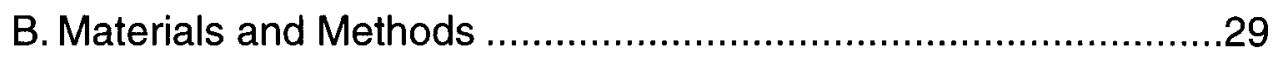

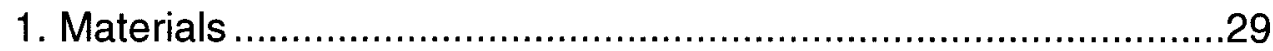

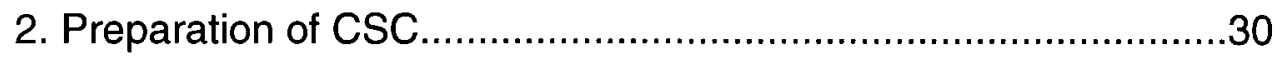

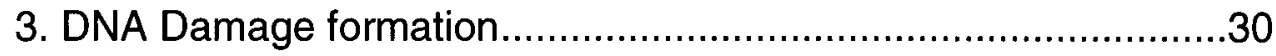

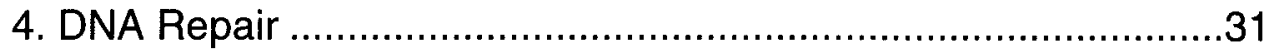

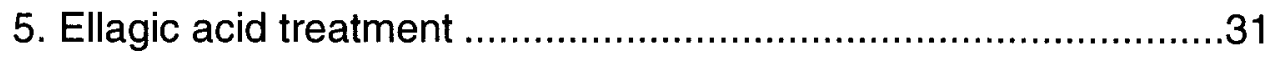

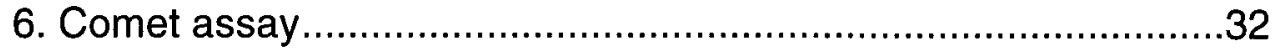

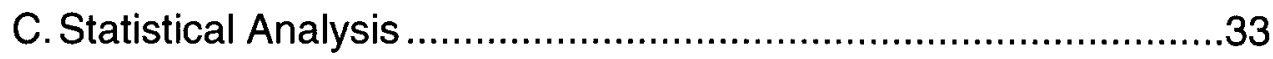

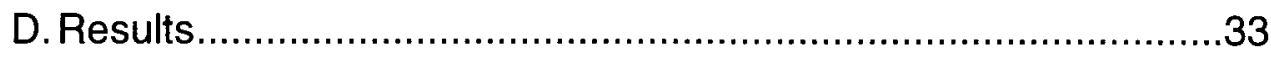

1. Effect of CSC on DNA strand breaks with time ...........................33

2. Single- and double-strand breaks induced by different doses

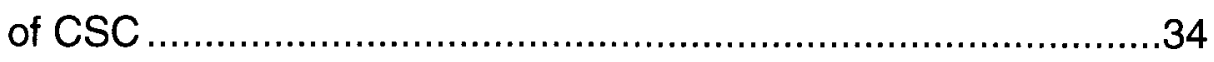

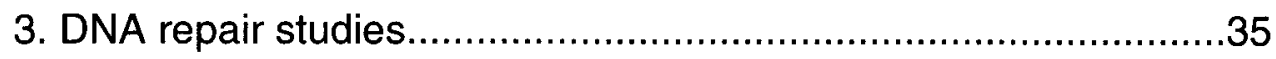

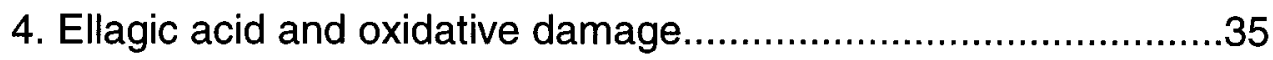

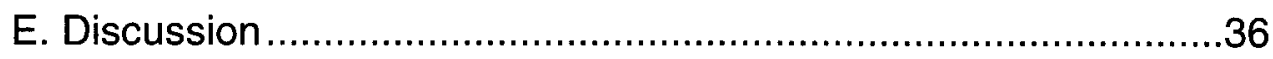


III. CIGARETTE SMOKE CONDENSATE-INDUCED OXIDATIVE DNA DAMAGE AND ITS REMOVAL IN HUMAN CERVICAL CANCER CELLS

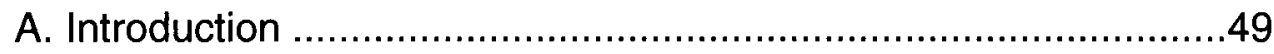

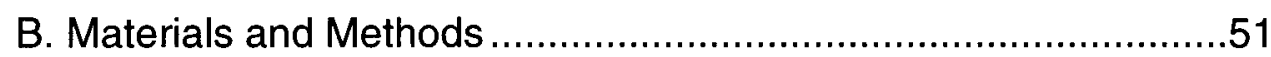

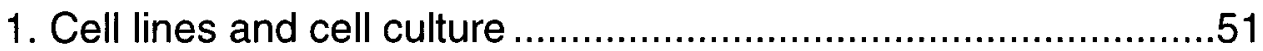

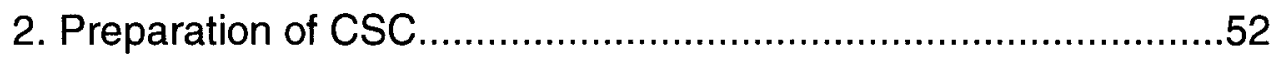

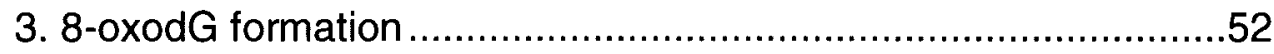

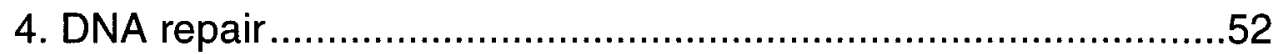

5. Flow cytometry and ImageStream analysis of 8-oxodG and

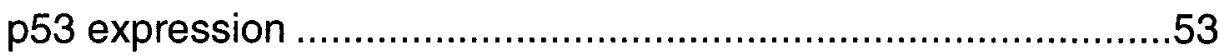

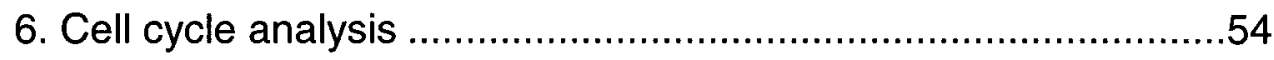

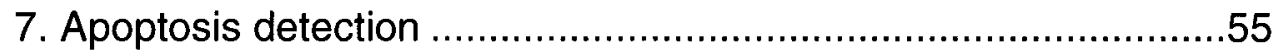

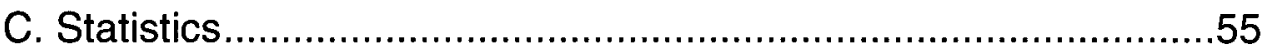

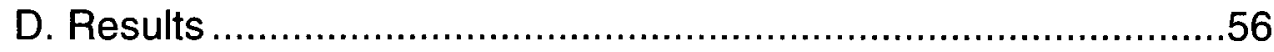

1. 8-oxodG formation in HPV-transfected cervical cells...................56

2. 8-oxodG removal in cervical cells ..........................................56

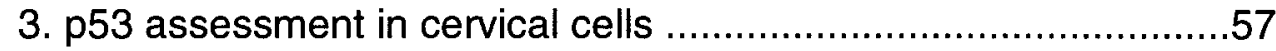

4. Cell cycle phase distribution in HPV-transfected ical cells............57

5. Apoptosis induction if HPV-transfected cervical cells ..................58

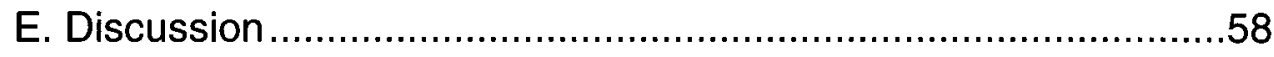


IV. THE INTERPLAY OF CIGARETTE SMOKING AND HPV INFECTION IN HUMAN VAGINAL CELLS:

AN EX VIVOSTUDY

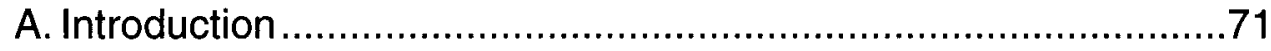

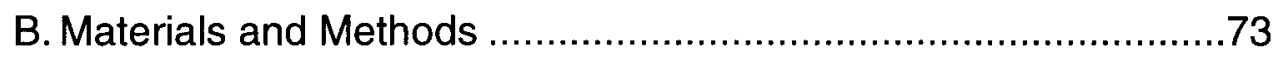

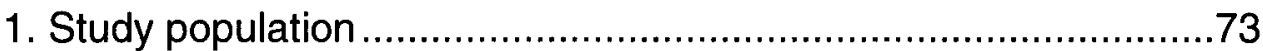

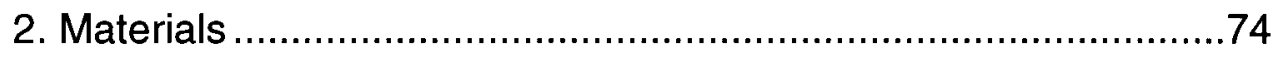

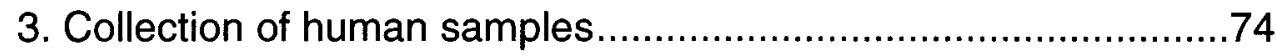

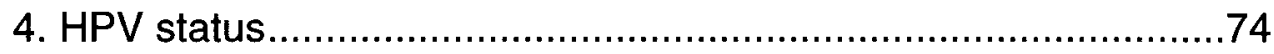

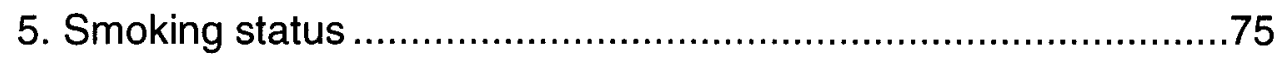

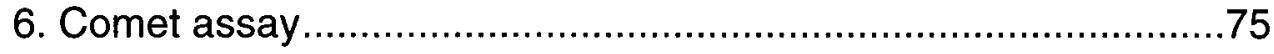

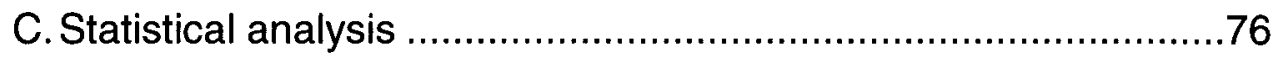

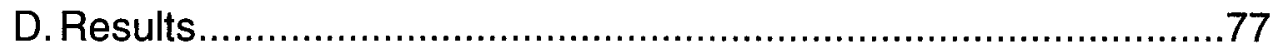

1. The influence of HPV infection on induction of DNA

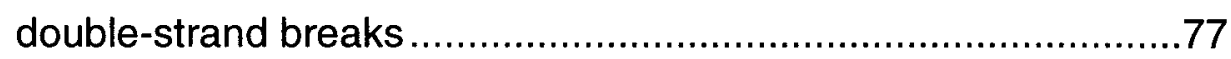

2. DNA double-strand breaks induced by cigarette smoking ...........78

3. The effect of age on DNA strand breaks....................................79

4. The interaction between HPV infection and smoking status ........79

5. The interaction among HPV infection, cigarette smoking

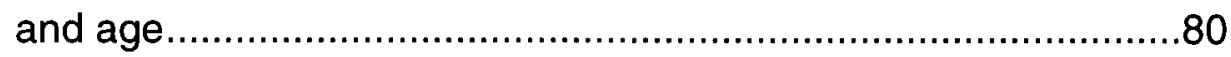

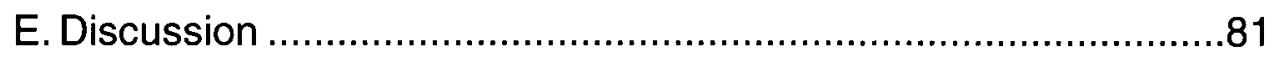

V. SUMMARY AND GENERAL DISCUSSION ..................................96

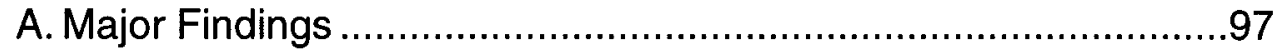


1. Cigarette smoke condensate can induce DNA

strand breaks

2. Cigarette smoke condensate can induce oxidative

DNA damage

3. Cigarette smoking and HPV infection act independently

in vaginal cells 101

4. DNA strand breaks detection. 103

B. Strengths and Weaknesses of this Dissertation 104

1. Strengths . 104

2. Weaknesses 107

C. Future Directions 109

1. Does cigarette smoke induce forms of damage in human cervical cancer cells? 109

2. Does cigarette smoking and/or HPV infection induce

Oxidative damage in vaginal cells 110

D. Significance of this Study... 110

E. Final Notes 112

REFERENCES 122

ABBREVIATIONS 143 CURRICULUM VITAE 


\section{LIST OF FIGURES}

FIGURE

PAGE

1.1: HPV and non-HPV factors that contribute to HPV-induced malignant progression 21

1.2: Structures and abbreviations of oxidative DNA damage ..................22

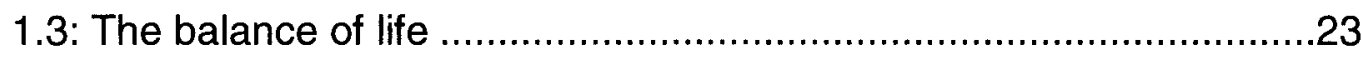

2.1: Representative comet assay images ..........................................43

2.2: Time response of CSC on DNA single-strand formation.................44

2.3: Dose response of CSC on DNA single- and

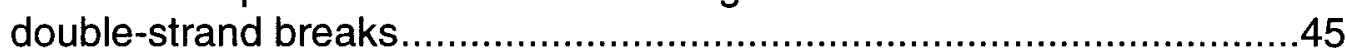

2.4: Repair of single- and double-strand breaks ..................................46

2.5: Effect of ellagic acid on cigarette smoke condensate-induced Single- and double-strand DNA breaks ........................................47

3.1: Cigarette smoke condensate-induced 8-oxodG lesions in ECT1/E6 E7.

3.2: Effects of cigarette smoke condensate on cell cycle distribution in HPV-transfected cervical cells ....

3.3: Cigarette smoke condensate-induced apoptosis in

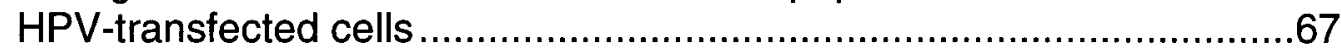

3.4: Removal of cigarette smoke condensate-induced oxidative

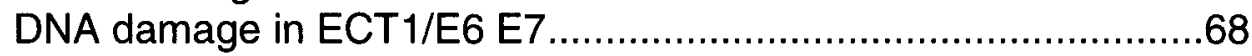

3.5: Assessment of p53 expression in different human cervical cells .....69

4.1: Representative comet assay images 
4.2: Scattered plot presentation of the DSBs in the studied

Population......

4.3: Correlation between HPV infection and smoking status presented

by scattered plot in the studied population ....................................91 


\section{LIST OF TABLES}

1.1: List of Cigarette Smoke Carcinogens ..........................................24

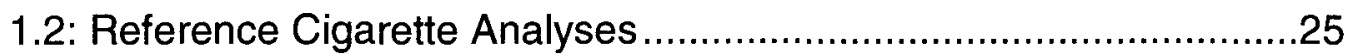

4.1: Clinical and General Characteristics of the Studied Population.......92

4.2: Comet Assay Measured in the Vaginal Cells of the Subjects ..........93

4.3: Comet Assay Measured in the Vaginal Cells of the Subjects stratified for HPV and Smoking Status...........................................94

4.4: Generalized Linear Regression Model on Age, Smoking and

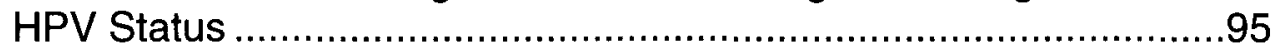

5.1: Comprehensive Comet Data ..................................................113 
CHAPTER I

INTRODUCTION 
The main focus of this dissertation was to investigate the effect of cigarette smoke on DNA damage and repair in human cervical cancer and vaginal cells since cigarette smoking is considered a significant cofactor in association with high-risk HPV infection in cervical/vaginal carcinogenesis. Two types of DNA lesions, namely, DNA strand breaks and oxidative DNA damage were analyzed. The findings of this study would serve as an essential step in identifying susceptible populations that are at risk for developing cervical/vaginal abnormalities.

\section{Cervical/Vaginal Cancer Statistics}

Cervical cancer is one of the leading cancer types among women worldwide, although it has the greatest potential for prevention (World Health Organization, PAHO, 2004). In the United States, an estimated 11,270 cases of invasive cervical cancer were diagnosed and approximately 4,070 deaths from cervical cancer occurred in 2009 [1]. In Kentucky, investigations on cervical cancer is of particular importance, since the age-adjusted incidence rate of this cancer for 2002-2006 is higher than the average rate in the United States $(9.48$ versus 8.26 per 100,000) (Kentucky Cancer Registry 2007). In 2004, current smoking 
prevalence in Kentucky was the highest in the nation at a rate of $27.6 \%$ (Center for Disease Control, 2005). The high prevalence of cervical cancer has been associated with increased cigarette smoking in the state [2]. Based on the Kentucky Cancer Registry data, $61 \%$ of women diagnosed with cervical cancer during 1997-1998 had a history of tobacco use [2].

Vaginal intraepithelial neoplasia is a rare disorder with an incidence of approximately 0.2 to 0.3 per 100,000 women [3]. Primary vaginal cancer is extremely rare and accounts for about $1-2 \%$ of all gynecological malignancies [4]. However, the incidence of secondary vaginal malignancies is $80-90 \%$ due to the anatomic proximity of the vagina to the urinary bladder and rectum. The primary tumors in those locations can spread to the vagina either by direct extension or by lymphatic metastasis [3]. According to Kentucky Cancer Registry, in 2007, approximately 59\% of women who were diagnosed with vaginal cancer were smokers (Kentucky Cancer Registry 2007). Therefore, studying the role of cigarette smoking in cervical and vaginal carcinogenesis could provide prophylactic and therapeutic applications that may ultimately be beneficial to women at high risk of or diagnosed with HPV-induced cervical/vaginal abnormalities. 


\section{Cervical/Vaginal Cancer Histopathology}

The morphology of cervical cancer and its pre-cancerous lesions are well defined [5], providing an excellent opportunity to study the etiology and to strategize prevention of this multi-staged cancer. Based on the National Cancer Institute Bethesda System 2001, cervical squamous epithelial abnormalities are classified as follows:

1. Atypical squamous cells (ASC), which encompass two subcategories: a) Atypical Squamous Cells of Undetermined Significance (ASC-US); and b) ASC with the possibility of high-grade squamous intraepithelial lesions (ASC-H)

2. Low-grade squamous intraepithelial lesions (LSIL), including mild cervical intraepithelial neoplasia (CIN I) and HPV

3. High-grade squamous intraepithelial lesions (HSIL), including moderate to severe intraepithelial neoplasia (CIN II/CIN III) and carcinoma in situ (CIS)

4. Invasive squamous cancer

The progression of cervical intraepithelial neoplasia from CIN I to CIN II, CIN III and invasive cancer is based on cytological and epithelial architecture abnormality [5]. Less than $5 \%$ of low-grade $(\mathrm{CIN} \mathrm{I/II)}$ cases will progress to high-grade lesions (CIN III), whereas only a small 
percentage of these will be associated with squamous cervical cancer [6]. On the contrary, approximately $36-76 \%$ of high-grade lesions will progress to cervical cancer in about 20 years [6]. The factors influencing the progression or regression of the neoplastic lesions are two-fold: genetic and environmental determinants [7].

The classification of vaginal intraepithelial neoplastic lesions is similar to CIN and is classified according to the depth of epithelial involvement [8]:

1. VAIN I: the involvement of the lower one-third or less of the distance from the basement membrane to the surface.

2. VAIN II: less than or equal to two-thirds involvement.

3. VAIN III: more than two-thirds of the distance is involved. Carcinoma in situ (CIS), which the entire thickness of the epithelium is involved, is also classified under VAIN III.

4. Invasive vaginal cancer: vaginal mucosa, submucosa or connective tissue is involved without cervical or vulvar invasion.

Vaginal cancer is usually clustered with "other and unspecified gynecologic neoplasms" including vulvar and fallopian tube cancers due to its rarity [8]. Vaginal cancers are considered primary if there is no clinical or histological involvement of the cervix or vulva [9-10]. 


\section{Cervical versus Vaginal Epithelia}

The cervical epithelium is composed of columnar and stratified nonkeratinizing squamous types. The squamocolumnar junction (also known as T-zone) is where those epithelia meet. T-zone is the most important cytologic landmark, since most cervical dysplasias arise from this area. Squamous metaplasia is a dynamic process that occurs throughout the reproductive age in the T-zone, and is a normal physiological process during which columnar epithelium is replaced by squamous type. Acidic vaginal $\mathrm{pH}$ and estrogen account for replacement of more delicate columnar epithelium with a more robust squamous type. There are two mechanisms responsible for this normal process: 1) reserve cell hyperplasia, a proliferation of reserve cells around the columnar glands, which eventually leads to the replacement of the epithelium; and 2) growth of squamous epithelium toward the center of ectocervical epithelium resulting in metaplasia, which, in turn, replaces the overlying columnar epithelium. The significance of the T-zone arises from the fact that almost all cervical neoplastic lesions originate from this area. During pregnancy and peripubertal years, the T-zone is predominantly active, which accounts for the observation that early first sexual intercourse and early age at first pregnancy are among cervical cancer risk factors. Furthermore, it is thought that reserve cells in adolescent and young women are more vulnerable to the carcinogenic HPV infection [11-12]. 
The epithelium of vagina is stratified non-keratinizing squamous type. The epithelial cells of vagina are classified into three types: parabasal, intermediate and superficial cells, which reflect a developmental continuum [11].

The vagina lacks a squamocolumnar junction [13], which is not necessary for HPV infection, although high-risk HPV distinctively affects the T-zone [14].

\section{Cervical/Vaginal Cancer Etiology and Risk Factors}

Cervical cancer risk factors can be divided into three groups: 1) viral cofactors, such as HPV variants, viral load and viral integration; 2) host cofactors, such as endogenous hormones and genetic influences; and 3) environmental cofactors, such as diet, use of oral contraceptives, parity, cigarette smoking [15-16] and low socioeconomic status [17] (Figure 1.1). It has been shown that parity and cigarette smoke are more consistently associated with the progression of cervical neoplasia toward cervical cancer [15]. The epidemiological and clinical data indicate that HPV infection is necessary but not sufficient for development and maintenance of cervical carcinoma [18-20], since the majority of HPV infections regress [21]. A typical epidemiological profile of CIN includes multiple sexual partners, earlier ages at first sexual intercourse, cigarette smoking, and lower-socioeconomic status with a strong association with 
HPV infection [22]. In fact, the HPV prevalence in cervical carcinoma is $99.7 \%$ worldwide, which accounts for the greatest causative factor involved in development of any human cancer [23].

Human papillomaviruses belong to the Papovaviridae family with a double-stranded DNA [24]. Three regions are identified in HPV genome: the long control region (LCR), which has no coding potential; the early proteins region (E1-E8); and the region of late proteins (L1 and L2), which are structural proteins [24]. There are at least 200 types of HPV viruses that are classified into 16 groups according to their ability to induce malignant transformation [24]. HPV types $16,18,31,33,35,39,45,51$, $52,56,58,59,68,73$, and 82 are classified as carcinogenic or high-risk types [25]. Among these carcinogenic types, HPV 16 and 18 are the most closely associated with cervical cancer, with a high prevalence of HPV 16 [26].

In benign cervical precursor lesions, the HPV DNA is usually extrachromosomal or episomal, whereas in many cervical cancer cells as well as in cervical cancer cell lines and HPV-transformed human keratinocytes, the HPV DNA is integrated in the host genome [27]. Upon integration of HPV DNA, the viral genome usually breaks in the E1/E2 region and is usually lost [27]. Moreover, disruption of E2-encoding gene causes the loss of expression of viral E2 protein causing uncontrolled overexpression of E6 and E7 oncogenes, which is the hallmark of HPVinduced cervical carcinoma [27-28]. The most significant oncogenes are 
E6 and E7, which play a major role in HPV-associated tumorigenesis [29]. In malignant tissue, E6 and E7 genes are consistently expressed. Furthermore, if their expression is inhibited, the malignant phenotype of cervical cancer cells is blocked [30]. E6 and E7 oncoproteins cause genomic aberrations, mitotic defects, and numerical chromosome instability, ultimately leading to carcinogenic progression [31]. The E6 oncoprotein degrades the cellular protein p53 via the ubiquitin-proteasome pathway [32]. E6, then suppresses the p53 gene products [27]. The E7 oncoprotein interacts with the retinoblastoma protein $(\mathrm{pRb})$ and inactivates [33]. pRb plays a crucial role in cell cycle control [34]. Even though HPV is a necessary factor in developing cervical abnormalities, it does not suffice as a cervical carcinogen, since the majority of the HPV infections are short-lived [35]. Additional cofactors are required to prolong expression of the HPV E6 and E7 oncogenes and genetic instability [36].

The majority of vaginal cancers have common risk factors with cervical cancer; the most reported shared risk factor among women with cervical and vaginal tumors is infection with cancer-associated HPV types. High-risk HPV prevalence is comparable in cervical and vaginal samples, which, in turn, signifies that both tissues can retain cancer-associated HPV infection [14]. 


\section{Cigarette Smoke Constituents}

The chemical constituents of cigarette smoke have been the subject of extensive chemistry analysis. It is well known that smoke toxicants are important in the development of various diseases, including cancer. More than 5,000 smoke constituents have been identified in cigarette smoke and approximately 60 to 70 of those are known toxic constituents of tobacco smoke [37]. Tobacco smoking was first listed as a human carcinogen in the $9^{\text {th }}$ Report on Carcinogens 2000. This identification was based on human studies indicating a casual relation between tobacco smoking and cancer (US Department of Health and Human Services, Report on Carcinogens, 2000). Tobacco smoking has been demonstrated to cause variety of human cancers such as lung, oral cavity, lips, larynx, esophagus, and urinary bladder [38]. According to the U.S. Department of Health and Human Services, the cigarette smoke carcinogens can be summarized in Table 1.1 (US Department of Health and Human Services, Report on Carcinogens, 2006).

Cigarette smoke contains a complex mixture of products resulting from organic substance combustion (acetaldehyde and formaldehyde) and from chemicals generated by the combustion of tobacco and the cigarette's other components (tobacco-specific nitrosamines) (US Surgeon General Reports, 1988). The International Agency for Research on Cancer (IARC) has listed 36 chemicals that are known human carcinogens. Ten of these compounds, in addition to many more 
mutagenic chemicals fall into Group 2 of IARC's classification of "probably or possibly carcinogenic" categories (IARC, 1999). Furthermore, the U.S. Environmental Protection Agency and IARC put cigarette smoke in Group 1 classification as a known carcinogen in humans.

The U.S. Surgeon General has defined "tar" as the nicotine-free, dry, and particulate mass of the tobacco smoke that contains many harmful carcinogenic compounds, such as metals, polycyclic aromatic hydrocarbons (PAHs), dioxins and nitrosamines (US Surgeon General Reports, 1988). PAHs are generated through combustion of any organic compound; the highest toxicologically potent of those compounds is benzo[a]pyrene (BP), which is extensively studied in relation to human carcinogenicity [37].

The University of Kentucky's Tobacco and Health Research Program developed a cigarette, the $2 \mathrm{R} 4 \mathrm{~F}$, which was used as an universal standard for research purposes and provided a basis for data comparison among scientific communities [39]. Other reference cigarettes, such as $1 \mathrm{R} 3 \mathrm{~F}$ and $1 \mathrm{R} 5 \mathrm{~F}$ that have been used in research, differ in the amount of chemical constituents compared with 1R4F (Table 1.2) [40].

\section{Role of Smoking as a Cofactor in Cervical/Naginal Cancer}

Cigarette smoke as a causative factor in the development of cervical cancer was proposed by Winkelstein [41]. Based on numerous epidemiological studies, cigarette smoke is a significant risk factor in 
developing cancer of numerous organs [42], including the uterine cervix (Figure 1.1) [26, 43-44]. Considering the fact that the cause of cervical cancer is multi-factorial and HPV infection alone is not sufficient, although necessary, the association of HPV and cigarette smoke has been suggested [44-46]. The following data support the hypothesis that cigarette smoking is a cofactor with HPV infection in cervical cancer etiology [47]:

1. There is strong association between smoking and $\mathrm{CIN} \mathrm{II/III/invasive}$ cervical cancer [48]. It has been proposed that cigarette smoke has a late stage synergistic effect in cervical carcinogenesis already initiated by HPV infection $[15,49]$. Infection with HPV 16 is demonstrated to be associated with high-grade lesions (HSIL), with increasing risk of HSIL directly related to number of cigarettes smoked per day [50]. Nakao and Yang et al. used an in vitro model system to demonstrate that cigarette smoke may be required as a co-carcinogen in the neoplastic progression of HPV-initiated high-grade cervical lesions [51-52].

2. Detection of tobacco specific carcinogens in cervical mucus such as nicotine and cotinine and 4-(methylnitrosamino)-1-(3-pyridyl)-1butanone (NNK) ([53-55] has been reported. These findings support the epidemiological data indicating that cigarette smoking is an actual risk factor in cervical carcinogenesis.

3. The association of cigarette smoking as a casual cofactor in development of cervical abnormalities is further strengthened by the 
evidence that tobacco-specific compounds, such as nitrosamine 4(methylnitrosamino)-1-(3-pyridyl)-1-butanone and benzo[a]pyrene [56-57] can be metabolized by human cervical epithelium into carcinogenic and genotoxic products.

4. It has been documented that tobacco smoke is an extreme example of systemic human mutagen [58]. The effect of cigarette smoke condensate and cigarette smoking, in inducing DNA damage, mainly DNA strand breaks, has been demonstrated by many studies [59-62]. Chemical carcinogens in cigarette smoke, such as nitrosamines, may damage DNA as well as impair local immune response of cervical epithelium [63]. Cigarette smoke exerts its cytogenetic effects in various forms, including micronuclei, sister chromatid exchange, chromosomal aberrations, microsatellite instability, DNA strand breaks and oxidative damage [58].

5. Female smokers with HPV-associated low grade cervical lesions have up to three times higher risk of developing cervical cancer than nonsmokers [48]. Further, cigarette smoking cessation decreases the size of early cervical lesions [64]. Therefore, behavioral modification to decrease the rate of cigarette smoke consumption [65] may have a positive effect on cervical cancer progression and/or development.

Epidemiological and etiological variables, such as cigarette smoking, associated with cervical cancer have also been reported to be pertinent to the etiology of vaginal tumors [66]. Few studies have reported a positive association between cigarette smoking and vaginal abnormalities [67-70]. 
These studies were based on an epidemiological association. However, conflicting data exist on the role of smoking in the development and progression of HPV lesions in vaginal cells. Hellman et al demonstrated that vaginal carcinoma was not significantly correlated with smoking [71]. Madsen et al found that current smoking was a risk factor in HPV infected individuals [66]. Another study by Brinton et al showed a modest nonsignificant correlation between smoking and vaginal cancer [72]. Thus, the role of cigarette smoking as a cofactor in vaginal cancer remains controversial. Nonetheless, the exact mechanism by which cigarette smoking exerts its cytotoxic effects is not entirely understood.

\section{Oxidative stress, cigarette smoke and cervical cancer}

Reactive oxygen species (ROS) are abundant free radicals in nature and play a significant role in induction of DNA damage [73]. Normal cellular processes, such as respiration, inflammation, cell injury and hydroxylation of steroids and drugs are endogenous sources of ROS [74]. ROS can induce damage in DNA, protein and lipid [75]. Oxidative stress is caused by the imbalance between the ROS production, scavenging and removal/repair of the resulting damage. Therefore, oxidative stress is considered a critical mechanism in the pathogenesis of many diseases including cancer [76-77]. Oxidative stress oxidizes cellular components, activates signal transduction pathways, affects gene and protein 
expression and alters activity of DNA polymerase leading to its low fedility conformation [78]. The exceptionally important target of oxidation is DNA, since mutations induced by such damage may be passed on to many generations. The oxidation of guanine to 8-oxo-7,8-dihydro-2'deoxyguanosine (8-oxodG) is the most commonly studied oxidative lesion [79] (Figure 1.2). This lesion may lead to G.C $\rightarrow$ T.A transversions [80]. Formation of an oxidative lesion may lead to accumulation and persistence of mutation, which may, in turn, play a role in carcinogenicity [81-82]. Furthermore, the environmental sources of ROS, such as cigarette smoke, are of particular importance in cancer pathogenesis [75]. Cigarette smoke can induce different oxidative DNA lesions, including 8oxodG [83]. In fact, the role of 8-oxodG formation in cigarette smokeinduced carcinogenesis has been suggested by many studies. The levels of this base lesion were reported higher in smokers as compared to nonsmokers [84-86].

\section{Cigarette Smoke, DNA repair and Cervical Cancer}

DNA repair machinery is one of the primary defense mechanisms in our body against mutagenic agents. There are two subgroups of DNArepair genes: 1) genes associated with regulation of DNA repair, and 2) genes associated with defined repair mechanisms, such as mismatch repair (MMR), nucleotide-excision repair (NER), base-excision repair (BER), and double-strand-break (DSB) repair [87]. The NER pathway is 
responsible for removing bulky DNA adducts caused by tobacco smoke, the BER pathway removes oxidized DNA bases caused by endogenous agents and/or oxidants in cigarette smoke, and DSB repairs double-strand breaks [88]. Homologous recombination (HR) and non-homologous end joining are the two complementary pathways of DSB repair [88]. DNA lesions, or persisting DNA strand breaks [89] and impaired DNA repair system may contribute to genomic instability.

Tobacco smoke carcinogens damage DNA [62], which subsequently involve repair pathways, particularly, NER, BER, and DSB repair pathways; the genes of those pathways may be involved in the initiation of tobacco-caused cancer [90]. In general, upon exposure to precarcinogenic compounds, the balance between an intact DNA repair system and genetic susceptibility may influence conversion of precarcinogenic compounds to DNA damaging agents [91] (Figure 1.3).

\section{9. p53 and Cervical Cancer}

The continued simultaneous expression of high-risk HPV E6 and E7 proteins in cervical cancer causes the inactivation of p53 and pRB tumor suppressor pathways, respectively [92]. The tumor suppressor p53 primarily functions as a transcription factor, but several responses can be generated by p53, including cell cycle arrest or apoptosis [93]. p53 gene mutations are the most frequently occurred genetic abnormalities in human cancers [94]. The role of p53 in cervical pathogenesis is two-fold. 
First, the short arm of chromosome 17, which is the location of p53, showed frequent abnormalities by karyotype analysis of cervical cancer specimens [95]. Second, the E6 oncoprotein of high-risk HPV binds to and promotes degradation of p53 [96] through a ubiquitin-dependent protease system [97]. p53 is inactivated in cervical carcinoma, either by its mutation or binding to E6 oncoprotein [98]. p53 mutations frequently occur in HPVnegative cervical carcinoma cell lines as compared to HPV-positive lines [99-100].

The role of p53 as an important sensor of cellular stress depends on the cell type and extent of stimuli; p53 can induce cell cycle arrest to permit repair [101]. Alternatively, p53 can induce apoptosis to prevent fixation of DNA mutation in stressed cells [101]. There is also evidence, however, that $\mathrm{p} 53$ has a more positive role in facilitating the repair of oxidative damage. First, activation of several p53-regulated genes yields products that act as antioxidants, such as GPX1 and ALDH4A1 [102-103]. Second, two p53-regulated sestrins, namely PA26 and Hi95, can reactivate peroxiredoxins, a ubiquitous family of antioxidant enzymes[104]. Third, several antioxidant genes are up-regulated by p53 resulting in a decrease of ROS levels[105].

Most HPV-positive cervical carcinoma cells include the wild-type p53 gene, although it is usually non-functional as a result of binding to E6 oncoprotein, which facilitates its degradation via an ubiquitin-dependent proteolytic pathway [106]. However, HPV-positive cervical cancer cells 
have been shown to have residual p53 activity, indicating that p53 is not completely inactivated by binding to the E6 oncoprotein [107-109]. The p53 gene is often mutated in HPV-negative cervical cancer cell lines [110].

\section{Rationale/lmportance of the Current Studies}

Worldwide, cervical cancer is the second leading cause of cancer death after breast cancer among women and the leading cause of cancer death in women in developing countries [111]. The World Health Organization estimates that 4.5 million smoke-related deaths, which are the most preventable cause of deaths, occur each year [111]. Cervical cancer in the United States and on a global scale is, therefore, an important public health problem. The issue of smoking is of particular interest in Kentucky, where the prevalence of tobacco smoking is very high (Kentucky Cancer Registry 2007). Moreover, based on available data on cervical cancer cases obtained from the Kentucky Cancer Registry from 1995-2005, Coker et al showed that cigarette smoking reduces cervical cancer survival [112]. The majority of women diagnosed with cervical cancer during 1997-1998 had a history of tobacco use [2, 112]. These statistics highlight the importance of investigating the plausible link

between cigarette smoke and cervical cancer to identify the high-risk population and lessen the economic and disease burden of Kentucky as well as nationwide. Since cigarette smoking is a strong epidemiological 
and etiological risk factor for cervical and vaginal cancer progression, investigation on the effect of cigarette smoke on DNA damage and repair in association with HPV infection in those cancers is warranted.

This study examines the role of cigarette smoke on DNA damage and repair. The findings of this study would serve as an essential step in identifying susceptible populations that are at risk for developing cervical/vaginal abnormalities by developing early biomarkers. Future investigations will be warranted to employ the early biomarkers developed in this study for clinical settings in order to prevent cervical precancerous and cancerous lesions in high-risk population. Furthermore, susceptible individuals can be subject to behavioral modification sessions to refrain from smoking and be enrolled in chemoprevention studies. In conclusion, the data from this study would serve as a stepping stone towards the ongoing efforts on primary prevention of cervical/vaginal cancer.

Chapter II focuses on cigarette smoke condensate (CSC)-induced DNA strand breaks and their removal in a human HPV-transfected cervical cell line. The role of ellagic acid, a potent antioxidant, in the removal of DNA damage was also examined in this chapter. CSC-induced oxidative DNA damage and its removal in human cervical cancer cell lines, in association with HPV, are examined in Chapter III. Chapter IV, an ex vivo study, investigates the effect of cigarette smoking alone and in association with high-risk HPV infection in human vaginal cells. 


\section{Rationale for Selecting Vaginal Cells for Ex vivo Study:}

Pap smear contains a heterogeneous cell population, including variety of epithelial and non-epithelial cells. To assess the DNA strand breaks at a cellular level, in ex vivo study, the first objective was to obtain a homogenous sample containing only epithelial cells. Several attempts were made to isolate epithelial cells, including magnetic and Percoll separation. However, even though the level of cell purity was acceptable, the cell recovery did not achieve any significant numbers. Therefore, collecting vaginal cells seemed to be the only plausible option to specifically assess DNA damage on the selected cell type. 


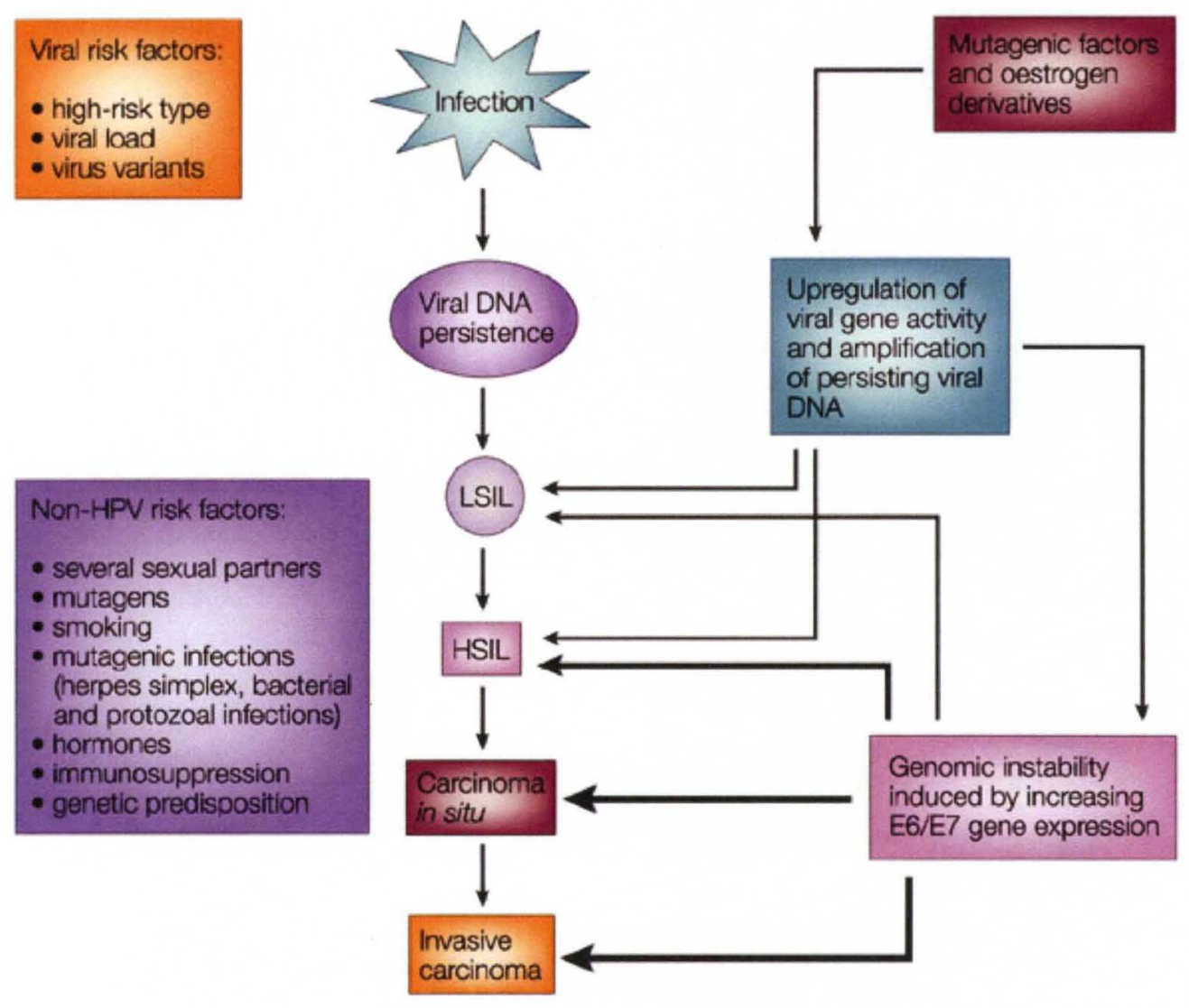

Nature Reviews | Cancer

Figure 1.1: HPV and non-HPV factors that contribute to HPVinduced malignant progression [30]. LSIL: Low-grade squamous intraepithelial lesion; HSIL: High-grade squamous intraepithelial lesion. 


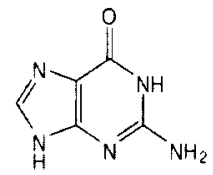

Gua

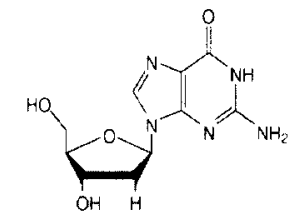

dG

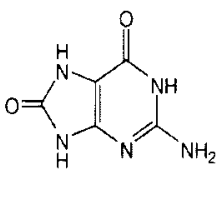

8-oxoGua

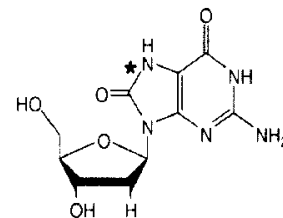

8-oxodG

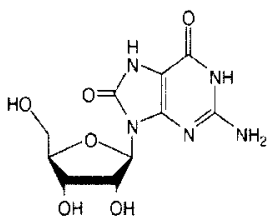

8-OXOG

Figure 1.2: Structures and abbreviations of guanine (Gua), deoxyguanosine (dG), 8-oxoguanine (8-oxoGua), 8-oxodeoxyguanosine (8-oxodG) and 8-oxoguanosine (8-oxoG), respectively. The asterisk on 8oxodG indicates the ${ }^{14} \mathrm{C}$ label [113]. 


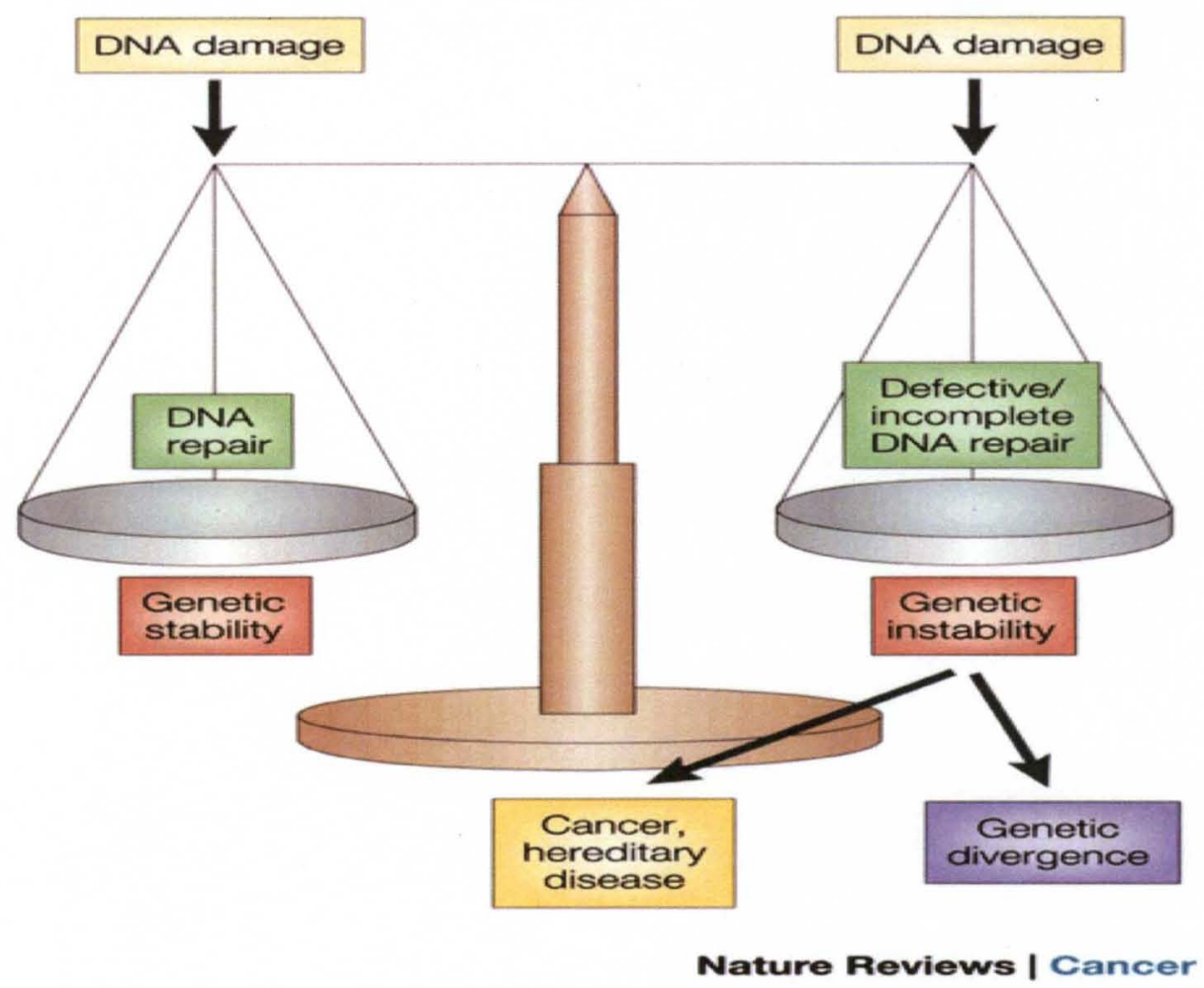

Figure 1.3: The balance of life [91]. 


\section{TABLE 1.1 \\ List of Cigarette Smoke Carcinogens}

\begin{tabular}{|c|c|}
\hline Chemical & Amount (per cigarette) \\
\hline Acetaldehyde & 980 micrograms to 1.37 milligrams \\
\hline Acrylonitrile & $\begin{array}{l}\text { Formerly } 1 \text { to } 2 \text { milligrams. This product was } \\
\text { used as a fumigant in tobacco. Its use has since } \\
\text { been discontinued. }\end{array}$ \\
\hline 4-Aminobiphenyl & 0.2 to 23 nanograms per cigarette \\
\hline o-Anisidine Hydrochloride & unknown \\
\hline Arsenic & unknown \\
\hline Benzene & 5.9 to 75 micrograms \\
\hline Beryllium & 0.5 nanograms \\
\hline 1,3-Butadiene & 152 to 400 micrograms \\
\hline Cadmium & 1.7 micrograms \\
\hline 1,1-Dimethylhydrazine & unknown \\
\hline Ethylene oxide & unknown \\
\hline Formaldehyde & unknown \\
\hline Furan & unknown \\
\hline Heterocyclic amines & unknown \\
\hline Hydrazine & 32 micrograms \\
\hline Isoprene & :3.1 milligrams \\
\hline Lead & unknown \\
\hline 2-Naphthylamine & 1.5 to 35 nanograms \\
\hline Nitromethane & unknown \\
\hline N-Nitrosodi-n-Butylamine & 3 nanograms \\
\hline N-Nitrosodiethanolamine & 24 to 36 nanograms \\
\hline N-Nitrosodiethylamine & up to 8.3 nanograms \\
\hline N-Nitrosodimethylamine & 5.7 to 43 nanograms \\
\hline N-Nitrosodi-n-Propylamine & 1 nanogram \\
\hline $\begin{array}{l}\text { 4-(N-Nitrosomethylamino)-1-(3- } \\
\text { Pyridyl)-1-Butanone }\end{array}$ & up to 4.2 micrograms \\
\hline N-Nitrosonornicotine & 14 micrograms \\
\hline N-Nitrosopiperidine & unknown \\
\hline N-Nitrosopyrrolidine & 113 nanograms \\
\hline N-Nitrososarcosine & 22 to 460 nanograms \\
\hline Polonium-210Citation needed & $\begin{array}{l}\text { variable, depending on soil and fertilizer used to } \\
\text { grow tobacco }{ }^{[2]}\end{array}$ \\
\hline $\begin{array}{l}\text { Polycyclic aromatic } \\
\text { hydrocarbons }\end{array}$ & 80 to 160 micrograms \\
\hline o-Toluidine & 32 nanograms \\
\hline Vinyl chloride & 5.6 to 27 nanograms \\
\hline
\end{tabular}

From: $11^{\text {th }}$ Report on Carcinogens by the U.S. Department of Health and Human Services, 2009. 
TABLE 1.2

Reference Cigarettes Analyses

\begin{tabular}{|c|c|c|c|}
\hline & $\begin{array}{c}\text { TPM } \\
\mathbf{m g} / \mathbf{C I G}\end{array}$ & $\begin{array}{c}\text { FTC TAR } \\
\mathbf{~} \mathbf{~ g} / \mathbf{C I G}\end{array}$ & $\begin{array}{c}\text { NICOTINE } \\
\mathbf{~} \mathbf{~ g} / \mathbf{C I G}\end{array}$ \\
\hline $\mathbf{1 R 3 F}^{\mathbf{1}}$ & 18.10 & 15.0 & 1.16 \\
\hline $\mathbf{1 R 5 F}^{2}$ & 2.08 & 1.67 & 0.16 \\
\hline $\mathbf{2 R 4 F}^{2}$ & 11.7 & 9.7 & 0.85 \\
\hline
\end{tabular}

$130 \mathrm{~mm}$ butt length (Length of cigarette butt remaining after smoking) $235 \mathrm{~mm}$ butt length (Length of cigarette butt remaining after smoking)

TPM - Total Particulate Matter

FTC - Federal Trade Commission

$\mathrm{CIG}$ - Cigarette

From: Chambers, O. The Reference Cigarette. College of Agriculture, Reference Cigarette Program. 


\section{CHAPTER II}

\section{CIGARETTE SMOKE-INDUCED DNA DAMAGE AND REPAIR DETECTED BY THE COMET ASSAY IN HPV-TRANSFORMED CERVICAL CELLS}




\section{A. Introduction}

Epidemiological and clinical data strongly support a major role by the Human Papillomavirus (HPV) in the etiology of cervical cancer [18-19, 23]. However, HPV alone appears to be insufficient for cervical cancer development as studies have shown that the majority of HPV infection is cleared by the immune response within 8-12 months [21]. Further, additional cofactors were found to be required for prolonged expression of the HPV E6 and E7 oncogenes leading to development and progression of cervical abnormalities [36]. One major risk factor in HPV-mediated cervical cancer is cigarette smoking, as it has been consistently linked with the progression of cervical neoplasias to invasive carcinoma [15]. Further, female smokers have two times higher risk of developing cervical cancer than non-smokers [114].

Cigarette smoke-induced genotoxicity results in induction of micronuclei, sister chromatid exchange, chromosomal aberrations, microsatellite instability, DNA strand breaks and oxidative DNA damage $[58,115]$. Cigarette smoke is a heterogeneous mixture of approximately 5,000 chemical compounds, of which several dozens of them are carcinogens, co-carcinogens, mutagens and tumor promoters [116], 
including polycyclic aromatic hydrocarbons (PAH), N-nitrosamines, inorganic and organic compounds [117-118].

Cigarette smoke has been shown to cause a variety of oxidative DNA damage, including the formation of 8-0xo-7,8-dihydro-2deoxyguanosine (8-oxoguanine) [119-120]. 8-Oxoguanine is a common mutagenic DNA lesion which is formed abundantly by intracellular oxidation and exogenous carcinogens like cigarette smoke [86, 121]. It has also been shown that cigarette smoke induces other forms of DNA damage, including single-strand breaks (SSBs) [59, 62] and possibly double-strand breaks (DSBs) [122-123]. In general, strand breaks result from the attack of a variety of endogenous and exogenous factors to the sugar residues of DNA [124]. SSBs represent the initial DNA damage and are often used as a biomarker of exposure [125-127]. DSBs are considered to be more biologically relevant since they can lead to chromosome translocation and cancer if repaired improperly in addition to genetic instability and cell death if left unrepaired [128]. Cellular DNA repair capacity is of particular importance since it is a primary factor in how well a cell can overcome DNA insults by a genotoxic agent. An intact DNA repair system is crucial in order to combat the effects of various carcinogens which can induce DNA damage.

HPV-transfected cervical cells were chosen since it has been proposed that cigarette smoke has a late stage synergistic effect in the cervical carcinogenesis already initiated by HPV infection [15, 129]. In 
order to study the role and possible mechanisms of cigarette smokeinduced DNA damage in the cells we employed Single Cell Gel Electrophoresis (SCGE), also known as the comet assay. It is a sensitive technique to detect DNA strand breaks as well as assess DNA repair kinetics at the single cell level $[125,130]$. We have employed comet assay [131-132] to investigate (i) single- and double-strand DNA breaks following exposure of the HPV16-transformed human ectocervical cell line (ECT1/E6 E7) to cigarette smoke condensate (CSC); (ii) the ability of the cells to repair CSC-induced DNA damage; and (iii) the possibility of oxidative damage as the source of CSC-induced DNA strand breaks by employing ellagic acid (EA) as a known scavenger of reactive oxygen species [133-134].

\section{B. Materials and Methods}

\section{Materials}

Keratinocyte serum-free medium (K-SFM), bovine pituitary extract (BPE), epithelial growth factor (EGF), penicillin/streptomycin, trypsin/EDTA solution and low-melting agarose were from Invitrogen (Carlsbad, CA, USA); sodium $\mathrm{N}$-lauroyl sarcosine, DMSO, Tris and spermine were from Sigma Aldrich (St. Louis, MO, USA); proteinase K was from Roche (Switzerland); EDTA was from Mallinckrodt Chemicals 
(Hazelwood, MO, USA); and ellagic acid was from LKT Laboratories (St. Paul, MN, USA).

\section{Preparation of CSC}

University of Kentucky research cigarettes (2R4F) were smoked in a Borgwardt 30-port smoking machine under standard FTC protocol [135]. The particulates were collected on Cambridge filters and were dissolved in DMSO to obtain a $4 \%$ solution. The stock cigarette smoke condensate solutions were stored in small aliquots at $-80^{\circ} \mathrm{C}$. A fresh vial was used for each experiment.

\section{DNA damage formation}

HPV-16 transformed human ectocenvical cells, ECT1/E6 E7, were a generous donation by Dr. Raina Fichorova, Brigham and Women's Hospital, Harvard Medical School. The cells were routinely cultured as monolayer in K-SFM supplemented with $0.3 \%$ BPE, $0.1 \mathrm{ng} / \mathrm{ml}$ EGF, 0.4 $\mathrm{mM} \mathrm{CaCl} 2,1 \%$ penicillin and streptomycin at $37^{\circ} \mathrm{C}$ and $5 \% \mathrm{CO}_{2}$. Cells were seeded at a density of approximately 6,000 cells $/ \mathrm{cm}^{2}$ in $25 \mathrm{~cm}^{2}$ cell culture flasks. After cells reached 60 to $70 \%$ confluence, they were treated with either $0.2 \% \mathrm{v} / \mathrm{v}$ DMSO or with 4,8 and $12 \mu \mathrm{g} / \mathrm{ml} \mathrm{CSC}$ in DMSO for up to $96 \mathrm{~h}$ in order to induce the maximum DNA strand breaks and then 
harvested by trypsin/EDTA solution. The cells were kept on ice at all times to minimize the DNA repair. All cell culture studies were performed independently three or four times.

\section{DNA repair}

ECT1/E6 E7 cells were treated with 4,8 or $12 \mu \mathrm{g} / \mathrm{ml} \mathrm{CSC} \mathrm{for} 72 \mathrm{~h}$, followed by CSC withdrawal. Residual CSC was removed by washing the cells three times with $5 \mathrm{ml}$ medium, followed by incubation of the cells with the fresh medium for an additional 24,48 , or $72 \mathrm{~h}$ at $37^{\circ} \mathrm{C}$ to allow repair of DNA strand breaks to occur.

\section{Ellagic acid treatment}

ECT1/E6 E7 cells were pre-treated with EA (5 or $15 \mu \mathrm{M}, 0.2 \%$ DMSO) for $20 \mathrm{~h}$. Following this, medium was removed and fresh media containing CSC $(4,8$ or $12 \mu \mathrm{g} / \mathrm{ml}, 0.2 \%$ DMSO) and $\mathrm{EA}(5$ or $15 \mu \mathrm{M}, 0.2 \%$ DMSO) were added for $72 \mathrm{~h}$. Vehicle (0.2\% DMSO)-treated controls were analyzed in parallel. 


\section{Comet Assay}

DNA single- and double-strand breaks were detected by alkaline and neutral comet assays, respectively, as described [130-131]. Briefly, 100,000 cells per slide were embedded in $1 \%$ low-melting agarose on frosted microscopic glass slides. The cells were subsequently lysed (1.25 $\mathrm{M} \mathrm{NaCl}, 0.1 \%$ sodium $\mathrm{N}$-lauroyl sarcosine, $50 \mathrm{mM} \mathrm{Na-EDTA}, 100 \mathrm{mM}$ Tris- $\mathrm{HCl}, \mathrm{pH} 10)$, digested with proteinase $\mathrm{K}(1.25 \mathrm{M} \mathrm{NaCl}, 5 \mathrm{mM}$ EDTA, 5 $\mathrm{mM}$ Tris- $\mathrm{HCl}, 0.5 \mathrm{mg} / \mathrm{ml}$ proteinase $\mathrm{K}, \mathrm{pH} 10)$ and DNA precipitated $(50 \%$ ethanol, $1 \mathrm{mg} / \mathrm{ml}$ spermine, $20 \mathrm{mM}$ Tris- $\mathrm{HCl}, \mathrm{pH} 7.4$ ).

For single-strand breaks, the DNA was unwound by first soaking the slides in strong alkaline buffer (10 mM Na-EDTA, $3 \mathrm{M} \mathrm{NaCl}, \mathrm{pH} 13$ ) and then electrophoresed in the same buffer $\left(26 \mathrm{~V} ; 400 \mathrm{~mA}\right.$, at $\left.4^{\circ} \mathrm{C}\right)$. For double-strand breaks, the DNA was uncoiled using a neutralizing buffer (500 mM Na-EDTA, 0.2\% DMSO, $500 \mathrm{mM} \mathrm{NaCl}, 100 \mathrm{mM}$ Tris-HCl, pH 9) and then electrophoresed in the same buffer $\left(26 \mathrm{~V} ; 250 \mathrm{~mA}\right.$ at $\left.4^{\circ} \mathrm{C}\right)$.

After staining the cells with ethidium bromide, comets were visualized using a light microscope attached to a digital camera with 510 excitation and 590 emission filters. The images were analyzed using the software Comet Assay IV. (Perspective Instruments, Haverhill, UK). A total of 50 cells per slide and 2 slides per sample were scored for "tail length" and "tail moment". Tail length is defined as the distance between the center of the comet head and the end of the tail. Tail moment is often 
considered a more significant indicator of DNA damage since it refers both to the distance of DNA migration and the amount of DNA in the tail [136]. The higher the values of tail length and tail moment, as computed by the software, the higher the level of DNA damage.

\section{Statistical analysis}

The differences between comet assay mean values were analyzed for statistical significance $(p<0.05)$ using Student's $t$-test. Statistical analysis of dose response was calculated using one-way Analysis of Variance (ANOVA).

\section{Results}

\section{Effect of CSC on DNA strand breaks with time}

Figure 2.1 depicts the typical comet-like appearance of DNA strand breaks. ECT1 E6/E7 cells were treated with vehicle and $8 \mu \mathrm{g} / \mathrm{ml} \mathrm{CSC}$ for 24, 48, 72, and $96 \mathrm{~h}$ (Fig. 2.2). The cell viability, as measured by trypan blue dye exclusion, following a dose of $8 \mu \mathrm{g} / \mathrm{ml} \operatorname{CSC}$ (up to $72 \mathrm{~h}$ ) was $\geq$ $80 \%$ contributing to lower background damage and therefore considered ideal to study time response (data not shown). Since the rate of induction of single- and double-strand breaks was almost the same (as described 
below) only single-strand breaks were measured. There was a timedependent increase (Figure 2.2) in cells with single-strand breaks for both tail length, ( 2.9 fold; $p<0.0001)$, and tail moment ( 14.4 fold; $p=0.0109$ ),

at $72 \mathrm{~h}$, compared to $0 \mathrm{~h}$. Beyond $72 \mathrm{~h}$, the tail length and tail moment plateaued. Taking this into account, the $72 \mathrm{~h}$ time point was chosen to conduct the DNA damage and repair studies, since the maximum DNA strand breaks occurred at this treatment time.

\section{Single- and double-strand breaks induced by different doses of CSC}

Cells treated with CSC showed a clear dose-response with respect to the tail length and tail moment from $4-12 \mu \mathrm{g} / \mathrm{ml}$ of CSC for both singleand double-strand breaks $(p<0.0001)$ (Figure 2.3). The rate of singleand double-strand break occurrences was essentially the same at all doses tested at $72 \mathrm{~h}$ of CSC treatment for tail length. The tail moment for double-strand breaks was slightly lower as compared to single-strand breaks, although not statistically significant.

Doses of CSC higher than $12 \mu \mathrm{g} / \mathrm{ml}$ had a lethal effect on the cells (not shown). Treatment of the cells with $12 \mu \mathrm{g} / \mathrm{ml} \mathrm{CSC} \mathrm{for} 72 \mathrm{~h}$ generated the longest comet tail indicating the largest number of strand breaks, which represents an increased number of DNA fragments. Panels $3 c$ and $3 d$ represent the number of cells with single- and double-strand breaks, 
respectively distributed at certain tail lengths following treatment with 0,4 , 8 , and $12 \mu \mathrm{g} / \mathrm{ml}$ concentrations of CSC; increase in concentration of CSC indicates a greater number of strand breaks.

\section{DNA repair studies}

A significant amount of both single- and double-strand breaks were repaired in the first $24 \mathrm{~h}$ following treatment with 4,8 and $12 \mu \mathrm{g} / \mathrm{ml} \mathrm{CSC}$ for $72 \mathrm{~h}$ (Figure 2.4): At the highest concentration of CSC, tail length and tail moment of single strand breaks were repaired by $27 \%$ and $32 \%$, respectively after $24 \mathrm{~h}$; tail length and tail moment of double-strand breaks were repaired by $21 \%$ and $44 \%$, respectively at the same concentration. No further removal of either single- or double-strand breaks was observed. DNA repair at the two lower concentrations of CSC followed essentially the same kinetics (Figure 2.4).

\section{Ellagic acid and oxidative damage}

Cells treated with $5 \mu \mathrm{M}$ EA showed a reduction in the level of single-strand breaks measured both as tail length (9\%) and tail moment (15\%) although not statistically significant (Figure 2.5). At a higher dose (15 $\mu \mathrm{M}$ ) of EA, however, single-strand breaks were diminished significantly $-28 \%(p=0.0019)$ reduction in tail length and $50 \%(p=$ 
0.0115 ) reduction in tail moment (Figure 2.5). The tail length of doublestrand breaks were also significantly reduced by nearly $8 \%(p=0.0076)$ and $14 \%(p=0.0042)$ with 5 and $15 \mu \mathrm{M}$ EA treatment, respectively. The tail moment, however, was unaltered.

\section{E. Discussion}

It has been reported that cigarette smoke has a late stage synergistic effect in cervical carcinogenesis initiated by HPV infection [15, 129]. Nonetheless, the mechanism of smoking on the neoplastic progression of cervical cells remains inconclusive. The aim of this study was to investigate CSC-induced DNA damage and subsequent repair in HPV-immortalized cervical cells. In order to further understand the interplay of smoking and cervical carcinogenesis, we employed the comet assay to measure single- and double-strand DNA damage and subsequent repair.

The principle of the comet assay is based on alterations found in DNA such as strand breaks resulting in the extension of DNA loops from lysed and salt-extracted nuclei, which, in turn, form a comet-like tail after either alkaline electrophoresis, indicating SSBs, or neutral electrophoresis, indicating DSBs $[130,137]$. In previous studies in which the effects of cigarette smoke condensate/cigarette smoke on DNA strand breaks were investigated by the comet assay, only DNA single-strand breaks were 
detected $[62,138-139]$. The interaction of CSC on DNA strand breaks in HPV-transformed cervical cells has not been reported previously.

In the present study, we showed that CSC in HPV-infected cervical cells is able to induce similar levels of DNA single- and double-strand breaks in a dose- and time-dependent manner. Based on experimental and epidemiological studies, cigarette smoke accounts for a significant risk factor in developing cancer of various organs [42], including those of the cervix [26, 43-44]. Numerous genotoxic effects of CSC, including DNA strand breaks, have also been demonstrated in other human culture cells $[59-62,140]$. However, this finding has not been demonstrated previously in HPV-infected cervical cells. We speculated that DNA integrity is compromised when cigarette smoke acts in conjunction with HPV in the cells. Nonetheless, the effects of CSC as a heterogeneous component on the extent of DNA damage in the cells are complex. Moreover, since CSC consists of many tumor promoters such as catechol and hydroquinone [141] as well as inhibitors such as unsaturated aldehydes [142], it is difficult to pinpoint the specific carcinogens, present in CSC, which are responsible for DNA strand breaks. Our finding supports epidemiological data suggesting that cigarette smoke acts in synergy with HPV in cervical carcinogenesis.

In the current study, single- and double-strand breaks were two types of DNA damage investigated. SSBs are considered an indicator of early damage [125]. Also, SSBs are intermediate processing products of 
DNA damage, which, if left unrepaired, may develop into mutagenic and lethal double-strand breaks [143]. Conversely, DSBs are considered more biologically relevant lesions [125]. DSBs are a more disruptive form of strand break since they can either lead to cell death or loss of genetic information, if left unrepaired, or they may cause neoplastic progression if the repair process is compromised $[128,144]$.

Since the DNA repair capability is an important factor believed to influence the outcome of DNA damage, we examined the repair efficiency of HPV-transformed cervical cells in combating CSC-induced strand breaks. From our results, it appears that cells attain DNA single- and double-strand breaks at all concentrations of CSC tested and that maximum repair of DNA single- and double-strand breaks occurred during the first $24 \mathrm{~h}$ and plateaued afterwards. The present study also suggests that the repair of CSC-induced DNA damage occurred only during the first $24 \mathrm{~h}$ and no further repair was observed. This trend was observed for both single- and double-strand breaks. This observation is in agreement with radiation-induced SSBs in leukocytes [145] and SSBs and DSBs in mouse embryo fibroblasts [125]. In the latter study, in contrast to the current findings, SSBs were completely repaired after $24 \mathrm{~h}$ post radiation, whereas DSBs were not [125]. Additionally, based on our repair studies, the ability of the cells to repair CSC-induced DNA strand breaks reached a plateau after first $24 \mathrm{~h}$ regardless of CSC concentration. Therefore, it can be concluded that the cellular repair response depends on the cell type, 
the nature of strand breaks, the type of carcinogen as well as the DNA repair capacity of the cells. It is possible that at CSC concentrations lower than the ones tested in this study, ECT1/E6 E7 cells endure less strand breaks, which could be repaired efficiently. However, if DNA repair capacity of the cells is compromised due to the HPV infection, the CSCinduced breaks may be poorly repaired which may lead to the accumulation of mutations.

It has been reported that HPV infection compromises the DNA repair system such as alteration in gene amplification, expression of DNA repair enzymes [146] and microsatellite instability [147]. It is conceivable that expression and function of genes responsible for the repair of strand breaks might be responsible for the differences in the rate of the repair of CSC-induced damage. The repair of HPV16-immortalized ectocervical epithelial cells to PAHs, such as benzo(a)pyrene (BP), present in cigarette smoke, was found to be impaired due to reduced p53 in those cells [148]. Moreover, BP has been shown to manipulate multiple HPV life cycle functions, which, in turn, may influence cervical cancer progression [149].

Cigarette smoke may also contribute to the deficiency of DNA repair in rejoining of the strand breaks. In this study, both single- and double-strand DNA breaks were highly persistent. We found that CSCinduced DNA damage was much more persistent than ionizing radiationinduced damage which was completely repaired within $2 \mathrm{~h}$ [62]. This finding might be due to genotoxic compounds present in CSC which have 
been shown to slow DNA repair kinetics [62]. It has been reported that acrolein, also a constituent of cigarette smoke, was found to inhibit the repair of DNA damage [150]. Therefore, it is reasonable to conclude that impaired DNA repair by CSC may have a role in fixation of DNA damage in cervical cells, leading to accumulation of mutations and cancer development. In theory, SSBs should be repaired by using the undamaged strand as a template, whereas DSBs can be repaired by two repair pathways, namely homologous recombination or non-homologous end-joining $[125,151]$. Indeed, further investigation is required to identify the repair pathway that may have been affected in the CSC-induced cervical cells. To the best of our knowledge, this is the first demonstration of the kinetics of CSC-induced DNA strand breaks and of global repair of the damage in human cervical cells.

In order to investigate if free radicals are the source of oxidative DNA damage, we examined the effect of an antioxidant, EA, in mitigating CSC-induced DNA damage. In our investigation, EA showed significant, dose-dependent reduction in CSC-induced single- and double-strand breaks. Cigarette smoke contains a broad range of carcinogens, including redox-active catechols, which may lead to the induction of oxidative stress and eventually contribute to increased genomic instability and cancer development [152-153], including cervical cancer [154]. It has been reported that the highly reactive hydroxyl radicals generated from cigarette smoke contribute in the formation of DNA single-strand breaks in vitro [59, 
120]. EA is a phenolic lactone that exerts its anticarcinogenic and antimutagenic activities through several mechanisms, including scavenging reactive oxygen species $[133,155-156]$. This observation is in agreement with previous studies investigating the antioxidant activities of EA on DNA strand breaks [157-158]. Our data suggest that CSC-induced DNA strand breaks may, in part, originate from free radicals.

Interestingly, we found that EA did not significantly reduce basal levels of both single- and double-strand breaks. Based upon our findings, we speculate that there may be two possible explanations for the lack of attenuation of basal levels of DNA strand breaks. First, cigarette smoke contains more than 5,000 chemicals with diverse interactions [158], which may influence the effectiveness of EA to act as an antioxidant. Second, in our laboratory, it has been reported that EA was a potent inhibitor of dibenzo[a,I]pyrene-DNA adducts in a microsome-mediated test system by $\geq 75 \%$ [159]. However, using a cellular system, EA inhibited the same adducts by only $16 \%$ [160]. Thus, it seems reasonable to speculate that, in the present study, limited EA uptake by the cells may be a possibility for lower inhibition of CSC-induced oxidative stress in the presence of the antioxidant. Despite the fact that EA has antioxidant activity and is a direct radical scavenger [133], the mechanisms by which EA can further reduce DNA strand breaks induced by CSC in the cervical cells await further study. There are ongoing experiments in this laboratory to further 
investigate whether reactive oxygen species are a source of CSC-induced DNA damage in the HPV- infected cervical cells.

In conclusion, our study highlights the inability of HPV-transfected cells to completely repair CSC-induced DNA damage. Furthermore, we demonstrated that the oxidative stress may be the source of DNA damage caused by CSC. The significance of our study stems from the fact that DNA lesions and/or persistent DNA strand breaks [89], caused by the inability of the cells to remove the damage, may result in accumulation of mutations leading to cancer. These findings support the previously found epidemiological association between HPV infection, cigarette smoke exposure and cervical cancer development $[46,161]$. Our result suggests that cigarette smokers infected with HPV may be at a higher risk for cervical cancer. 

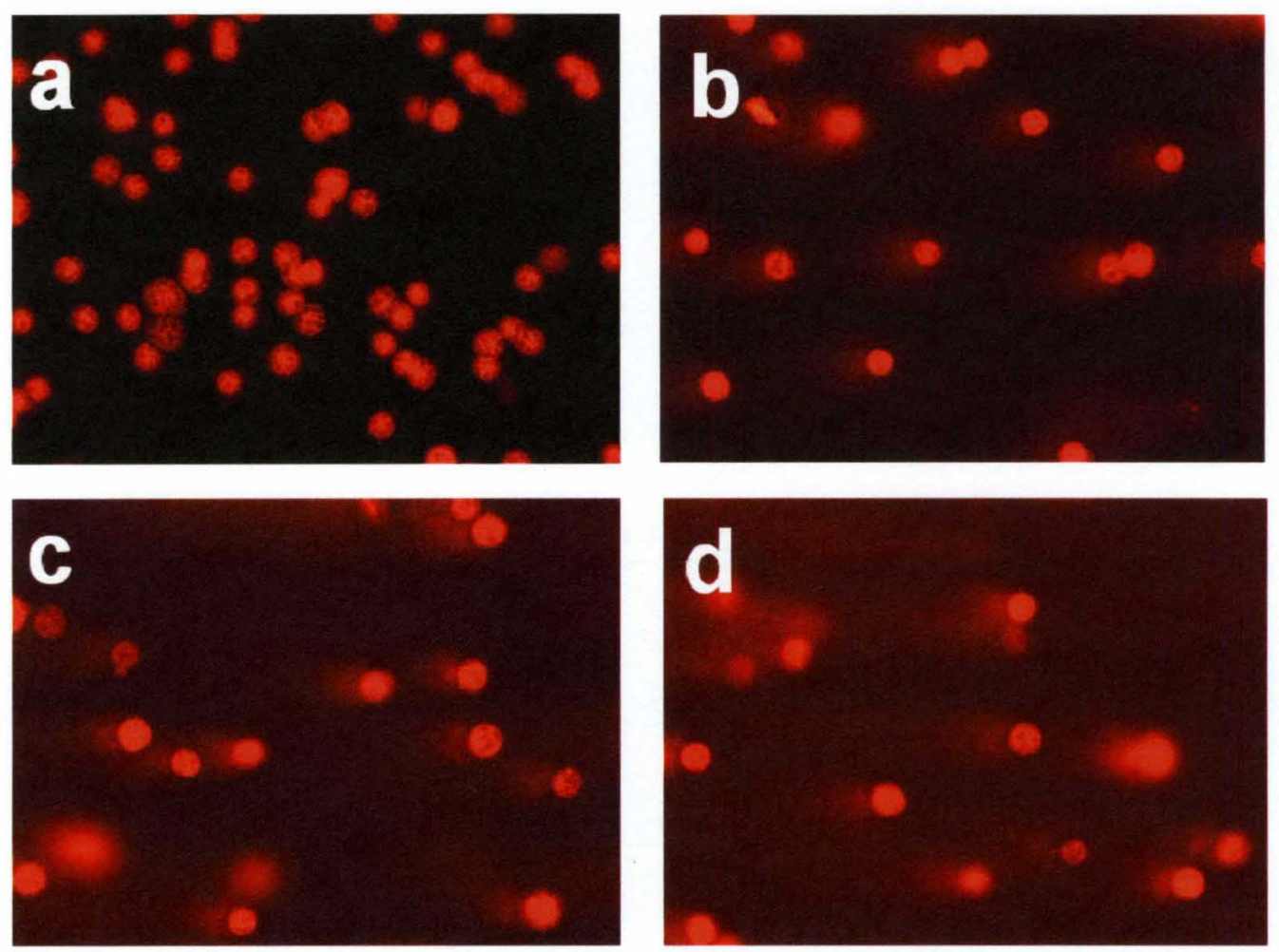

Figure 2.1: Representative comet assay images showing single-strand breaks in DNA of ECT1/E6 E7 cells treated with vehicle, $0.2 \%$ DMSO (a), and 4 (b), 8 (c) and 12 (d) $\mu \mathrm{g} / \mathrm{ml} \mathrm{CSC} \mathrm{for} 72 \mathrm{~h}$. 

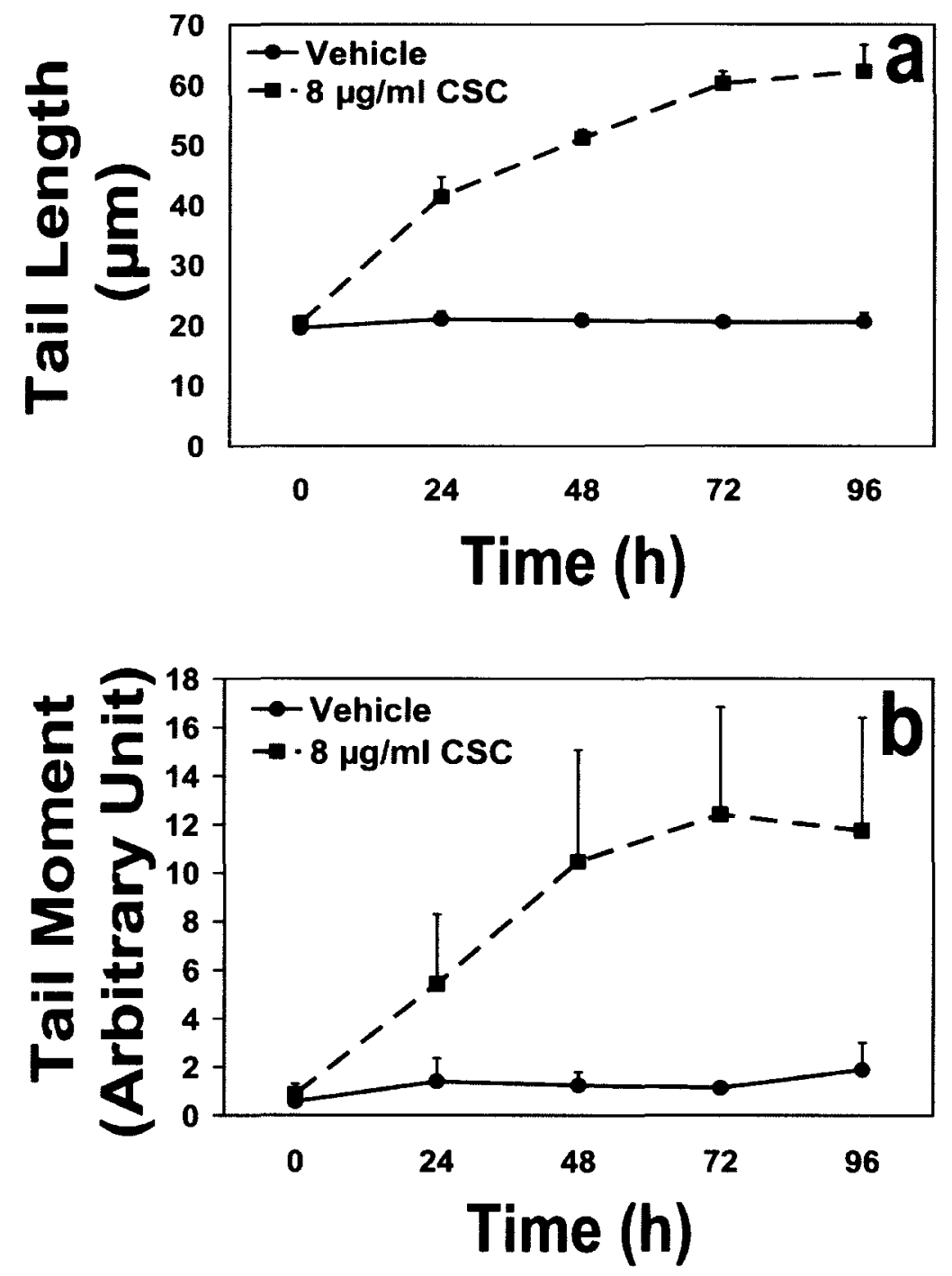

Figure 2.2: Time response of CSC on DNA single-strand formation as detected by (a) mean tail length (b) mean tail moment in alkaline comet assay following treatment of cells with $8 \mu \mathrm{g} / \mathrm{ml}$ CSC. Data represent mean $\pm \mathrm{SD}$ of 4 independent experiments. 

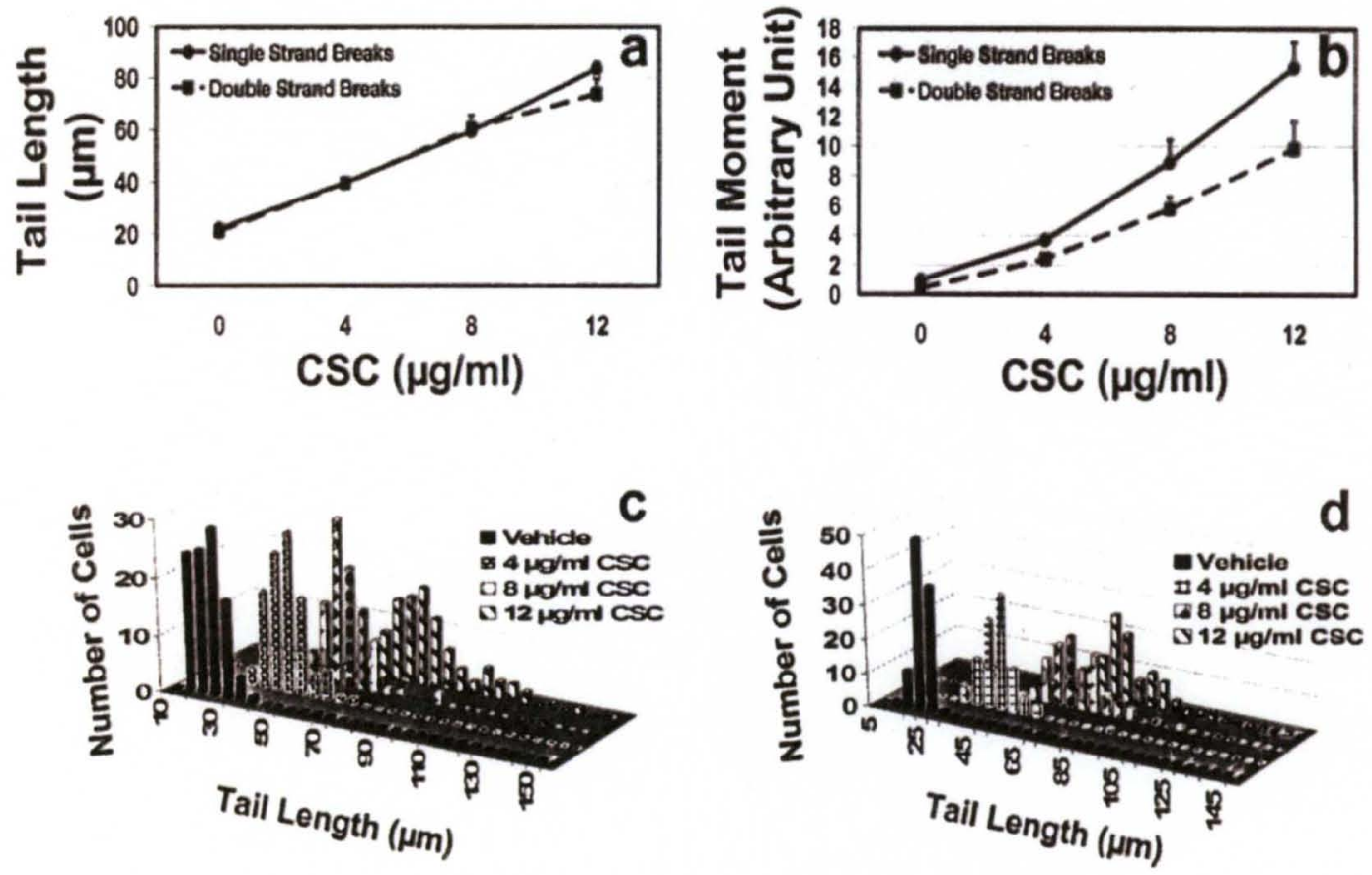

Figure 2.3: Dose response of CSC on single- and double-strand breaks:

(a) mean tail length; (b) mean tail moment; and (c) and (d) distribution pattern of cells with single- and double strand breaks, respectively as measured by tail length after $72 \mathrm{~h}$, respectively. Data represent mean \pm SD of 4 independent experiments. 

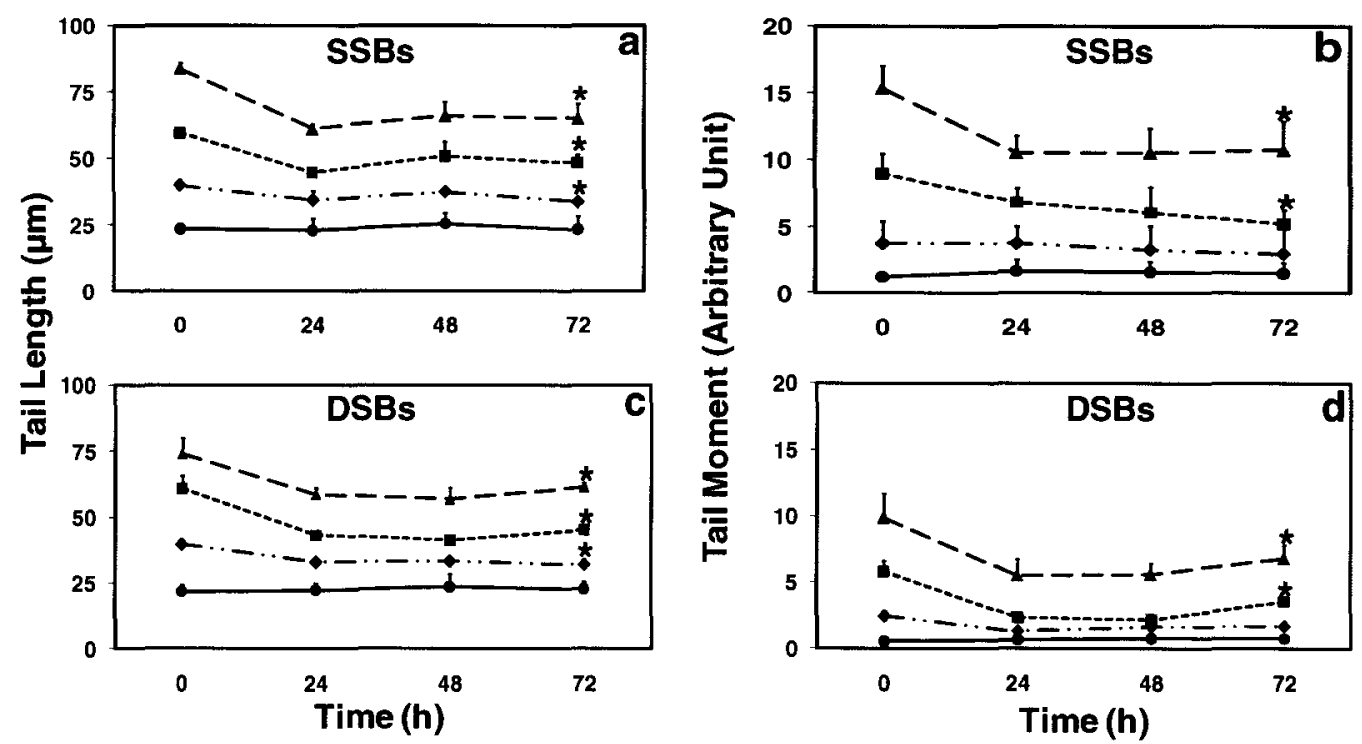

Figure 2.4: Repair of single- (a, b) and double-strand (c, d) DNA breaks. a, c: tail length; c, d: tail moment. Cells were treated for $72 \mathrm{~h}$ with $0(-\bullet), 4$ $(\rightarrow-, 8(-)$ and $12(-) \mu \mathrm{g} / \mathrm{ml} \mathrm{CSC}$, freed from residual CSC, and then incubated for up to $72 \mathrm{~h}$ for DNA repair to occur. Data represent mean \pm SD of 4 independent experiments. ${ }^{*} P<0.05$. 

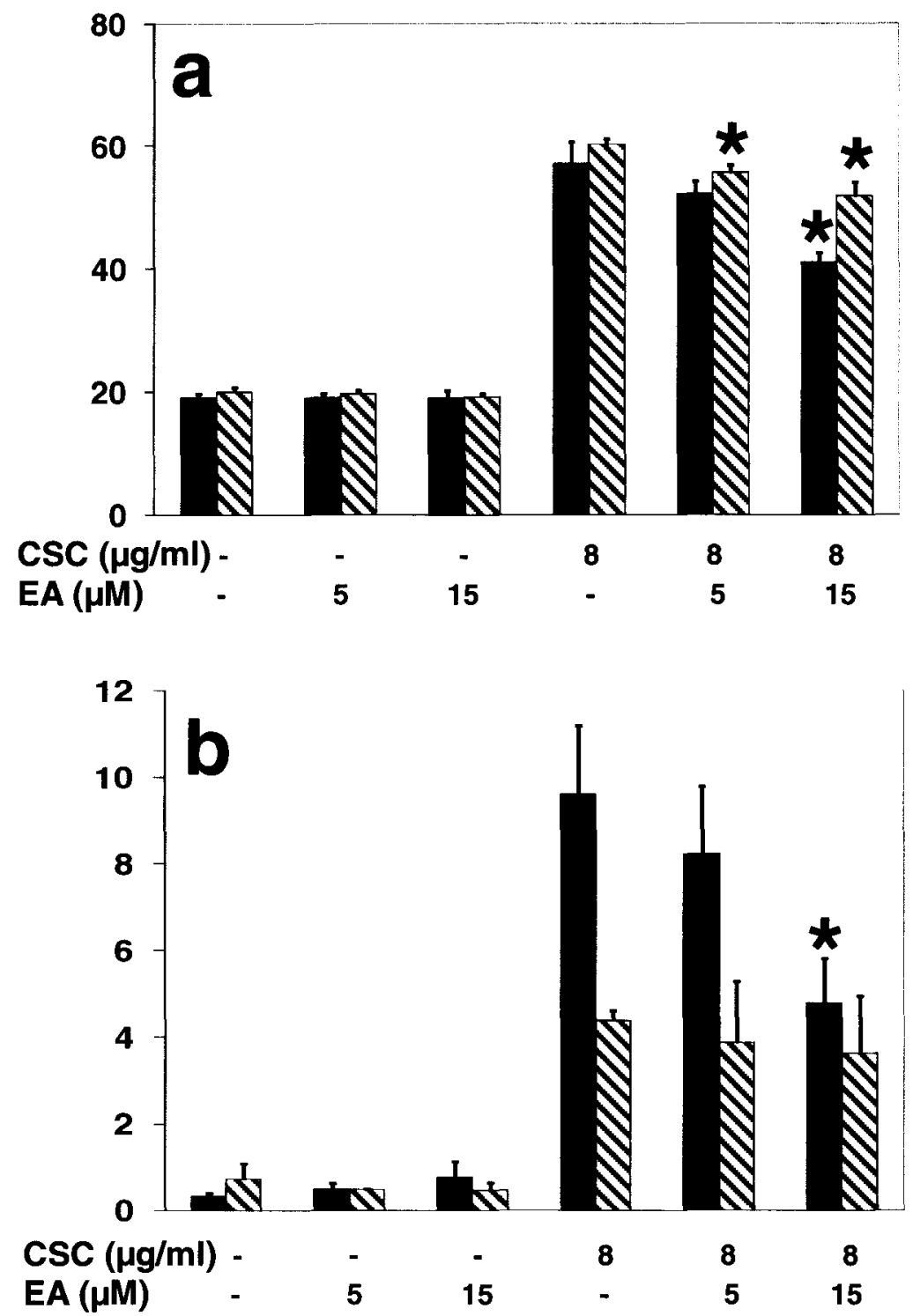

Figure 2.5: Effect of ellagic acid on cigarette smoke condensate-induced single- and double-strand DNA breaks as measured by tail length (a) and tail moment (b). The cells were pretreated with 5 or $15 \mu \mathrm{M}$ ellagic acid for $20 \mathrm{~h}$, followed by co-treatment with $8 \mu \mathrm{g} / \mathrm{ml}$ cigarette smoke condensate for $72 \mathrm{~h}$. Data represent mean $\pm \mathrm{SD}$ of 3 independent experiments. ${ }^{*} \mathrm{P}<$ 0.05. single-strand breaks; \$louble-strand breaks. 


\section{CHAPTER III}

\section{CIGARETTE SMOKE CONDENSATE-INDUCED OXIDATIVE DNA}

DAMAGE AND ITS REMOVAL IN HUMAN CERVICAL CANCER CELLS 


\section{A. Introduction}

A role of cigarette smoking as a causative factor in the development of cervical cancer was proposed by Winkelstein [41]. Considering the fact that the cause of cervical cancer is multifactorial and HPV infection alone is not sufficient but necessary in its etiology, the interaction of HPV and cigarette smoke has been proposed [44-46]. The effects of cigarette smoke as a heterogeneous component on the extent of oxidative DNA damage in cells are two-fold. First, the tar and gas-phase of smoke are rich sources of free radicals, such as the quinonehydroquinone-semiquinone system and nitric oxide [162], which can induce different oxidative DNA lesions, such as 8-oxo-7,8-dihydro-2'deoxyguanosine (8-oxodG) [163]. Second, the involvement of cigarette smoke free radicals in carcinogenesis has been well documented and reviewed elsewhere $[75,164-165]$. The levels of oxidative base lesions were reported higher in smokers as compared to non-smokers [84-86]. Insight into the mechanisms by which DNA of high-risk HPV transforms cervical cells arose from the realization that the virus oncoproteins interact with specific cell regulatory proteins. The E6 oncoprotein causes degradation of the cellular protein p53 by the ubiquitin-proteasome pathway; the E7 oncoprotein interacts with the retinoblastoma protein and 
inactivates it [32]. The tumor suppressor p53 primarily functions as a transcription factor, but several responses can be generated by $p 53$, including cell cycle arrest or apoptosis [93]. The status of p53 in cervical cancer has previously been investigated. It appears that the inactivation of the normal function of $\mathrm{p} 53$ is a critical step in human cervical carcinogenesis, which can be either caused by mutation, as in HPVnegative cells [166], or from complex formation with E6 oncoproteins in case of HPV-positive cervical cancer cells [97].

HPV-positive cervical cancer cells have been shown to possess residual p53 activity indicating that p53 is not completely inactivated by binding to E6 oncoprotein [107-109]. These findings might indicate the possibility of p53 involvement in HPV-positive cells' response in removing the oxidative DNA damage. There is evidence that p53 has a more positive role in facilitating the repair of oxidative lesion by its involvement in base excision repair (BER), a DNA repair pathway [167]. However, the existence of p53-independent repair pathway should also be considered since cells devoid of HPV sequence did not show a p53-mediated response to oxidative DNA damage [168].

This work was designed to investigate i) the effect of CSC on 8oxodG formation in and its removal from HPV-transfected (ECT1/E6 E7), HPV-positive (CaSki) and HPV-negative (C33A) human cervical cancer cells; and ii) the cell-cycle progression and apoptosis in the CSC-treated ECT1/E6 E7 cells. The transfected cell line was chosen as a standardized 
in vitro model [169] to further understand the interplay of cigarette smoke free radicals and cervical carcinogenesis.

\section{B. Materials and Methods}

\section{Cell Lines and cell culture}

HPV-16 transformed human ectocervical cells, ECT1/E6 E7, were a generous donation by Dr. Raina Fichorova, Brigham and Women's Hospital, Harvard Medical School. HPV-16 positive human cervical cells, CaSki, and HPV-negative human cervical cells, C33A, were purchased from ATCC (Manassas, VA). ECT1/E6 E7 cells were cultured as monolayer in K-SFM supplemented with $0.3 \%$ BPE, $0.1 \mathrm{ng} / \mathrm{ml}$ EGF, 0.4 $\mathrm{mM} \mathrm{CaCl}, 1 \%$ penicillin and streptomycin at $37^{\circ} \mathrm{C}$ and $5 \% \mathrm{CO}_{2}$. CaSki and C33A cells were routinely cultured in RPMI-1640 media supplemented with $5 \%$ fetal bovine serum (FBS) in a humidified atmosphere of $5 \% \mathrm{CO}_{2}$ in air at $37^{\circ} \mathrm{C}$. All the cell lines were seeded at a density of approximately 6,000 cells $/ \mathrm{cm}^{2}$ in $25 \mathrm{~cm}^{2}$ cell culture flasks. All the cell lines were authenticated by DNA (STR) profiling at the Core Fragment Analysis Facility at Johns Hopkins University on March, 15, 2010. 


\section{Preparation of CSC}

University of Kentucky research cigarettes (2R4F) were smoked in a Borgwardt 30-port smoking machine under standard FTC protocol [135]. The particulates were collected on Cambridge filters and were dissolved in DMSO to obtain a $4 \%$ solution. The stock CSC solutions were stored in small aliquots at $-80^{\circ} \mathrm{C}$. A fresh vial was used for each experiment.

\section{8-oxodG formation}

CSC treatment of the cells was carried out as described elsewhere [170]. Briefly, after cells reached 60 to $70 \%$ confluence, they were treated with either $0.2 \% \mathrm{v} / \mathrm{v}$ DMSO or with 4,8 and $12 \mu \mathrm{g} / \mathrm{ml} \mathrm{CSC}$ in DMSO for up to $72 \mathrm{~h}$ in order to induce the maximum oxidative DNA damage and then harvested by trypsin/EDTA solution. The cells were kept on ice at all times to minimize the DNA repair. 8-oxodG formation was measured by flow cytometry.

\section{DNA repair}

The cells were treated with 4,8 or $12 \mu \mathrm{g} / \mathrm{ml} \mathrm{CSC}$ for $72 \mathrm{~h}$. Residual CSC was removed by washing the cells three times with $5 \mathrm{ml}$ medium, followed by incubation of the cells with the fresh medium for an additional 
24,48 , or $72 \mathrm{~h}$ at $37^{\circ} \mathrm{C}$ to allow repair of oxidative DNA damage to occur. Subsequently, 8-oxodG levels were measured by flow cytometry.

\section{Flow cytometry and ImageStream analysis of 8-oxodG and p53} expressions

Primary polyclonal goat anti-8-OHdG antibody was purchased from Chemicon International; and primary polyclonal goat anti-p53 antibody was purchased from Santa Cruz biotechnology. Briefly, all cell lines were harvested and fixed in $70 \%$ ethanol and stored at $-20^{\circ} \mathrm{C}$ for later processing. Upon thawing, cells were washed one time in phosphate buffered saline (PBS) followed by another wash with FACS buffer (1\% BSA in PBS). Next, cells were permeabilized with $0.1 \%$ Triton-X-100 for 20 minutes on ice at room temperature (RT), followed by washing with PBS. For 8-oxodG staining, primary antibody $(1-3 \mathrm{mg} / \mathrm{ml})$ was incubated with Zenon Fab-Alexa Fluor 488 goat IgG labeling reagent $(5 \mu l)$ (Invitrogen, Carlsbad, CA), and cells were stained for $30 \mathrm{~min}$ at room temperature in dark. Alternatively, to stain for p53, fixed, washed and permeabilized cells were stained with $1 \mu \mathrm{g}$ p53 primary antibody labeled with $5 \mu$ of the Zenon Fab-Alexa Fluor 488 goat IgG labeling reagent for $30 \mathrm{~min}$ at room temperature in dark. Cells were washed with FACS buffer. For nuclear staining, $10^{6}$ cells were incubated with $0.25 \mu \mathrm{g}$ of 7-AminoActinomycin D (7AAD; BD-PharMingen) resuspended in FACS buffer and 
analyzed within $30 \mathrm{~min}$. Around $5 \times 10^{4}$ cells were analyzed by flow cytometry using a FacsCalibur flow cytometry and CellQuest ${ }^{\mathrm{TM}}$ software (Becton-Dickenson, USA) to assess cell cycle, apoptosis and p53 expression. Expression of p53 was defined in terms of total fluorescent intensity, which was calculated by multiplying number of cell events by mean intensity. Correspondingly, $10^{4}$ stained cells were analyzed using an ImageStream System and IDEAS 3.0 software (Amnis) to assess 8-oxodG expression. 8-oxodG total fluorescent intensity was calculated by multiplying the cell events by mean fluorescent intensity.

\section{Cell cycle analysis}

Cell cycle phase distribution of ECT1/E6 E7 cells was analyzed by flow cytometry (BD Biosciences, San Jose, CA). CSC-treated cells and appropriate controls $\left(2 \times 10^{5}\right)$ were collected after $24 \mathrm{~h}$, washed twice with PBS and fixed with ice-cold $70 \%$ ethanol at $4^{\circ} \mathrm{C}$ for $30 \mathrm{~min}$ to $1 \mathrm{~h}$. The cells were then treated with $10 \mu \mathrm{g} / \mathrm{ml}$ propidium iodide (PI, Sigma- Aldrich, St. Louis, MO), $2.5 \mu \mathrm{g} / \mathrm{ml}$ RNase A (Sigma- Aldrich, St. Louis, MO) and $0.1 \%$ Triton $\mathrm{X}-100$ in dark at $37^{\circ} \mathrm{C}$ for $30 \mathrm{~min}$. Data were collected, stored and analyzed using FlowJo software (Becton Dickinson). 


\section{Apoptosis detection}

Apoptosis in ECT1/E6 E7cells was detected using an Alexa Fluor 488 annexin V/propidium iodide kit (Invitrogen Co., Carlsbad, CA), according to the manufacturer's instructions. Briefly, $1 \times 10^{6}$ cells were treated with vehicle or $4,8,12 \mu \mathrm{g} / \mathrm{ml} \mathrm{CSC}$ for $24 \mathrm{~h}$. After harvesting, cells were washed with cold PBS, and then stained with $5 \mu$ annexin V-FITC and $0.1 \mu \mathrm{g} / \mathrm{ml}$ propodium iodide (PI) for each $100 \mu \mathrm{l}$ of cell suspension and incubated at room temperature for $15 \mathrm{~min}$. The apoptotic cells were determined using FACScalibur flow cytometry (Becton Dickinson, San Jose, CA). Data analysis was performed using FlowJo software (Becton Dickinson). It is important to note that a quadrant quantification method could not be used in apoptotic cell determination, since CSC treatment affected the cells' distribution using that method. Therefore, both early apoptotic (Annexin V-positive and PI-negative) and late apoptotic (Annexin V-positive and PI-positive) cells were determined in the cell death determination.

\section{Statistics}

The total fluorescent intensity levels are expressed as the mean \pm SD (standard deviation) and analyzed for statistical significance $(p<0.05)$ 
using Student's t-test. Statistical analysis of dose response was calculated using One-way Analysis of Variance (ANOVA).

\section{Results}

\section{8-OxodG formation in HPV-transfected cervical cells}

A significant increase (3-fold; $p=0.004$ ) in 8-oxodG level was detected following treatment of cells with $12 \mu \mathrm{g} / \mathrm{ml} \mathrm{CSC} \mathrm{for} 24 \mathrm{~h}$ compared with vehicle treatment (Fig. 3.1a,b); the 8-oxodG levels were further increased (3-fold; $p=0.01$ ) after $72 \mathrm{~h}$ (Fig. 3.1c,d). Formation of 8-oxodG lesion was both dose- $(p=0.01)$ and time- $(p=0.002)$ dependent (Fig. $3.1 e, f)$.

\section{8-OxodG removal in cervical cells}

To examine the ability of cervical cells to remove CSC-induced oxidative DNA damage, we investigated the residual 8-oxodG total fluorescent intensity for different periods of recovery time. The highest level of oxidative DNA damage measured as total fluorescent intensity $x$ $10^{5}$ was found to be in ECT1/E6 E7 cells (104 \pm 19 ), followed by CaSki $(2.7 \pm 0.71)$ and $C 33 A(0.66 \pm 0.083)$ cells. 
ECT1/E6 E7 and C33A cells showed a 3- $(p=0.007)$ and 2-fold ( $p$ $=0.02$ ) increase in 8-oxodG level in the first $24 \mathrm{~h}$, respectively (Fig. 3.2a, $c$, iv). In contrast, a 3 -fold $(p=0.07)$ decrease in oxidative damage was observed in CaSki cells in the first $24 \mathrm{~h}$ (Fig. 3.2b, iv). However, 8-oxodG lesion was essentially removed from all the cell lines by $72 \mathrm{~h}$ (Fig. 3.2a, b, c: i, ii, iii, iv).

\section{3. p53 assessment in cervical cells}

The different cervical cells treated with vehicle or CSC during the repair phase of 8 -oxodG were also analyzed for p53 levels in order to elucidate its involvement in cell cycle phase distribution, apoptosis induction, and removal of oxidative DNA lesion. As quantified by flow cytometry. p53 total fluorescent intensity was increased by 2 and 5 fold in ECT1/E6 E7 (Fig. 3.3a) and CaSki cells (Fig. 3.3b), respectively, but it was diminished by 1.7 fold in C33A cells (Fig. 3.3c).

\section{Cell cycle phase distribution in HPV-transfected cervical cells}

p53 is non-functional in cervical cells harboring HPV infections due to the co-expression of the E6 oncoprotein. Therefore, a CSC-induced cell cycle arrest is not expected in these cells. To test this, we investigated the cell cycle changes in immortalized cervical cells after CSC exposure for 24 
h. Nearly one half $(46.6 \%)$ of vehicle-treated cells were at $G_{1}$ phase, $24.9 \%$ in $S$ phase and and $28.3 \%$ in $\mathrm{G}_{2}$ phase. After treatment with CSC (12 $\mu \mathrm{g} / \mathrm{ml}$ ), the $G_{1}$ phase cells increased to $60.3 \%$ while the proportion of $S$ phase decreased to $17.4 \%$. However, there was no significant change in percentage of cells in $\mathrm{G}_{2}$ phase post-CSC exposure (Fig. 3.4). These data suggest that $C S C$ treatment resulted in $G_{0} / G_{1}$ phase arrest.

\section{Apoptosis induction in HPV-transfected cervical cells}

We examined the percentage of cells going through apoptosis as a possible mechanism by which CSC affects cells. CSC treatment induced apoptosis, as evidenced by a dose-dependent increase in the percentage of apoptotic cells at $24 \mathrm{~h}$ treatment in ECT1/E6 E7 cells: $9.7 \%$ of vehicletreated cells were apoptotic which increased to $11.5 \%, 16.6 \%$, and $26.6 \%$ after treatment with $4,8,12 \mu \mathrm{g} / \mathrm{ml} \mathrm{CSC}$ treatment, respectively. Fig. 3.5 depicts the effect at the highest concentration tested.

\section{E. Discussion}

We previously showed that CSC can induce both dose- and timedependent single- and double-strand breaks in cervical cells [170]. In the present study, we show that CSC induces 8-oxodG lesion in a dose- and time-dependent fashion in the HPV-transfected cervical cell line, ECT1/E6 
E7. It is well documented that cigarette smoke or its components induce oxidative DNA damage [58], which is believed to be highly mutagenic and carcinogenic [171]. In the present study, the highest levels of oxidative DNA damage was observed by treatment of cervical cells with $12 \mu \mathrm{g} / \mathrm{ml}$ CSC for $72 \mathrm{~h}$. This highlights the inherent vulnerability of cervical cancer cells to CSC-induced oxidative stress; a dose- and time-related increase in 8-oxodG lesion in cervical cells emphasizes the important role of the CSC-induced oxidative DNA damage in cervical carcinogenesis. Our finding supports epidemiological and experimental data suggesting that cigarette smoke induces oxidative stress.

Furthermore, our data showed that there is a difference in the extent of DNA damage between HPV-transfected and -positive cell lines. We observed that ECT1/E6 E7 cells showed a much higher level of CSCinduced oxidative damage compared to CaSki cells. One possible explanation is that the immortalized cells may be more prone to oxidative injury. This is in agreement with the study of Wilmer and coworkers who showed that cystinotic cell lines immortalized with HPV E6/E7 appear to show increased oxidative stress and altered redox status compared to control cells [172]. C33A cells showed the lowest level of 8-oxodG in response to CSC compared with ECT1/E6 E7 and CaSki cells. This observation might be due to the lack of synergistic impact of HPV on CSCinduced oxidative DNA damage in C33A cells, which are devoid of HPV sequences. This contrasts with the studies of Wei et al. that showed the 
DNA damage and mutation were decreased in cells harboring high risk HPV infection in response to nitric oxide, a source of oxidative damage resulting from cigarette smoking [173]. Nonetheless, we speculate that carcinogenic HPV induces a higher burden of oxidative DNA damage in cervical cells, which may directly point to the critical role of HPV in CSCinduced oxidative injury.

Oxidative DNA damage has been shown to trigger activation of several cellular processes, such as apoptosis and cell cycle checkpoint, in order to maintain cellular homeostasis [174]. The current study demonstrates that in addition to increasing 8-oxodG lesion levels in cervical cells, CSC can induce a dose-dependent increase in apoptosis in ECT1/E6 E7 cells with an arrest at $G_{0} / G_{1}$ phase of cell cycle. However, CSC-induced apoptosis occurred in small percentages of cells. The remaining surviving cells may undergo proliferation, which, in turn, compromises the genomic integrity of the cells by increasing the possibilities of accumulation of DNA mutations. Similar observation was reported by Liu et al. on the effect of cigarette smoke extract on human bronchial epithelial cells [175]. The fact that almost $50 \%$ of cells resist the cell cycle arrest as shown in this study may also play a role in genomic instability; these cells have altered function, which may eventually contribute to cervical pathogenesis. These results also suggest that DNA repair processes can be initiated in response to DNA damage by cigarette smoke since many cells undergo oxidative DNA damage, apoptotic 
activation pathway and cell cycle checkpoint but survive; these cells may harbor genomic instability.

Intriguingly, 8-oxodG removal was most efficient (93\%) in HPVpositive CaSki cells compared to HPV-negative C33A, which did not reveal any significant removal of the oxidative DNA damage up to $48 \mathrm{~h}$. Different scenarios could be considered to explain the differences in the responses of HPV-positive and -negative cell lines to CSC-induced oxidative DNA damage in the present study. One possibility may be due to the residual activity of p53 that has been reported in cervical cancer cells [108-109]; CaSki cells have the highest basal p53 activity [107]. Our data support these findings that basal p53 activity exists in CaSki cells, and to some extent in ECT1/E6 E7 cells, despite the co-expression of the viral E6 oncogene. However, C33A, containing mutant p53 genes lacked the p53mediated response to DNA damage [108]. In concordance with the notion that the p53 protein is functional in HPV-infected cells, we observed that oxidative DNA damage was removed most efficiently in the following order: CaSki $>$ ECT1/E6 E7 > C33A. These findings suggest that the presence of residual p53 activity in HPV-infected cells may have a role in removal of oxidative DNA damage.

Our data clearly showed that expression of p53 differed between HPV-positive and -negative cervical cells in response to CSC-induced DNA damage. The data revealed that p53 expression was not altered in C33A. In contrast, in HPV-positive cells, p53 expression was higher during 
the removal phase of the oxidative DNA damage. These findings are congruent with the results of several studies indicating the existence of residual wild-type p53 activity in cervical carcinoma cells [108-109]. The authors showed HPV-positive cancer cells contained enough p53 to elucidate the activity of a downstream p53 upon exposure to genotoxic stress. On the other hand, Kessis et al [176] showed that DNA damage could not stimulate p53-dependant activities in HPV 16 E6-expressing cells. This finding was due primarily to an augmented E6 response generated by constitutive promoters. The observation that the HPVnegative cells could achieve the same level of DNA repair after $72 \mathrm{~h}$ postexposure along with their unaltered p53 expression may thus provide possible evidence for the existence of the $\mathrm{p} 53$-independent repair pathway [168]. This is due to the inactivation of p53 by the mutation of the gene in these cells $[99,177]$. The precise mechanistic pathway responsible for the delayed repair in C33A and HPV-transfected cells as compared to HPVpositive cells requires further investigation.

The notion that p53 plays a role in BER is supported by the observation that the cell extracts expressing wild-type p53 exhibit an enhanced BER response, which was later abolished upon p53 depletion [167]. Further, a study by Zhou et al. has suggested that p53 is directly involved in BER, which might be due to its dual functions: as a responder of DNA damage and also as an active participant in repairing the induced damage [178]. These studies directly support our findings that p53 may 
have played an integral role in removal of the CSC-induced oxidative damage in the cells expressing wild-type p53 despite the co-expression of the E6 oncogene.

It is of interest to note that oxidative DNA damage was sharply increased in the first $24 \mathrm{~h}$ after withdrawal of CSC in HPV-transfected and -negative cells. A similar observation of a transient increase of oxidative DNA damage following cessation of smoke exposure in the lung of $A / J$ mice has been made [83]. This finding could be explained by the heterogeneous nature of CSC, including carcinogens, promoters, tumor inhibitors, and DNA repair inhibitors $[62,179]$. Thus, the transient increase in oxidative DNA damage detected in our studies could possibly be due to the effect of DNA repair inhibitors in conjunction with free radicalproducing quinones/semiquiniones in CSC.

To conclude, we have demonstrated that CSC-induced oxidative DNA damage is more pronounced in HPV infected cells. We also have shown that 8-oxodG was removed almost completely $72 \mathrm{~h}$ post-exposure in all the cervical cell lines tested, regardless of HPV status. The similarity. of responses to CSC-induced oxidative DNA damage between cell lines expressing mutant p53 or the E6 oncoprotein suggests that interaction of E6 and p53 may be functionally comparable to p53 mutations. These observations lead us to presume the possibility of both p53-dependent and -independent DNA repair pathways in our experimental setting. Though CSC-induced oxidative DNA damage was eventually removed in 
all the cells, the possibility of error-prone DNA repair, however, cannot be ruled out. Chakravarti et al. have shown that $\mathrm{DB}[a, \Omega \mathrm{P}$-induced DNA depurinating lesions are subject to error-prone excision repair in pre-Sphase cells, which generates heteroduplex mutations in the $\mathrm{H}$-ras gene [180]. The error-prone DNA repair may render cells susceptible to the accumulation of genetic mutations associated with carcinogenesis and tumor progression. 

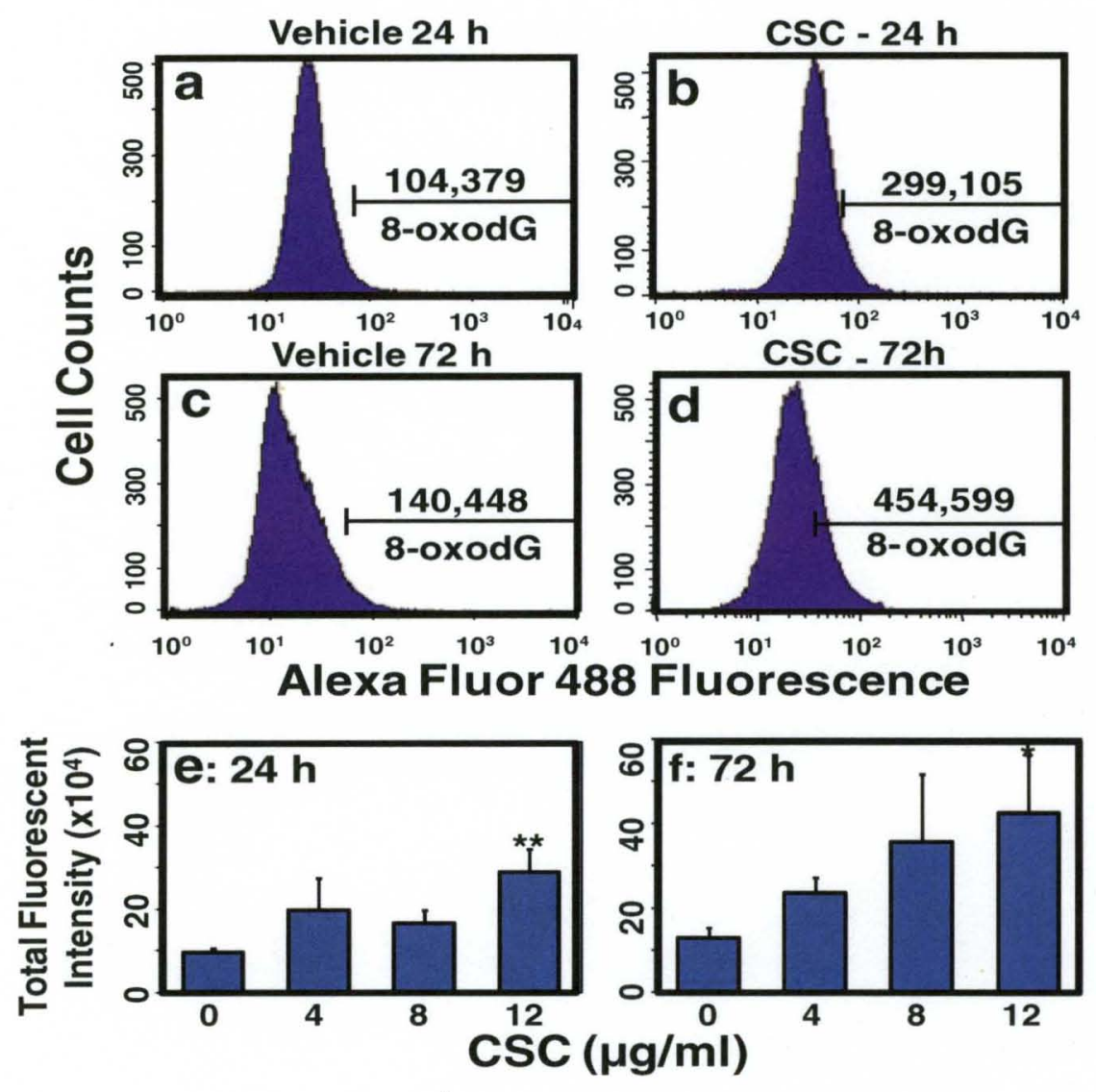

Figure 3.1: Cigarette smoke condensate (CSC)-induced 8-oxodG lesion in ECT1/E6 E7. Cells treated with vehicle for $24 \mathrm{~h}$ (a) and $72 \mathrm{~h} \mathrm{(c)} \mathrm{and}$ CSC $(12 \mu \mathrm{g} / \mathrm{ml})$ for $24 \mathrm{~h}$ (b) and $72 \mathrm{~h}$ (d) were stained with Alexa Flour 488-Conjugated anti-8-OHdG and quantified by flow cytometry. e and $f$ represent dose- and time-response to CSC-induced oxidative DNA damage as measured by 8 -oxodG total fluorescent intensity. Data represent mean $\pm \mathrm{SD}$ of three independent experiments $\left({ }^{\star} p<0.01 ;{ }^{\star \star} p<\right.$ 0.004). 
a. HPV-transfected cells

Bright 8-oxodG 7AAD Merged
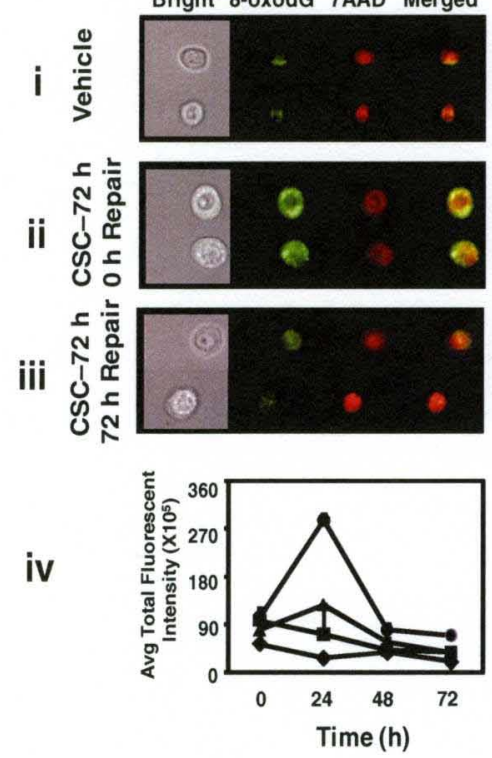

b. CaSki Cells

Bright 8-oxodG 7AAD Merged
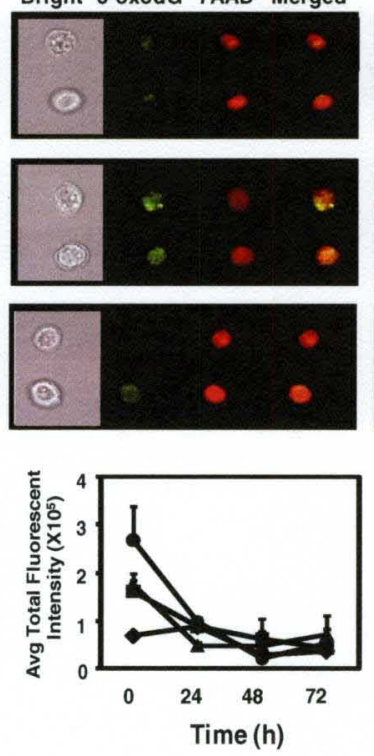

c. C33A Cells

Bright 8-oxodG 7AAD Merged
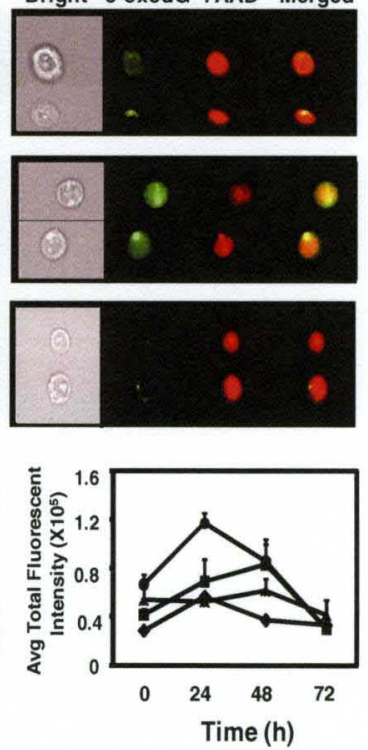

Figure 3.2: Removal of cigarette smoke condensate (CSC)-induced oxidative DNA damage in ECT1/E6 E7 (a), CaSki (b), and C33A (c) cells: Cells treated with vehicle (i) and CSC (12 $\mathrm{g} / \mathrm{ml}$ ) (ii) for $72 \mathrm{~h}$, and $72 \mathrm{~h}$ post CSC exposure (iii) were stained with Alexa Flour 488-Conjugated anti-8-OHdG, and the images were acquired by multispectral imaging flow cytometry. (iv) denotes kinetics of removal of CSC-induced oxidative DNA damage: rhombus (0), square (4), triangle (8), and circle (12) $\mu \mathrm{g} / \mathrm{ml} \mathrm{CSC.}$ Data represent mean $\pm S D$ of three independent experiments. 


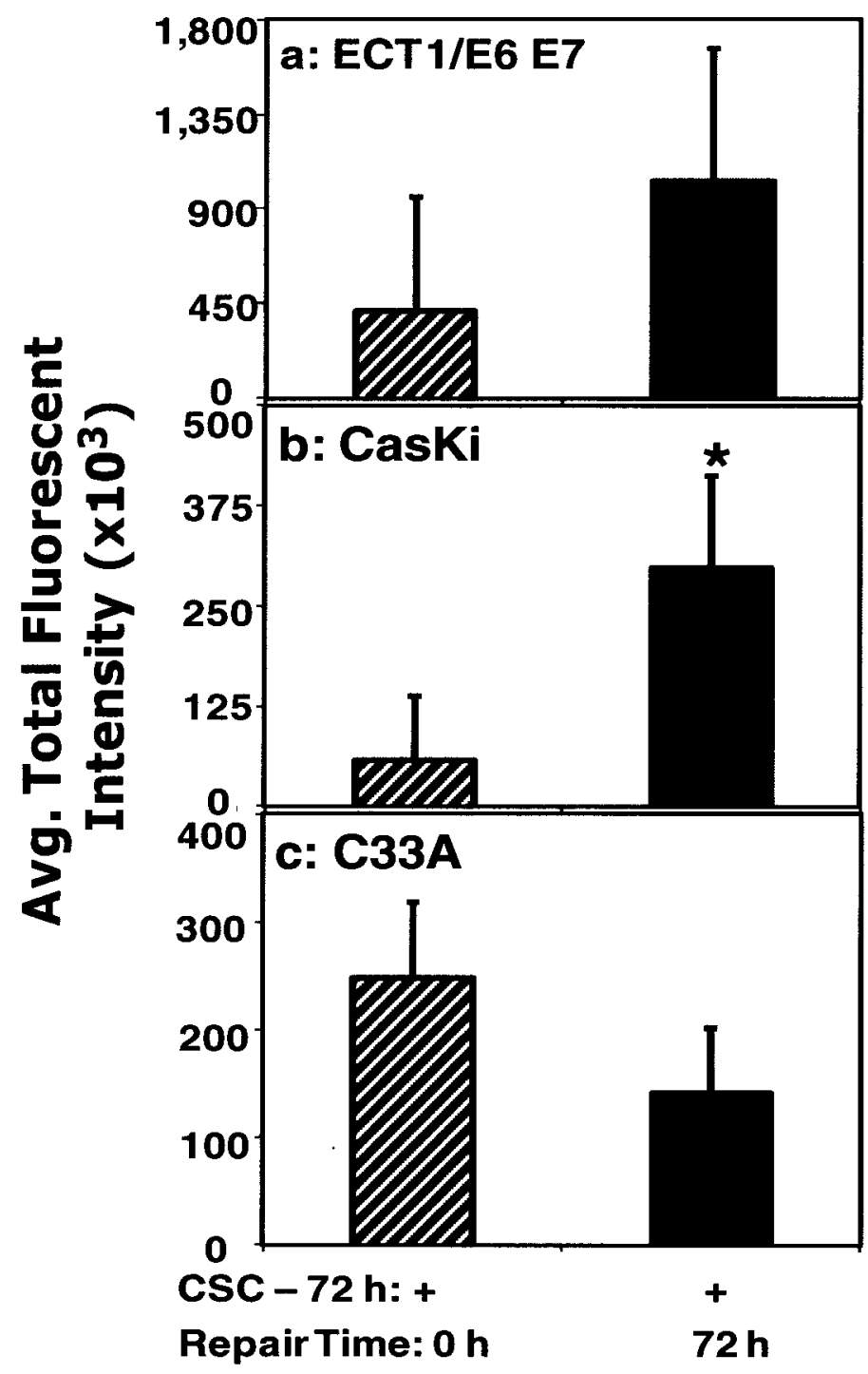

Figure 3.3: Assessment of p53 expression in different human cervical cells. ECT1/E6 E7 (a), CaSki (b), and C33A (c) cells were treated with cigarette smoke condensate (CSC) $(12 \mu \mathrm{g} / \mathrm{ml})$ for $72 \mathrm{~h}$ to induce the 8 oxodG lesion. Then, cells were freed of the residual CSC and further incubated for $72 \mathrm{~h}$ for repair of oxidative DNA damage to occur, stained with Alexa Flour 488-conjugated anti-p53 antibody and quantified by flow cytometry. Data represent mean $\pm \mathrm{SD}$ of three independent experiments $(p<0.04)$. 

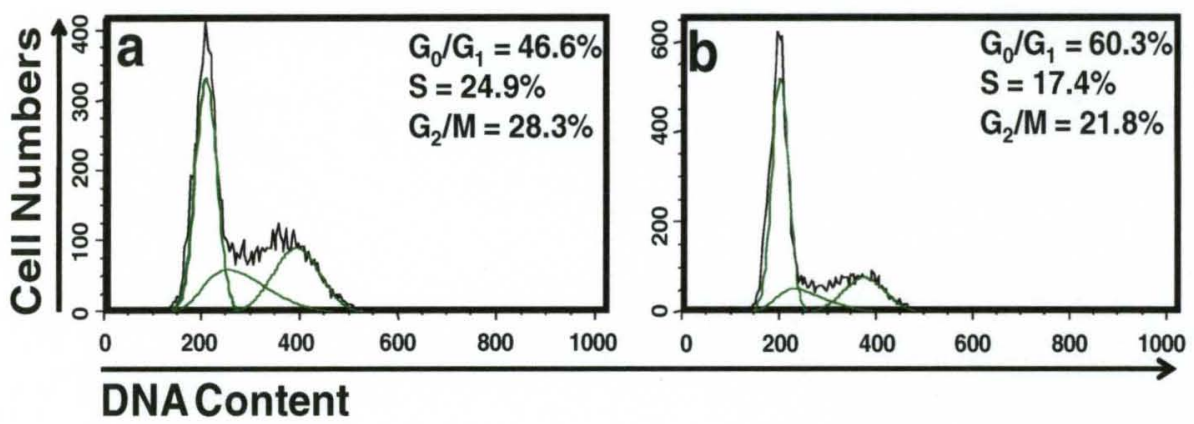

Figure 3.4: Effects of cigarette smoke condensate (CSC) on cell cycle distribution in HPV-transfected cervical cells. Flow cytometry analysis using propidium iodide staining to determine cell cycle phase distribution following vehicle (a), and CSC (12 $\mathrm{g} / \mathrm{ml})(\mathrm{b})$ treatment for $24 \mathrm{~h}$. 

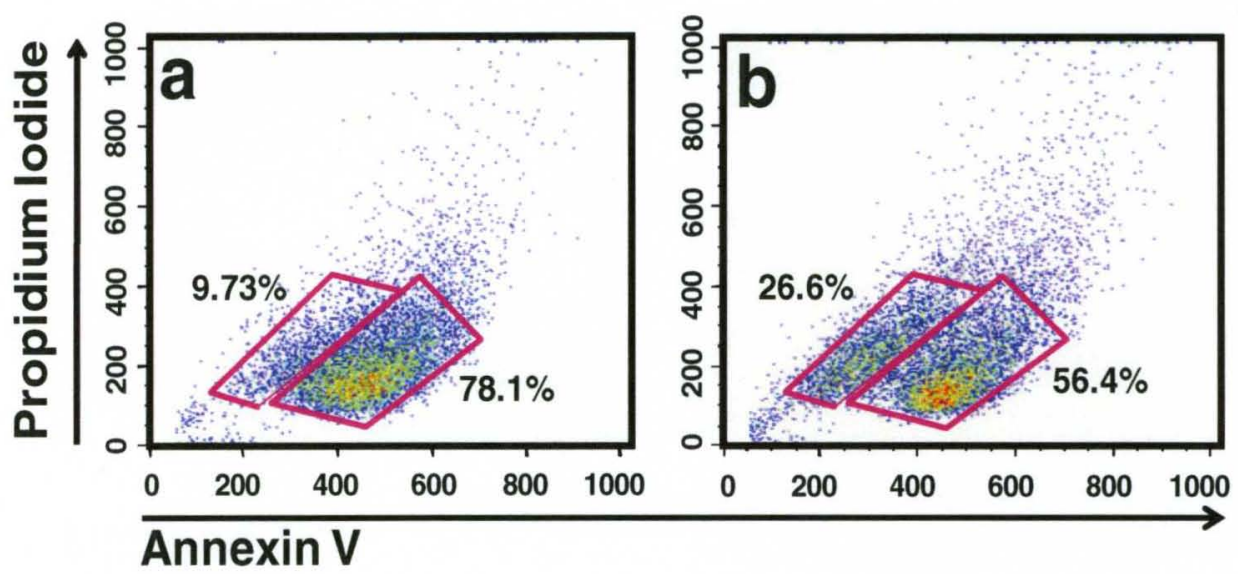

Figure 3.5: Cigarette smoke condensate (CSC)-induced apoptosis in HPV-transfected cells. Apoptosis was induced with 0 (a) and $12 \mu \mathrm{g} / \mathrm{ml}$ CSC (b) for $24 \mathrm{~h}$ and cells were stained with Annexin V-FITC and quantified by flow cytometry. Left and right square boxes of each panel represent the apoptotic and live cell populations, respectively. 
CHAPTER IV

THE INTERPLAY OF CIGARETTE SMOKING AND HPV INFECTION IN HUMAN VAGINAL CELLS: AN EX VIVO STUDY 


\section{A. Introduction}

Vaginal tumors account for an incidence of approximately $1-2 \%$ of lower genital tract malignancies $[3,71]$ The etiology of vaginal cancer mainly remains equivocal. Nevertheless, there are a few population-based case-control studies for the etiology of this rare abnormality [66-68, 72]. These studies reveal that the majority of vaginal cancers have common risk factors with cervical cancers; the most reported shared risk factor among women with cervical and vaginal tumors is infection with cancerassociated human papillomavirus (HPV) types. High-risk HPV prevalence is comparable in cervical and vaginal samples [14], which, in turn, signifies that both tissues can retain cancer-associated HPV infection. However, cervical abnormalities are far more common compared with vaginal

tumors [181]. The possible justification for the infrequent occurrence of vaginal cancer, despite infection with cancer-associated HPV, may be due to the different transformation potential of the virus in cervical and vaginal tissues [182].

Other epidemiological and etiological variables associated with cervical cancer have also been reported to be pertinent to the etiology of vaginal tumors, such as cigarette smoking [66]. Although conflicting data 
exist on the role of smoking in the development and progression of HPV lesions in vaginal cells $[66,183-184]$, the exact mechanism by which cigarette smoking exerts its cytotoxic effects is not fully understood.

Cigarette smoke is a heterogeneous mixture of approximately 5,000 chemical compounds, of which several dozen are carcinogens, cocarcinogens, mutagens and tumor promoters [116], including polycyclic aromatic hydrocarbons (PAHs), N-nitrosamines, inorganic and organic compounds $[118,185]$. It has been reported that cigarette smoke-induced genotoxicity results in induction of DNA damage, such as double-strand breaks (DSBs) [58]. Single-strand breaks are considered an indicator of early damage [125] and they are intermediate processing products of DNA damage, which, if left unrepaired, may develop into mutagenic and lethal double-strand breaks [143]. DSBs are a more disruptive form of strand break since they can either lead to cell death or genetic instability, if left unrepaired, or they may cause neoplastic progression if the repair process is compromised [128, 144].

Previous studies with human HPV-transfected Ect1/E6 E7 cervical cells suggested that cigarette smoke-mediated DNA DSBs are highly persistent, which may lead to increased mutation and ultimately higher cancer risk [170]. Hence, the effect of cigarette smoking on human vaginal cells warrants an investigation. The aim of this study was to investigate whether cigarette smoking, given the infection with high risk HPV types, leads to detectable DNA damage in vaginal cells. In order to examine this, 
we employed single cell gel electrophoresis (SCGE), also known as the comet assay. That is a sensitive technique to detect DNA strand breaks at the single cell level $[131,186]$.

\section{B. Materials and Methods}

\section{Study population}

Eligible patients $(n=100)$ who visited the Gynecologic Oncology Clinic at James Graham Brown Cancer Center and University of Louisville Ob/Gyn Colposcopy Clinic during 2007 through 2009 participated in the study (Table 4.1). Each patient was informed about the study protocol at the time of her visit and given a written informed consent prior to the study. Patients answered an $\mathrm{NIH}$-approved questionnaire about their medical history and smoking habits. The patients' high-risk HPV status was obtained from hospital records and/or a detailed questionnaire. The protocol, consent form and questionnaire for this study were approved by the Institutional Review Board at the University of Louisville. Women who were pregnant and/or receiving radiation/chemotherapy in the last year

prior to the time of their visit were excluded from the study. Thus, 76 subjects who satisfied the exclusion criteria were included. The study was conducted in a blinded fashion. 


\section{Materials}

Keratinocyte serum-free medium (K-SFM), bovine pituitary extract (BPE), epithelial growth factor (EGF), penicillin/streptomycin, trypsin/EDTA solution and low-melting agarose were from Invitrogen (Carlsbad, CA, USA); sodium $\mathrm{N}$-lauroyl sarcosine, DMSO, Tris and spermine were from Sigma Aldrich (St. Louis, MO, USA); proteinase $\mathrm{K}$ was from Roche (Switzerland); EDTA was from Mallinckrodt Chemicals (Hazelwood, MO, USA).

\section{Collection of human specimens}

A Dacron ${ }^{\mathrm{TM}}$ cervical swab was used to obtain vaginal material from the lateral vaginal wall. Swabs were immediately placed in a 5-ml solution consisting of K-SFM pre supplemented with $0.3 \% \mathrm{BPE}, 0.1 \mathrm{ng} / \mathrm{ml} \mathrm{EGF}$, $0.4 \mathrm{mM} \mathrm{CaCl}_{2}, 1 \%$ penicillin and streptomycin at $4^{\circ} \mathrm{C}$ for up to $2 \mathrm{~h}$.

\section{HPV status}

The assessment was made based on either the HPV testing or the Pap results done at the time of the visit. In case HPV testing was not done, the Pap results of low- grade squamous intraepithelial lesion (LGSIL) or high squamous intraepithelial lesion (HGSIL) were classified as 
HPV positive. The final decision on the HPV status of each participant was confirmed by the Gynecologic Oncologist, Dr. Lynn Parker.

\section{Smoking status}

Information on the smoking history of the patients was obtained from the questionnaires. Patients were characterized to two broad categories: those who currently or formerly smoked (ever smoker) and those who did not smoke (never smoker). Thus, there were 49 ever smokers (28 current and 21 ex-smokers) and 27 never smokers.

\section{Comet assay}

DNA DSBs were detected by neutral comet assay, as described previously $[131,170,186]$. Briefly, vaginal samples were centrifuged, washed with PBS and processed immediately. 100,000 cells per slide were embedded in $1 \%$ low-melting agarose on frosted microscopic glass slides. The cells were subsequently lysed $(1.25 \mathrm{M} \mathrm{NaCl}, 0.1 \%$ sodium $\mathrm{N}$ lauroyl sarcosine, $50 \mathrm{mM} \mathrm{Na-EDTA}, 100 \mathrm{mM}$ Tris- $\mathrm{HCl}, \mathrm{pH} 10$ ), digested with proteinase $\mathrm{K}(1.25 \mathrm{M} \mathrm{NaCl}, 5 \mathrm{mM}$ EDTA, $5 \mathrm{mM}$ Tris- $\mathrm{HCl}, 0.5 \mathrm{mg} / \mathrm{ml}$ proteinase $\mathrm{K}, \mathrm{pH} 10)$ and the DNA was precipitated $(50 \%$ ethanol, $1 \mathrm{mg} / \mathrm{ml}$ spermine, $20 \mathrm{mM}$ Tris- $\mathrm{HCl}, \mathrm{pH}$ 7.4). DNA was unwound using a neutralizing buffer (500 mM Na-EDTA, 0.2\% DMSO, $500 \mathrm{mM} \mathrm{NaCl}, 100$ 
$\mathrm{mM}$ Tris- $\mathrm{HCl}, \mathrm{pH} 9.0)$ and then electrophoresed in the same buffer (26 V; $250 \mathrm{~mA}$ at $4^{\circ} \mathrm{C}$ ). After staining the cells with ethidium bromide, comets were visualized using a light microscope attached to a digital camera with 510 excitation and 590 emission filters. The images were analyzed using the software Comet Assay IV (Perspective Instruments, Haverhill, UK). A total of 50 cells per slide and 2 slides per sample were scored for tail length (TL) and tail moment (TM) as described before [170]. Tail length is defined as the distance between the center of the comet head and the end of the tail. Tail moment is often considered a more significant indicator of DNA damage since they refer both to the distance of DNA migration and the amount of DNA in the tail [136]. The higher the values of tail length and tail moment, as computed by the software, the higher the level of DNA damage.

\section{Statistical analysis}

The analysis was conducted to examine the influence of age, HPV infection, smoking and disease status as individual variables and multivariables on the extent of DNA double-strand breaks using the generalized linear regression model [187]. The mean, standard deviation (SD), median, minimum and maximum along with 95\% confidence intervals for TL and TM were computed within each level of the categorical variables. The $p$-values were computed using the Wilcoxon rank-sum test 
between HPV positive and negative subjects, ever and never smokers, and between old ( $>36$ years) and young ( $\leq 36$ years) patients for TL and TM. We further performed the subset analyses on smokers and nonsmokers based on their HPV status. Age was grouped using a median cut-off and non-parametric test was used. Furthermore, we performed the multi-variable analysis to estimate the simultaneous effects of the HPV and smoking covariates on TL and TM. We have observed very strong association between HPV status and disease status $(p<0.001)$. Therefore, age, HPV infection and smoking status were analyzed using PROC GLM [187] in SAS system (v9), where age was considered as both a categorical and continuous variable.

\section{Results}

\section{The influence of HPV infection on induction of DNA double-} strand breaks

We investigated the potential role of cancer-associated HPV types in inducing DNA DSBs. The percentage of women enrolled in this study with high-risk HPV DNA was higher $(n=46 ; 60.5 \%)$ compared with women who were reported to be negative for the virus $(n=30 ; 39.5 \%)$. Two most common types of DNA strand break measurements were recorded: tail length and tail moment. The mean tail length for those who 
were infected with HPV was significantly $(p<0.001)$ lower $(31.2+/-18.7$ $\mu \mathrm{m})$ compared with women who were HPV negative $(61.7+/-22.6 \mu \mathrm{m})$ (Figure 4.1, Table 4.2). These data indicate that those with HPV infection showed a lower degree of DNA damage compared to those who did not have HPV DNA. Similar results were found for tail moment (HPV positive, 2.4 +/-2.8 AU; HPV negative, 8.7 +/- 4.9 AU) demonstrating the significant $(p<0.001)$ inverse association between HPV infection and extent of double-strand DNA breaks in the studied population.

\section{DNA double-strand breaks induced by cigarette smoking}

We examined whether DNA strand breaks correlated with the smoking status of the study population. The study group was $(n=76)$ comprised of the population who never smoked $(n=27 ; 35.5 \%)$ and ever smokers (either currently or formerly) ( $n=49 ; 64.5 \%$ ). The clinical and general characteristics of the study population are presented in Table 4.1. The mean tail length for never smokers was $57.7+/-24.5 \mu \mathrm{m}$. The ever smokers group had a mean tail length of $35.3 \mu \mathrm{m}+/-21.9$. We found a significant inverse association between smoking status and tail length $(p<$ 0.001) indicating that those who never smoked have, on average, a higher degree of DNA DSBs compared with individuals who had reported as smokers (Figure 4.1; 4.2, Table 4.2). Similarly, mean tail moment was 7.5 +/- 5.5 AU among never smokers compared with $3.4+/-3.7 \mathrm{AU}$ for those 
who smoked. This finding signifies that those who never smoked showed a higher extent of DNA strand breaks $(p<0.001)$.

\section{The effect of age on DNA double-strand breaks}

In order to understand the effect of age on DNA damage, analysis was carried out taking into account the age as both a continuous and categorical variable (Table 4.2$)$. Forty patients $(52.6 \%)$ were less than or equal to the median age of 36 and 36 patients $(47.4 \%)$ were above the median age. There were significantly higher DNA DSBs in older women compared with younger women: mean TL of $61.2+/-22.5$ versus $27.1+/-$ $13.9 \mu \mathrm{m}(p<0.001)$ and mean TM of $8.3+/-5.0 \mathrm{AU}$ versus $1.8+/-1.6 \mathrm{AU}$ $(p<0.001)$.

\section{The interaction between HPV infection and smoking status}

Subjects with HPV-positive and -negative status were further categorized based on their smoking status as summarized in Table 4.3. Ever-smoker and HPV-positive women $(n=32)$ had significantly lower mean TL compared to never-smoker and HPV-positive individuals $(n=14)$ $(23.9 \pm 11.3 \mu \mathrm{m}$ versus $48.0 \pm 21.8 \mu \mathrm{m} ; p<0.001)$. This inverse association was also observed in mean TM (Ever smoker and HPV positive, $1.4 \pm 1.0 \mathrm{AU}$ versus never smoker and HPV positive, $4.7 \pm 4.1$ 
AU) (Figure 4.3). A non-significant association with TL $(p=0.258)$ and TM ( $p=0.079)$ was observed among smokers who were negative for HPV infection.

\section{The interaction among HPV infection, cigarette smoking and} age

We examined the influence of HPV infection, smoking status and age on induction of DNA DSBs in the study population (Table 4.4). Age as either a categorical ( $\leq 36$ and $>36$ ) or continuous variable showed a strong association when using the multivariable generalized linear regression model. Significant association was observed between TL and HPV for age as categorical $(p=0.019)$ and as continuous $(p=0.034)$ variable. This finding indicates that women with HPV infection had a lower mean TL $(31.2 \pm 18.7 \mu \mathrm{m})$ compared to HPV negative individuals $(61.7 \pm 22.6 \mu \mathrm{m})$ regardless of their age. Similarly, TM and HPV status conferred a significant association $(p=0.002)$ for age as both categorical and continuous variable, indicating a lower TM $(2.4 \pm 2.8 \mathrm{AU})$ in women with HPV infection compared with those who were HPV negative $(8.7 \pm 4.9$ AU). The smoking status was significantly correlated with $T L(57.7 \pm 24.5$ $\mu \mathrm{m}$ vs. $35.3 \pm 21.9 \mu \mathrm{m})$ and TM $(7.5 \pm 5.5 \mathrm{AU}$ vs. $3.4 \pm 3.7 \mathrm{AU})$ for age as categorical $(p<0.001)$ and continuous variable $(p=0.003)$. These 
findings suggest the negative correlation between smoking status and DNA DSBs regardless of age.

\section{E. Discussion}

We examined the interplay of cigarette smoking and high-risk HPV infection on the DNA integrity of vaginal cells. Based on our experimental findings, we confirmed that the levels of DNA double-strand breaks are inversely correlated with both smoking and HPV status. This observation suggests that the vaginal epithelium may have a different transformational ability by HPV infection.

About 17 to $20 \%$ of the individuals who were approached to take part in the study were not considered based on the defined exclusion criteria: i) radiation/chemotherapy in a year prior to the time of visit, and ii) current pregnancy. The rationale for excluding individuals undergoing radiation/chemotherapy treatment was based on an earlier study reporting that radiation treatment resulted in 5- to 6-fold increase in DNA adduct levels, detected by ${ }^{32} \mathrm{P}$-postlabeling, compared with the initial level [188]. Pregnant women were excluded from the study due to an observed higher incidence of HPV infections [189] and a more rapid progression of cervical dysplastic lesions to carcinoma compared to non-pregnant women [190]. Moreover, progesterone induces the expression of several anogenital HPV genes, including HPV 16, through hormone response elements 
within regulatory regions of the viral genome [191-192]. The choice of location for collecting the vaginal specimens is one of the strengths of our study. We collected the vaginal specimens from the lateral vaginal wall to minimize the possible contamination by cervical and metaplastic epithelial cells. This site-specific specimen collection was further validated by microscopic evaluation of the mature squamous cells encompassing the vaginal epithelium. However, we cannot rule out the possibility of sloughed cervical cells in those vaginal samples. Nonetheless, the great majority of the cells were mature squamous types and the homogeneous nature of the collected samples was cytologically confirmed.

One of the intriguing findings that emerged from our study was that HPV infection showed an inverse relation with the extent of DNA strand breaks in the studied population. Considering that a link between high-risk HPV and Vaginal Intraepithelial Neoplasia has been reported [193], the induction of DNA damage by the virus is a logical hypothesis. Moreover, even though the natural histories of cervical and vaginal lesions appear similar [194], neoplastic and invasive vaginal abnormalities are far less common than both cervical intraepithelial neoplasia and invasive cervical carcinoma [181]. This obvious discrepancy may be explained by considering two facts. One is that the vagina lacks a squamo-columnar junction, known as transformation zone [13]. The importance of the transformation zone is evident by the fact that most of the dysplasia caused by persistent HPV infection frequently arises, for unknown 
reasons, in areas where two different types of epithelium merge such as that occurring in the cervix, anus and oro-pharynx [195]. It has also been reported that the transformation zone is more sensitive to HPV infection [14] since the squamous metaplastic cells - constituents of the transformation zone - are needed to support the carcinogenic alteration by high-risk HPV [14]. Secondly, the discrepancy may also be explained by the variable manifestations of HPV infection in the vagina compared to that in the cervix, even though the virus infects vagina and cervix with the same frequency [196]. HPV replication in lytic infection is more efficient and results in producing progeny virions, which eventually destroy the infected vaginal cells. In contrast, HPV replicates less efficiently in the cervix and tends to remain within the cells as latent infection, a phenomenon involved in persistence of the infection [182].

Even though persistent high-risk HPV infections account for a great majority of cervical cancers [26, 197], cell-mediated immunity plays a significant role in clearance of the infection within 1-2 years of exposure [198]. There are, however, no data reported on role of HPV persistence on DNA damage particularly in vaginal walls. Based on our experimental data indicating decreased level of DSBs in HPV-positive individuals, we deduce that vaginal cells may be more resistant to the DNA damaging effect of HPV infection. This speculation was partly derived from the fact that HPV has the ability to hinder host defenses by several means, such as the lack of viral-induced cell death in keratinocytes and downregulation of the 
expression of interferon [198]. As part of the HPV infectious cycle, which depends on the differentiation status of the target cell, the virus infects primitive keratinocytes; the expression of viral proteins and viral assembly occur at much higher level in the superficial squamous cells that are terminally differentiated [199]. These differentiated keratinocytes that mainly cover the vaginal wall are intended for death and desquamation. Therefore, HPV replication, assembly and particle release do not trigger any cytolysis, and therefore a immune response due to lack of inflammatory reaction [198]. A limitation of the study is that the HPV status was based on the detection of the collective presence of carcinogenic HPV types instead of the individual HPV genotypes. Stratification of the patients based on specific HPV genotypes may provide further insights into the complex interrelation of smoking and progression of HPV infection in vaginal carcinogenesis. The HPV testing used for this study, however, employed a combination of DNA probes to test for high-risk viral types, including HPV 16, which is the most prevalent high-risk HPV strongly associated with vaginal carcinogenicity [67, 200-201].

Based on significant increase in DNA DSBs in HPV-negative individuals, we infer that, in our study population, the extent of DNA damage is independent of HPV infection. However, DNA strand breaks were the only measured endpoint used in this study. Investigation of other forms of HPV-associated damage, including chromosomal instabilities [202] is warranted. Other pre-disposing factors, such as history of cervical 
and/or vaginal abnormalities, chronic irritation [3] and cigarette smoking [68] may have an impact on DNA integrity of vaginal cells.

We have clearly shown that the extent of DNA DSBs increases as a function of age. Our finding is congruent with the studies of Singh et al. and Morris et al. who demonstrated an increase in DNA strand breaks with age in human sperm $[132,203]$. Additionally, age-related differences have been reported among individuals diagnosed with cervical cancers compared to those with vaginal cancers [71]. Carcinoma of vagina mainly occurs in elderly women ( $\geq 60$ years) $[71,204-206]$. This finding signifies the age-associated alterations in DNA structure, such as double-strand breaks [132] that may, in turn, attribute to genetic instability and ultimately vaginal carcinogenesis. The extent of double-strand DNA breaks increases with age of the population examined, which implies that older women are at higher risk for accumulation of mutation and genetic instability. Thus, the relevance of our findings to public health in identifying high-risk population is significant.

Our analysis demonstrated a significant inverse correlation between DNA strand breaks and smoking habit. Data on smoking was obtained by self-reporting smoking history. However, the smoking history was obtained prior to medical examination, which minimizes the chance of reporting inaccurate smoking habit (underestimation or denial) among the participated women in the study. Furthermore, measurement of biochemical parameters such as cotinine, thiocyanate and carbon 
monoxide are not considered to be impeccable due to several factors, such as short half-life of smoking by-products in the body [207]. Selfreporting smoking history, when compared with biochemical validation, has been reported to have sensitivity and specificity of above $85 \%$ [207].

Few studies, however, have reported a positive association between cigarette smoking and vaginal abnormalities [67-70]. These studies were based on an epidemiological association that appears to link cigarette smoking with vaginal cancer. In contrast, in the current study, DNA strand breaks, as a biological endpoint, was measured to provide insights into the mechanistic effect of the cigarette smoking on the etiology of vaginal cancer. We found no positive correlation between smoking and vaginal abnormalities. In contrast, two other studies found a nonsignificant epidemiological association with smoking in vaginal carcinoma [71-72]. Furthermore, oxidative DNA damage caused by treatment with cigarette smoke condensate were repaired in HPV-transfected, HPVpositive and HPV-negative human cervical cancer cells with equal efficiency, which may be attributed to p53-dependent and -independent DNA repair pathways (Chapter III). We infer from this and other studies, that cigarette smoke exposure can alter the mechanisms of gene expression or their functions, which may, in turn, have a variable effect on DNA integrity. Equally important, we cannot overlook the confounding cumulative effects of polymorphisms in DNA repair genes, the heterogeneous nature of cigarette smoke constituents, and exposure to 
other environmental factors in evaluating the influence of smoking on HPV-mediated vaginal tumorigenesis.

The role that cigarette smoking plays in the development and/or progression of HPV infection is convoluted and not yet entirely understood. Our data derived from the ex-vivo study clearly showed an inverse relationship between the interaction of cigarette smoking and HPV infection in the induction of DNA strand breaks regardless of age. These findings are not in aggreement with the results of Sellors et al., who reported that smoking was not a risk factor for HPV infection or persistence [184]. On the contrary, in several studies elevated levels of tobacco related carcinogens such as benzo[a]pyrene and nitrosamine 4(methylnitrosamino)-1-(3-pyridyl)-1-butanone (NNK) were identified in cervical mucosa of cigarette smokers compared to non-smokers $[53,55$, 57]. It is worth noting that the systemic effect of tobacco smoke on vaginal epithelium may not manifest itself by DNA DSBs, the only endpoint investigated in this study. Importantly, the scarcity of literature on the biological effects of cigarette smoke on vaginal epithelium provide us with a challenging and unique prospect to caution ourselves in making a generalized statement from a public health perspective.

In conclusion, we found that HPV infection, cigarette smoking and the interaction between the two have a significant inverse relation with DNA DSBs detected in vaginal epithelium of the population studied. To the best of our knowledge, there are no other studies that assessed any DNA 
damage endpoint in vaginal cells in relation to smoking and HPV infection status. Lack of DNA damage in HPV-positive patients may partially explain the relatively lower incidence of vaginal cancers compared to cervical cancers subsequent to HPV infection. Even though the overall conclusion is restricted by the small sample size, the highly differentiated nature of vaginal squamous cells and lack of persistence of HPV infection may partly explain the negative association between the investigated parameters. Previous findings are supportive of this notion where a reduction in DNA strand breaks of human cervical cancer cells was observed by ellagic acid [170], a polyphenol present in significant amounts in berries. Therefore, the higher degree of DNA damage in older women may signify the benefits of consumption of foods rich in antioxidants. From an etiological point of view, further studies with broader scope and larger sample size are required to elucidate the impact of cigarette smoking as a cofactor in vaginal carcinogenesis. 

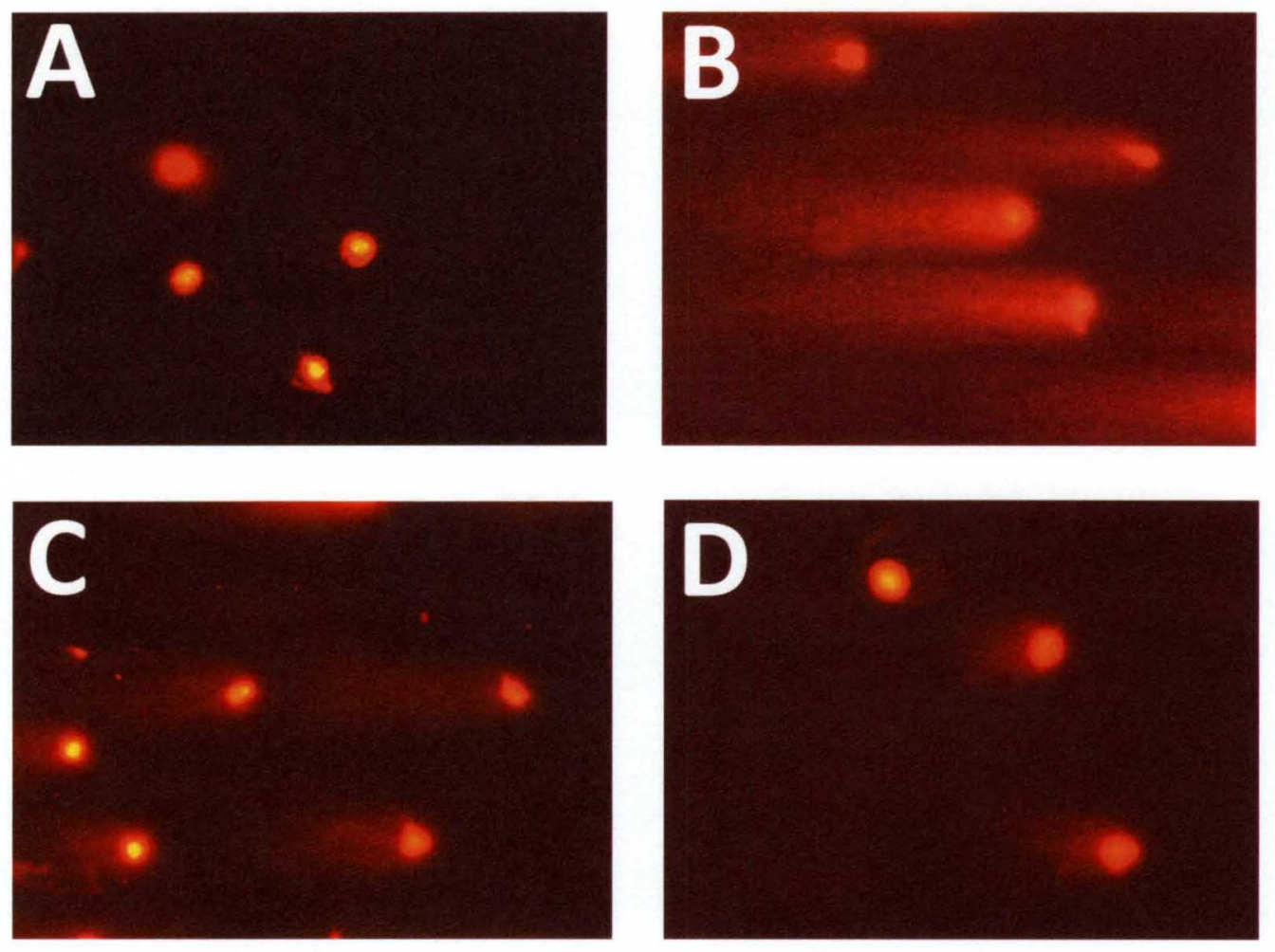

Figure. 4.1: Representative comet assay images. Panel (A) depicts intact nuclei in a HPV positive individual. Panel (B) shows DNA doublestrand breaks in a HPV negative participant. Panels (C) and (D) represent double-strand breaks in DNA of never and ever smokers, respectively. 


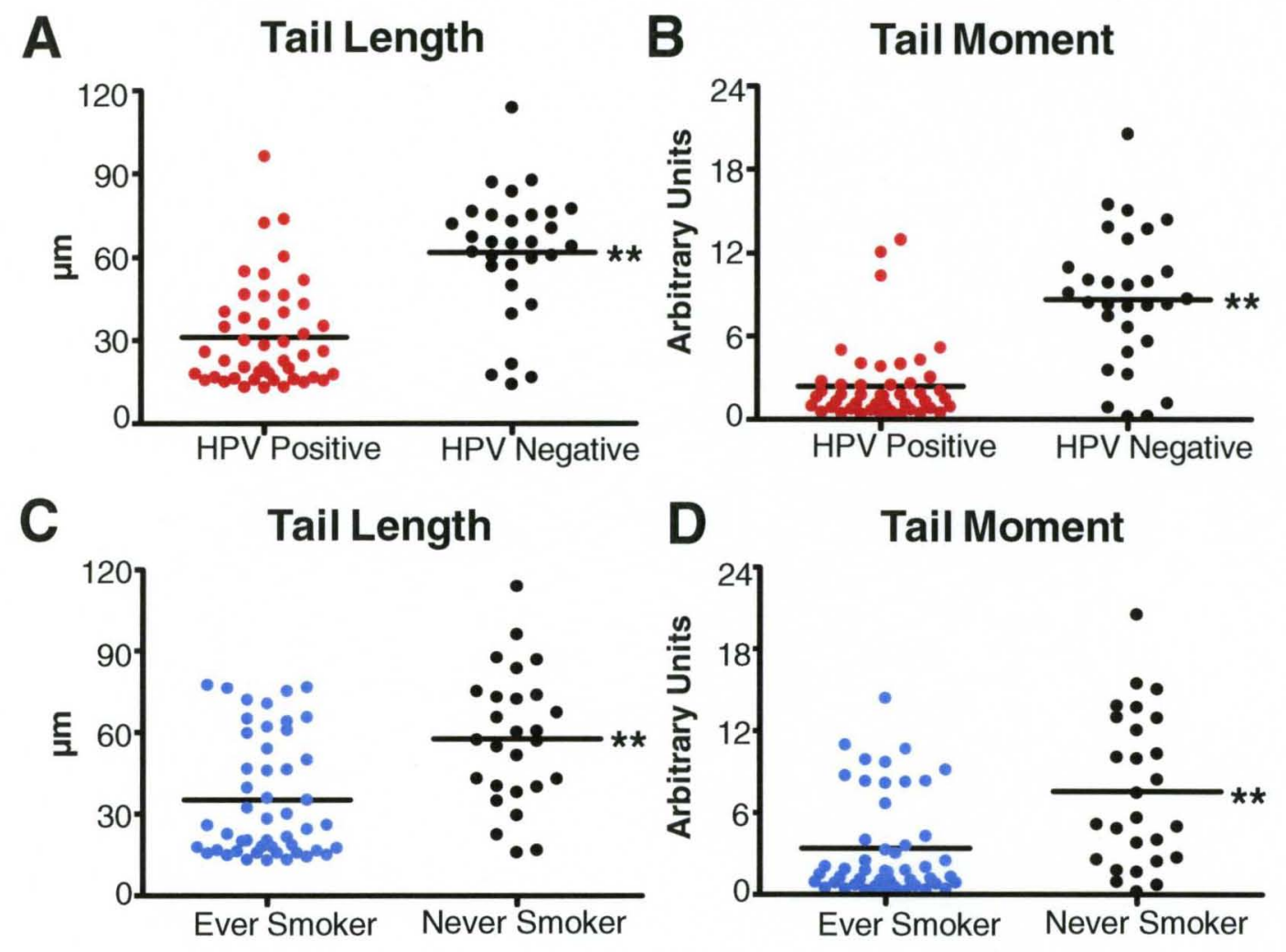

Figure. 4.2: Scattered plot presentation of the DSBs in the studied population. Panels represent the distribution of $(A)$ tail length and $(B)$ tail moment, respectively in HPV-positive and -negative individuals. Panels (C) and (D) depict the distribution of tail length and moment among ever- and never-smokers $(p<0.001)$. Lines signify the mean. 

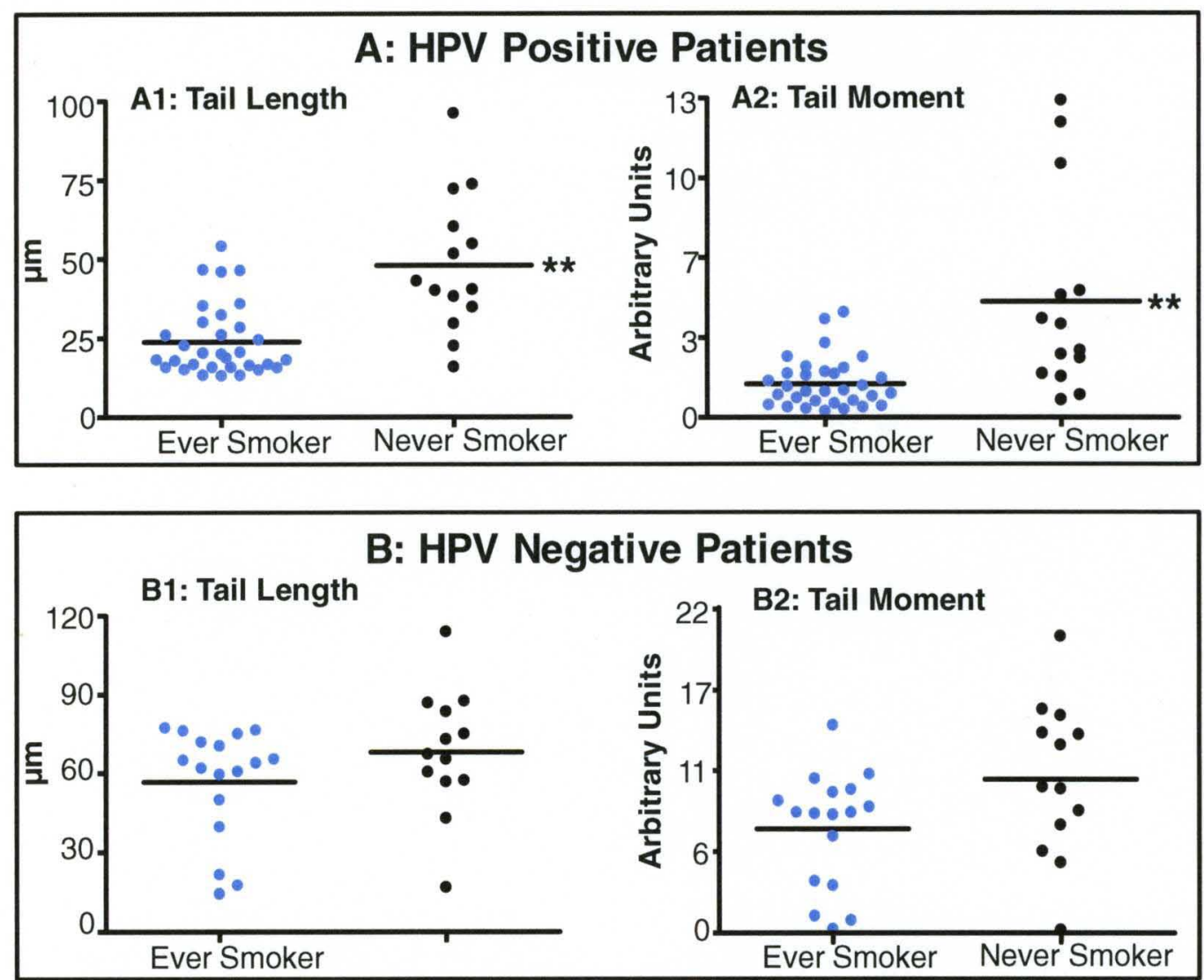

Figure 4.3: Correlation between HPV infections and smoking status presented by scattered plot in the studied population. Panel $(A)$ represents the distribution of tail length (A1) and tail moment (A2) in HPV positive women. Panel (B) depicts the distribution of tail length (B1) and tail moment (B2) in HPV negative individuals with respect to smoking status $(p<0.001)$. Lines signify the mean. 


\section{Table 4.1. Clinical and General Characteristics of the Studied Population

Characteristics $\quad$ Numbers (\%)

Total

Age

Mean \pm SD

Median (Min-Max)

Race

White

African American

Unknown
$76(100)$

$40.6 \pm 17.1$

$36.0(18.0-80.0)$

50

15

11

HPV Infection

Positive

Negative

30 (39)

Smoking Status

Never

Ever

27 (36)

49 (64)

Pap/Pathology Status

Normal

30 (39)

LGSIL

$16(21)$

HGSIL 
Table 4.2. Comet Assay Measured in the Vaginal Cells of the Subjects

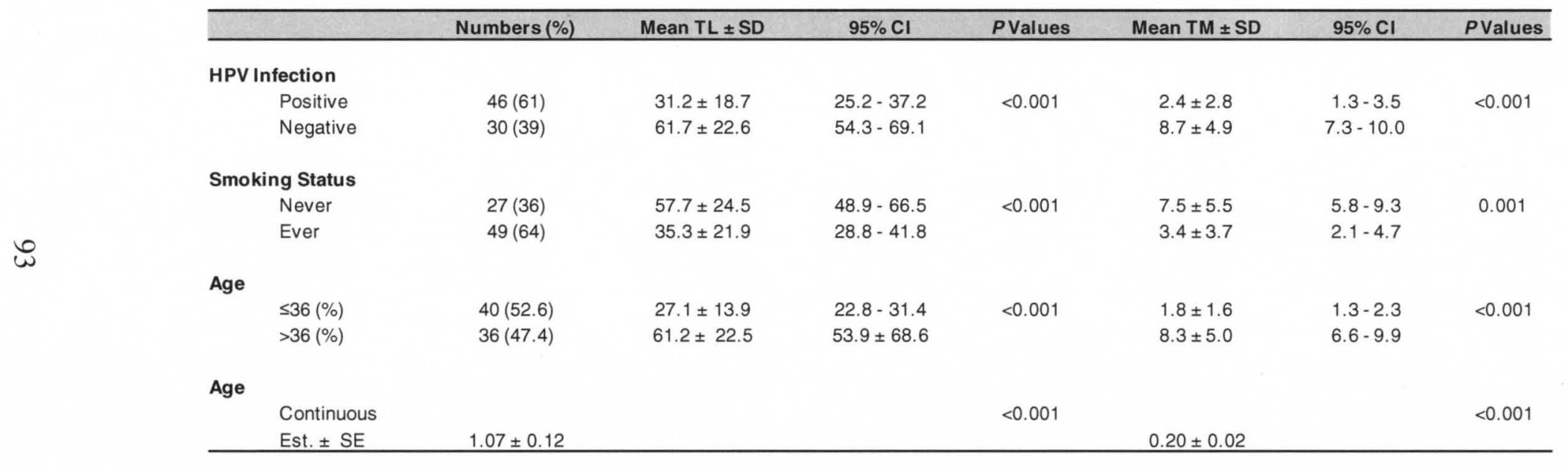


Table 4.3. Comet Assay Measured in the Vaginal Cells of the Subjects Stratified for HPV and Smoking Status

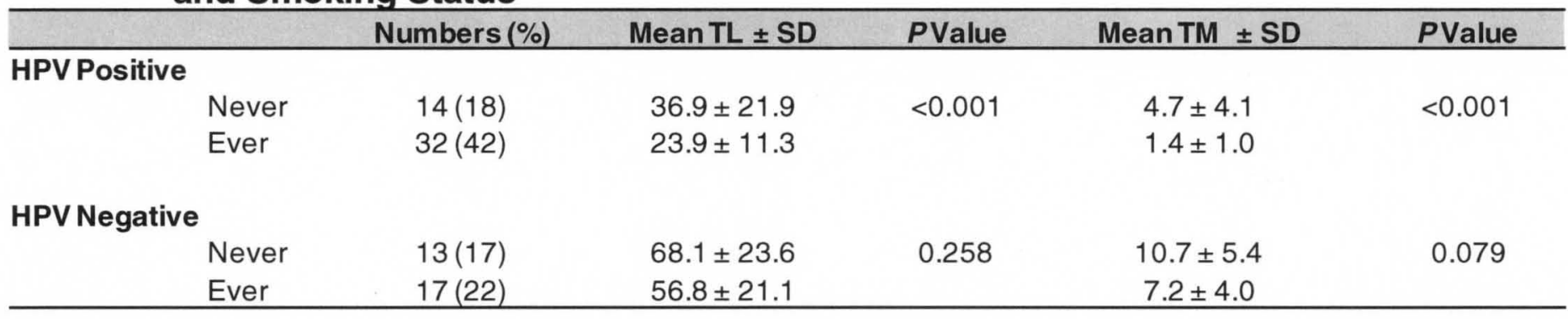


Table 4.4. Generalized Linear Regression Model on Age, Smoking and HPV Status

\begin{tabular}{|c|c|c|c|c|c|c|c|}
\hline \multirow{2}{*}{ Dependent } & & \multicolumn{2}{|c|}{ Intercept } & \multicolumn{2}{|c|}{ HPV Positive } & \multicolumn{2}{|c|}{ Ever Smoking } \\
\hline & & Est. & $P$ Value & Est. & $P$ Value & Est. & $P$ Value \\
\hline \multirow{3}{*}{ Age as Categorical } & TL & 59.56 & $<0.001$ & -13.015 & 0.019 & -15.318 & $<0.001$ \\
\hline & & & & & & & \\
\hline & TM & 7.2 & $<0.001$ & -3.419 & 0.002 & -2.852 & $<0.001$ \\
\hline \multirow{3}{*}{ Age as Continuous } & TL & 16.93 & 0.0155 & -11.312 & 0.034 & -12.582 & 0.003 \\
\hline & & & & & & & \\
\hline & TM & 0.61 & 0.644 & -3.298 & 0.002 & -2.468 & 0.003 \\
\hline
\end{tabular}




\section{CHAPTER V}

SUMMARY AND GENERAL DISCUSSION 


\section{A. Major Findings}

The experiments performed in Chapter II of this dissertation were designed to test the hypothesis that cigarette smoke is a major cofactor in cervical carcinogenesis. We examined the role of CSC in inducing DNA damage in a HPV-transfected human cervical cell line (ECT1/E6 E7). Additionally, the effect of ellagic acid, a potent antioxidant protective against the CSC-induced oxidative DNA damage was examined. Experiments described in Chapter III were built on results of Chapter II, and examine the role of CSC in induction and removal of oxidative DNA damage. The selection of a human cervical cancer cell line was expanded to include both HPV-positive (CaSki) and -negative cervical cancer cells (C33A) in addition to HPV-transfected cells in order to further investigate the effect of CSC on the induction of oxidative DNA damage in association with HPV. Chapter IV is an ex vivo study, which focuses on examining the role of cigarette smoking and high risk HPV infection in human vaginal cells. Specific findings of these chapters are described below. 


\section{Cigarette smoke condensate can induce DNA strand breaks}

As noted in Chapter II, cigarette smoking is one of the major risk factors in HPV-mediated cervical cancer, since it has been consistently linked with the progression of cervical neoplasia [15]. In fact, female smokers are at two times higher risk of developing cervical cancer than non-smokers [208]. The mechanism of smoking in mediating neoplastic transformation of cervical cells, however, remains inconclusive and was the main question of this chapter. Experiments were designed to investigate CSC-induced DNA damage and subsequent repair in HPVimmortalized cervical cells.

First, a time- and dose-response of CSC on human ECT1/E6 E7 was determined. Next, we employed single-cell gel electrophoresis, also known as the comet assay, to further examine the role of CSC in the induction of DNA single- (SSBs) and double-strand breaks (DSBs). To investigate the ability of the cells to repair CSC-induced DNA strand breaks, the residual DNA damage subsequent to removal of CSC was further determined by the comet assay. In order to investigate if free radical-producing constituents of CSC are the source of DNA damage, we examined the effect of an antioxidant, ellagic acid, in mitigating CSCinduced DNA damage. 
The major findings of this chapter are that CSC can induce DNA strand breaks in human HPV-transfected cells in a time- and dosedependent fashion. Equally important is the fact that our study reveals the inability of HPV-transfected cells to entirely repair CSC-induced DNA damage. Additionally, we have also demonstrated that oxidative stress may be the source of DNA damage caused by CSC. The data presented in this chapter suggest that persistent DNA strand breaks caused by the inability of the cells to remove the damage may result in accumulation of mutations leading to cancer [89]. These findings provide experimental evidences that support the previously reported epidemiological association between HPV Infection, cigarette smoking and cervical cancer development $[46,161]$.

\section{Cigarette smoke condensate can induce oxidative DNA damage}

One of the findings of this dissertation is that CSC can be a source of oxidative stress (Chapter II), which serves as a building block to further investigate the effect of CSC in association with HPV infection in human cervical cancer cells (Chapter III). The rationale for the experiments designed in this chapter was based on the epidemiological and experimental findings that cigarette smoke or its components induce

oxidative DNA damage [58], such as 8-oxo-7,8-dihydro-2'- 
deoxyguanosine (8-oxodG), which is highly mutagenic and carcinogenic [171]. In fact, the levels of oxidative base lesions were reported higher in smokers as compared to non-smokers [84-86]. Therefore, the goal of this chapter was to determine the effect of CSC on oxidative DNA damage formation and its removal from HPV-transfected (ECT1/E6 E7), HPVpositive (CaSki) and HPV-negative (C33A) human cervical cancer cells. We further investigated the cell cycle progression and apoptosis in the CSC-treated ECT1/E6 E7 cells as a standardized in vitro model [169] to further understand the effect of cigarette smoke-free radicals and cervical carcinogenesis.

In this chapter, the role of tumor suppressor p53 as a transcription factor and regulator of cell cycle arrest or apoptosis [93] was also examined. It appears that the inactivation of the normal function of p53 is a critical step in human cervical carcinogenesis, which can be either caused by mutation, as in HPV-negative cell [166] or from complex formation with E6 oncoproteins in the case of HPV-positive cervical cancer cells [97].

The major finding of this chapter is the first demonstration of oxidative DNA damage induced by cigarette smoke constituents and its repair in human cervical cancer cells using multispectral imaging flow cytometry techniques.

These data suggest that CSC-induced oxidative DNA damage is more pronounced in HPV-infected cells. Furthermore, we showed that 8- 
oxodG was removed almost completely 72 hours post-exposure in all cervical cell lines tested, regardless of HPV status. The similarity of responses to CSC-induced oxidative DNA damage between cell lines expressing mutant p53 or the E6 oncoprotein suggests that interaction of E6 and p53 may be functionally comparable to p53 mutations. These observations lead us to infer the possibility of both p53-dependent and independent DNA repair pathways in our experimental setting. Although CSC-induced oxidative DNA damage was eventually removed in all cells, the possibility of error-prone DNA repair, however, cannot be ruled out, which may lead to the accumulation of genetic mutations associated with carcinogenesis and tumor progression.

\section{Cigarette smoking and HPV infection act independently in vaginal cells}

Our in vitro findings (Chapters II and III) showed that CSC can induce DNA strand breaks as well as oxidative DNA damage. Moreover, our previous studies with human HPV-transfected ECT1/E6 E7 cervical cells suggested that cigarette smoke-mediated DNA DSBs are highly persistent, which may lead to increased mutation and ultimately higher cancer risk [170]. These findings led us to design an ex vivo study to further examine the role of cigarette smoking in human vaginal cells. The rationale behind the selection of vaginal cells, which are mature squamous 
types, is to obtain a homogenous sample. The main objective of Chapter IV was to investigate whether cigarette smoking, given the infection with high-risk HPV types, would produce DNA damage in vaginal cells.

Conflicting data exists on the role of smoking in the development and progression of HPV lesions in vaginal cells [66, 183-184]; the exact mechanism by which cigarette smoking exerts its cytotoxic effects is not fully understood. Results from Chapter IV of this dissertation directly support a negative association of smoking with vaginal abnormalities, which is in agreement with the two other studies, where a non-significant epidemiological relationship was found [71-72].

Age-related differences have been reported among individuals diagnosed with cervical cancer compared with those women with vaginal cancer [71]. Carcinoma of vagina mainly occurs in individuals older than 60 years old $[71,204-206]$. Our study showed a clear positive correlation between age and DSBs detected in vaginal cells of the studied population. This finding signifies the age-associated alterations in DNA structure, such as double-strand breaks [132] that may, in turn, attribute to genetic instability and ultimately vaginal carcinogenesis.

The endpoint measured in this chapter was DNA DSBs, which can lead to chromosome translocation and cancer if improperly repaired, in addition to genetic instability and cell death if left unrepaired [128].

Considering that a link between high-risk HPV and Vaginal Intraepithelial Neoplasia has been reported [193], the induction of DNA 
damage by the virus is a logical hypothesis. However, this hypothesis has not been directly tested, nor do our results support this theory. This may be due to the variable manifestations of HPV infection in the vagina compared to those in the cervix, even though the virus infects the vagina and cervix with the same frequency [196].

The most intriguing findings of this chapter is that the HPV infection and cigarette smoking have a significant inverse relation with DNA doublestrand breaks detected in vaginal epithelium of the population studied. Also, non-smokers with HPV infection tend to have more DNA DSBs compared to smokers, while there was no difference between smokers and non-smokers who had no HPV infection. There are no data reported as to DNA lesions in vaginal cells in relation to smoking and HPV infection status. This investigation suggests that vaginal cells differ in response to carcinogenic HPV infection and cigarette smoking, due to variety of factors, such as lytic versus latent HPV infection in vaginal and cervical cells, respectively, and resistance of highly differentiated vaginal epithelial cells to HPV.

\section{DNA Strand Breaks Detection}

The rational for detecting DNA double-strand breaks in vaginal cells was based on the finding that single-strand breaks were not detectable in $64 \%$ of the vaginal samples, whereas only in $25 \%$ of the samples DNA 
double-strand breaks were undetectable. There is no report in the literature indicating such observations. The samples with undetectable single- and/or double-strand breaks were categorized as "undefined". Table 5.1 depicts the summary of comet assay data for all 101 samples along with their representative images.

\section{B. Strengths and Weaknesses of this Dissertation}

\section{Strengths}

This dissertation has many points of strength. First, it solidifies the role of cigarette smoke on the induction of DNA strand breaks and oxidative damage in human cervical cancer cells. Although there have been epidemiological and experimental findings on the causal role of cigarette smoke on DNA integrity of various organs, a biological endpoint demonstrating cytotoxic effects of cigarette smoke in human cervical cancer cells was provided by this work. Second, there has been speculation about the association of cigarette smoking, as an important cofactor, with high-risk HPV infection in cervical carcinogenesis. This study further supports the persistence of cigarette smoke-associated DNA damage in the presence of HPV infection, which may lead to accumulation of mutations in cervical cells and ultimately higher cancer risk. Third, literature on the biological effects of cigarette smoke on vaginal epithelium 
is scarce. This work further contributed to the limited body of knowledge in understanding the interplay of cigarette smoking and HPV infection in an unprecedented ex vivo study. This work also suggests that cigarette smoking and HPV infection have a significant inverse relation with DNA double-strand breaks detected in vaginal epithelium of the studied population.

Furthermore, the extent of double-strand DNA breaks increases with age of the population examined, which is suggestive that older women might be at higher risk for accumulation of mutation and genetic instability. Therefore, the relevance of our findings to public health in identifying high-risk population is significant.

From a technical standpoint, the strength of this work was using a cell-based analysis known as the comet assay. It is a sensitive technique used to detect DNA strand breaks as well as assess DNA repair kinetics at the single-cell level $[125,130]$. The advantages of the comet assay compared with other genotoxicity assays include i) sensitivity to detect low levels of DNA damage [209]; 2) use of small number of cells per sample [210]; 3) automated analysis [211]; 4) completion of an experiment in relatively short time [212]; 5) relatively low cost [213]; and 6) application to all nucleated eukaryotic cells [214]. Due to the various advantages of comet assay, it has been applied in diverse studies [214] including in vivo genotoxicity testing [215]. In previous studies in which the effects of cigarette smoke condensate/cigarette smoke on DNA strand breaks were 
investigated by the comet assay, the focus was only on SSBs [62, 138139]. DSBs are a more disruptive form of strand break compared with SSBs, since they can either lead to cell death or loss of genetic information if left unrepaired, or they may cause neoplastic progression if the repair process is compromised $[128,144]$. Therefore, both single- and double-strand breaks were detected in this work (Chapters II).

Furthermore, we employed state-of-the-art multispectral imaging flow cytometry to detect and visualize oxidative DNA damage in human cervical cancer cells (Chapter III). This work benefited from a sophisticated and yet undisputable visualizing approach to identify cigarette smoke-induced oxidative DNA damage. The oxidative DNA damage can be indirectly visualized with a microscope by immunostaining with anti-8-OHdG antibody. The ImageStream automatically and objectively acquires thousands of images to quantify a specific lesion in single population of cells more efficiently than regular flow cytometer, since the obtained information on the cells can be further expanded to measure various parameters. .

Another strength of this work is the use of cell culture experiments (Chapters II and III). This experimental setting is suitable to understand the mechanistic effect of cigarette smoking under a controlled environment, allowing the results of these studies to be translated to in vivo models. This work also employed an ex vivo study (Chapter IV), which allows the results of such studies to be better translated to the 
human disease. Such studies provide data as proof-of principle, which may serve as a building block toward developing early biomarkers in identifying high-risk population.

\section{Weaknesses}

The main focus of this dissertation was to investigate the effect of cigarette smoke on DNA damage and repair in human cervical and vaginal cells mainly due to its role as a significant cofactor in association with high-risk HPV infection in cervical/vaginal carcinogenesis. However, there are many other forms of damage (i.e. DNA base bulky adducts, DNA cross links, etc.) that can potentially attribute to mutagenicity of those diseases.

Chapter II and III investigate the role of cigarette smoke in HPVtransfected cells using a standardized in vitro model [169] in cervical carcinogenesis. However, it could be beneficial to study HPV-negative normal cervical cells to address the role of HPV infection as either dependent or independent factor as well as to further investigate the possible effect of cigarette smoking (additive or synergistic) in association with HPV infection. It is noteworthy that several unsuccessful attempts were made to culture HPV-negative normal cervical cells.

One of the limitations of Chapter III was the inability to investigate the role of $\mathrm{p} 53$ in DNA repair pathways. Our data demonstrated that the 
level of oxidative stress induced by cigarette smoke condensate is higher in HPV-positive compared with HPV-negative cervical cancer cells, and that the removal of the damage takes place by p53-dependent and independent DNA repair pathways. It may be useful to confirm the results of activation, or lack thereof, of p53 protein expression in human cervical cancer cells by performing western blotting.

Chapter IV investigated whether cigarette smoking, given the infection with high-risk HPV types, leads to detectable DNA damage in vaginal cells by employing the comet assay. One of the advantages of this study was to examine DNA integrity at a single-cell level. However, double-strand break detection might not be the only cigarette smoking induced damage in these cells. The study may very well benefit from detection of other biological endpoints, such as single-strand breaks, oxidative DNA damage, bulky DNA adducts, etc. It is worth noting that remaining vaginal samples were preserved in formalin for future studies.

One of the limitations in researching the association of smoking with HPV infection (Chapter IV) is a lack of information on the duration and intensity of smoking for the study population. The smoking information used in this study was based on self reporting. The association between self reporting and biochemical validation is approximately $85 \%$ [207] and could potentially influence the data interpretation. These data could contribute to further establish a correlation of the factors investigated. Another limitation is that the presented HPV data was based on the detection of the 
collective presence of carcinogenic HPV types instead of providing information on the individual HPV genotypes. Therefore, it may be useful to determine specific HPV genotypes in order to provide further insights into the complex interrelation of smoking and HPV infection in vaginal carcinogenesis.

\section{Future Directions}

Future directions described herein are intended to address issues stated in Weaknesses (Chapter V). The rationale behind these proposed experiments is to strengthen the findings of this dissertation, although these future projects are independent of the completion of this dissertation.

\section{Does cigarette smoke induce other forms of damage in human cervical cancer cells?}

Cigarette smoke-induced genotoxicity results in induction of micronuclei, sister chromatid exchange, chromosomal aberrations, microsatellite instability, DNA strand breaks [58] and oxidative DNA damage $[75,165]$. It has been well established that cigarette smoke accounts for a significant risk factor in developing cancer of various organs [42], including those of the cervix [43-44]. However, a mechanistic 
approach to investigate other forms of damage caused by cigarette smoke in cervical cells has not been pursued. Therefore, a future study could investigate the effect of cigarette smoke in those cells and establish a correlation with HPV infection to broaden the knowledge in cervical carcinogenesis.

\section{Does cigarette smoking and/or HPV infection induce oxidative damage in vaginal cells?}

Cigarette smoke has been shown to cause a variety of oxidative DNA damage, including the formation of 8-oxodG [119-120]. 8-oxodG is a common mutagenic DNA lesion which is formed abundantly by intracellular oxidation and exogenous carcinogens like cigarette smoke $[86,121]$. Mentioned previously, cell blocks of the collected human vaginal samples were also prepared at the time of sample processing. These samples can be used to investigate 8-oxodG expression by immunohistochemistry method. This information further adds to the scarce body of knowledge on the effect of cigarette smoking in vaginal cells.

\section{Significance of this Study}

As mentioned throughout this dissertation, cigarette smoking accounts as a significant cofactor in cervical/vaginal carcinogenesis. The 
significance of the study in Chapter II stems from the fact that DNA lesions and/or persistent DNA strand breaks caused by the inability of the cells to remove the damage, may result in accumulation of mutations leading to cancer [89].

In Chapter IIII of this dissertation, the detection of oxidative DNA damage and its repair in human cervical cancer cells by multispectral imaging flow cytometry analysis was reported. The detection and visualization of oxidative DNA damage in human cervical cancer cells are novel findings of this study, which may serve as early biomarkers of cancer. This is the first demonstration indicating higher degree of 8-oxodG by cigarette smoke constituents in HPV-positive compared to -negative human cervical cells.

To date, there are no other studies that assess a biological endpoint such as DNA strand breaks in vaginal cells in relation to smoking and HPV infection status (Chapter IV). This finding builds on the limited knowledge on the effect of cigarette smoking as a cofactor in vaginal carcinogenesis. 


\section{E. Final notes}

There are number of factors associated with carcinogenic HPV infection of the cervix and vagina that have been implicated in development and progression of cervical/vaginal cancers. Cigarette smoking represents the strongest cofactor [66]. However, in depth experimental investigation is needed to link the numerous epidemiological findings as well as to understand the molecular mechanisms of high-risk HPV-associated vaginal cancer. Indeed, it is not yet clear if all vaginal cancers can be attributed to cofactors such as cigarette smoking in association with oncogenic HPV infection. Finally, the exact mechanism by which cigarette smoke mediates carcinogenesis could provide prophylactic and therapeutic applications that could ultimately be beneficial to women at high risk of or diagnosed with HPV-induced cervical/vaginal abnormalities. 


\section{Table 5.1}

Comprehensive Comet Data

\begin{tabular}{|c|c|c|c|c|c|c|c|c|}
\hline ID \# & $\begin{array}{c}\text { SM } \\
\text { Status }\end{array}$ & $\begin{array}{l}\text { HPV } \\
\text { Status }\end{array}$ & $\begin{array}{c}\text { Mean } \\
\text { TL } \\
(\mu \mathrm{m})\end{array}$ & $\begin{array}{l}\text { Mean } \\
\text { TM } \\
(\mathrm{AU})\end{array}$ & $\begin{array}{c}\text { Mean } \\
T L \\
(\mu \mathrm{m})\end{array}$ & $\begin{array}{l}\text { Mean } \\
\text { TM } \\
(\mathrm{AU})\end{array}$ & \multirow{2}{*}{$\begin{array}{l}\text { Rep. Comet } \\
\text { Image } \\
\text { Alkaline }\end{array}$} & \multirow{2}{*}{$\begin{array}{l}\text { Rep. Comet } \\
\text { Image } \\
\text { Neutral }\end{array}$} \\
\hline & & & \multicolumn{2}{|c|}{ Alkaline } & \multicolumn{2}{|c|}{ Neutral } & & \\
\hline VG-60 & Never & Pos & Undef. & Undef. & 38.01 & 3.79 & & \\
\hline VG-61 & Ever & Neg & 51.29 & 9.07 & 71.88 & 10.63 & $*$ & $a^{2}-2$ \\
\hline VG-62 & Never & Neg & 49.44 & 6.49 & 87.43 & 13.69 & $x^{2}=6$ & 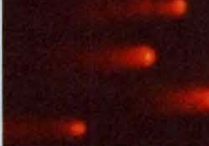 \\
\hline VG-63 & NA & NA & Undef. & Undef. & Undef. & Undef. & & W. \\
\hline VG-64 & Ever & Neg & 56.33 & 9.03 & 63.82 & 8.13 & & $i^{*}$ \\
\hline VG-65 & Never & $\mathrm{Neg}$ & Undef. & Undef. & 42.89 & 4.82 & & \\
\hline VG-66 & NA & NA & Undef. & Undef. & Undef. & Undef. & NA & NA \\
\hline VG-67 & Ever & Neg & Undef. & Undef. & 39.59 & 3.55 & $4^{6}$ & $a^{a}$ \\
\hline VG-68 & Ever & Neg & Undef. & Undef. & 49.82 & 3.24 & & $y$ \\
\hline VG-69 & NA & NA & Undef. & Undef. & Undef. & Undef. & NA & NA \\
\hline
\end{tabular}




\begin{tabular}{|c|c|c|c|c|c|c|c|c|}
\hline ID \# & $\begin{array}{c}\text { SM } \\
\text { Status }\end{array}$ & $\begin{array}{l}\text { HPV } \\
\text { Status }\end{array}$ & $\begin{array}{c}\text { Mean } \\
\text { TL } \\
(\mu \mathrm{m})\end{array}$ & $\begin{array}{c}\text { Mean } \\
\text { TM } \\
\text { (AU) }\end{array}$ & $\begin{array}{c}\text { Mean } \\
\text { TL } \\
(\mu \mathrm{m})\end{array}$ & $\begin{array}{c}\text { Mean } \\
\text { TM } \\
\text { (AU) }\end{array}$ & \multirow{2}{*}{$\begin{array}{c}\text { Rep. Comet } \\
\text { Image } \\
\text { Alkaline }\end{array}$} & \multirow{2}{*}{$\begin{array}{l}\text { Rep. Comet } \\
\text { Image } \\
\text { Neutral }\end{array}$} \\
\hline & & & \multicolumn{2}{|c|}{ Alkaline } & \multicolumn{2}{|c|}{ Neutral } & & \\
\hline VG-70 & Ever & $\mathrm{Neg}$ & Undef. & Undef. & 65.31 & 8.68 & & 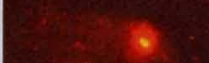 \\
\hline VG-71 & NA & NA & Undef. & Undef. & Undef. & Undef. & NA & \\
\hline VG-72 & Ever & Pos & NA & NA & 53.85 & 4.25 & & 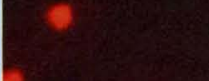 \\
\hline VG-73 & NA & NA & Undef. & Undef. & Undef. & Undef. & & \\
\hline VG-74 & NA & NA & Undef. & Undef. & Undef. & Undef. & & NA \\
\hline VG-75 & NA & NA & Undef. & Undef. & Undef. & Undef. & & NA \\
\hline VG-76 & NA & NA & Undef. & Undef. & Undef. & Undef. & & NA \\
\hline VG-77 & Ever & $\mathrm{Neg}$ & Undef. & Undef. & 21.43 & 1.15 & & 8 \\
\hline VG-78 & Never & $\mathrm{Neg}$ & $\begin{array}{c}102.9 \\
7\end{array}$ & 28.38 & 113.76 & 20.5 & 198 & $x^{6}-4$ \\
\hline VG-79 & Never & Pos & $\begin{array}{c}100.3 \\
3\end{array}$ & 18.28 & 96.08 & 10.32 & & ? \\
\hline VG-80 & Never & Pos & Undef. & Undef. & 60.10 & 5.14 & & \\
\hline
\end{tabular}




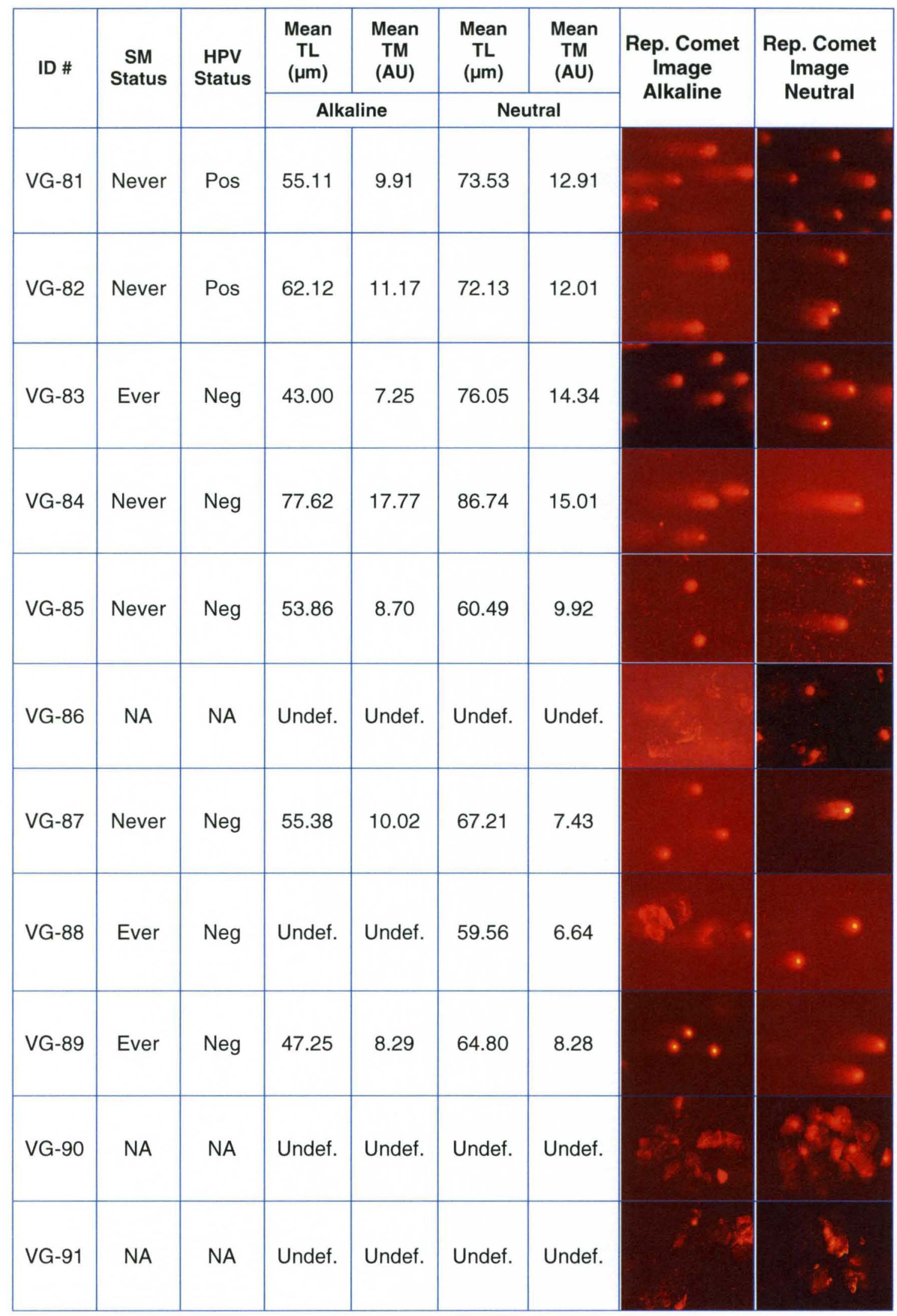




\begin{tabular}{|c|c|c|c|c|c|c|c|c|}
\hline \multirow[t]{2}{*}{ ID \# } & \multirow[t]{2}{*}{$\begin{array}{c}\text { SM } \\
\text { Status }\end{array}$} & \multirow[t]{2}{*}{$\begin{array}{l}\text { HPV } \\
\text { Status }\end{array}$} & $\begin{array}{c}\text { Mean } \\
\text { TL } \\
(\mu \mathrm{m})\end{array}$ & $\begin{array}{l}\text { Mean } \\
\text { TM } \\
\text { (AU) }\end{array}$ & $\begin{array}{c}\text { Mean } \\
\text { TL } \\
(\mu \mathrm{m})\end{array}$ & $\begin{array}{c}\text { Mean } \\
\text { TM } \\
\text { (AU) }\end{array}$ & \multirow{2}{*}{$\begin{array}{l}\text { Rep. Comet } \\
\text { Image } \\
\text { Alkaline }\end{array}$} & \multirow{2}{*}{$\begin{array}{l}\text { Rep. Comet } \\
\text { Image } \\
\text { Neutral }\end{array}$} \\
\hline & & & \multicolumn{2}{|c|}{ Alkaline } & \multicolumn{2}{|c|}{ Neutral } & & \\
\hline VG-92 & Ever & $\mathrm{Neg}$ & 67.73 & 16.98 & 76.35 & 10.94 & $8=4$ & 8 \\
\hline VG-93 & Never & $\mathrm{Neg}$ & Undef. & Undef. & 16.64 & 0.19 & & $\cdot \quad \cdot$ \\
\hline VG-94 & Never & $\mathrm{Neg}$ & 66.94 & 15.59 & 74.94 & 12.98 & & \% \\
\hline VG-95 & Never & $\mathrm{Neg}$ & 55.45 & 10.66 & 72.81 & 13.81 & 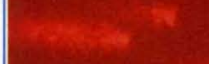 & 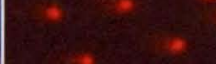 \\
\hline VG-96 & NA & NA & Undef. & Undef. & Undef. & Undef. & & 8. \\
\hline VG-97 & NA & NA & Undef. & Undef. & Undef. & Undef. & Q $e^{2}$ & $6+5=$ \\
\hline VG-98 & Never & $\mathrm{Neg}$ & 62.98 & 10.63 & 83.49 & 15.44 & & 20 \\
\hline VG-99 & Ever & $\mathrm{Neg}$ & Undef. & Undef. & 77.26 & 8.21 & t. & \\
\hline VG-100 & Never & $\mathrm{Neg}$ & 50.08 & 11.60 & 56.71 & 5.62 & & \\
\hline VG-101 & NA & NA & Undef. & Undef. & Undef. & Undef. & 283 & 8 \\
\hline VG-102 & Never & $\mathrm{Neg}$ & 49.67 & 10.83 & 65.33 & 10.05 & $\Leftrightarrow$ & 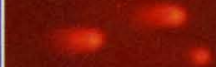 \\
\hline VG-103 & Ever & $\mathrm{Neg}$ & 48.65 & 11.51 & 61.86 & 9.10 & 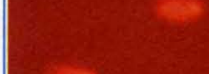 & 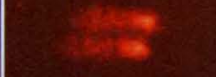 \\
\hline VG-104 & Ever & $\mathrm{Neg}$ & Undef. & Undef. & 14.18 & 0.23 & & 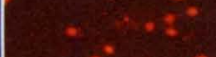 \\
\hline
\end{tabular}




\begin{tabular}{|c|c|c|c|c|c|c|c|c|}
\hline ID \# & $\begin{array}{c}\text { SM } \\
\text { Status }\end{array}$ & $\begin{array}{c}\text { HPV } \\
\text { Status }\end{array}$ & $\begin{array}{c}\text { Mean } \\
\text { TL } \\
(\mu \mathrm{m})\end{array}$ & $\begin{array}{l}\text { Mean } \\
\text { TM } \\
(\mathrm{AU})\end{array}$ & $\begin{array}{c}\text { Mean } \\
\text { TL } \\
(\mu \mathrm{m})\end{array}$ & $\begin{array}{l}\text { Mean } \\
\text { TM } \\
(\mathrm{AU})\end{array}$ & \multirow{2}{*}{$\begin{array}{l}\text { Rep. Comet } \\
\text { Image } \\
\text { Alkaline }\end{array}$} & \multirow{2}{*}{$\begin{array}{c}\text { Rep. Comet } \\
\text { Image } \\
\text { Neutral }\end{array}$} \\
\hline & & & \multicolumn{2}{|c|}{ Alkaline } & \multicolumn{2}{|c|}{ Neutral } & & \\
\hline VG-105 & Ever & Neg & 63.00 & 11.39 & 70.34 & 9.87 & & $+\infty$ \\
\hline VG-106 & Never & Neg & 60.34 & 12.41 & 57.27 & 8.41 & 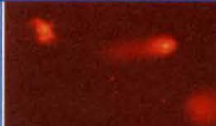 & $*$ \\
\hline VG-107 & Ever & Neg & Undef. & Undef. & 17.45 & 0.85 & & - \\
\hline VG-108 & Ever & Neg & 61.11 & 13.73 & 60.68 & 8.29 & & + \\
\hline VG-109 & NA & NA & Undef. & Undef. & Undef. & Undef. & & Wrise \\
\hline VG-110 & Ever & $\mathrm{Neg}$ & 65.93 & 13.86 & 74.91 & 9.67 & & +2 \\
\hline VG-111 & Never & Pos & Undef. & Undef. & 22.47 & 0.92 & & $=;$ \\
\hline VG-112 & NA & NA & Undef. & Undef. & Undef. & Undef. & & $\frac{60}{8}$ \\
\hline VG-113 & Ever & Pos & Undef. & Undef. & 13.03 & 0.45 & & $\therefore$ \\
\hline VG-114 & Ever & Pos & Undef. & Undef. & 15.57 & 0.41 & & 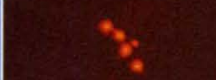 \\
\hline VG-115 & NA & NA & Undef. & Undef. & Undef. & Undef. & 19. & 90 \\
\hline VG-116 & Ever & Pos & Undef. & Undef. & 46.19 & 1.99 & & 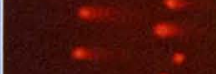 \\
\hline
\end{tabular}




\begin{tabular}{|c|c|c|c|c|c|c|c|c|}
\hline \multirow[t]{2}{*}{ ID \# } & \multirow[t]{2}{*}{$\begin{array}{c}\text { SM } \\
\text { Status }\end{array}$} & \multirow[t]{2}{*}{$\begin{array}{l}\text { HPV } \\
\text { Status }\end{array}$} & $\begin{array}{c}\text { Mean } \\
\text { TL } \\
(\mu \mathrm{m})\end{array}$ & $\begin{array}{l}\text { Mean } \\
\text { TM } \\
\text { (AU) }\end{array}$ & $\begin{array}{c}\text { Mean } \\
\text { TL } \\
(\mu \mathrm{m})\end{array}$ & $\begin{array}{l}\text { Mean } \\
\text { TM } \\
\text { (AU) }\end{array}$ & \multirow{2}{*}{$\begin{array}{l}\text { Rep. Comet } \\
\text { Image } \\
\text { Alkaline }\end{array}$} & \multirow{2}{*}{$\begin{array}{l}\text { Rep. Comet } \\
\text { Image } \\
\text { Neutral }\end{array}$} \\
\hline & & & \multicolumn{2}{|c|}{ Alkaline } & \multicolumn{2}{|c|}{ Neutral } & & \\
\hline VG-117 & Ever & Pos & Undef. & Undef. & 16.44 & 1.03 & & ${ }^{*}$ \\
\hline VG-118 & Never & Pos & Undef. & Undef. & 34.74 & 4.00 & $\because \quad$. & \\
\hline VG-119 & Ever & Pos & Undef. & Undef. & 29.91 & 1.70 & & $\because \quad \because$ \\
\hline VG-120 & Ever & Pos & Undef. & Undef. & 17.98 & 1.47 & sinet. & 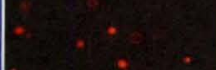 \\
\hline VG-121 & NA & NA & Undef. & Undef. & Undef. & Undef. & $70^{\circ}$ & 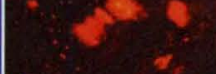 \\
\hline VG-122 & Ever & Pos & Undef. & Undef. & 25.91 & 2.04 & $x=$ & - \\
\hline VG-123 & Ever & Pos & Undef. & Undef. & 35.73 & 1.24 & &.$\quad x$ \\
\hline VG-124 & Never & Pos & Undef. & Undef. & 40.28 & 2.56 & & 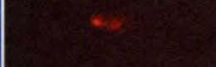 \\
\hline VG-125 & Ever & Pos & 43.19 & 8.30 & 35.08 & 1.76 & & . . \\
\hline VG-126 & Ever & Pos & Undef. & Undef. & 25.79 & 1.84 & & 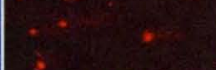 \\
\hline VG-127 & NA & NA & Undef. & Undef. & Undef. & Undef. & & $\therefore \circ .8$ \\
\hline
\end{tabular}




\begin{tabular}{|c|c|c|c|c|c|c|c|c|}
\hline \multirow[t]{2}{*}{ ID \# } & \multirow[t]{2}{*}{$\begin{array}{l}\text { SM } \\
\text { Status }\end{array}$} & \multirow[t]{2}{*}{$\begin{array}{l}\text { HPV } \\
\text { Status }\end{array}$} & $\begin{array}{c}\text { Mean } \\
\text { TL } \\
(\mu \mathrm{m})\end{array}$ & $\begin{array}{c}\text { Mean } \\
\text { TM } \\
(\mathrm{AU})\end{array}$ & $\begin{array}{c}\text { Mean } \\
T L \\
(\mu \mathrm{m})\end{array}$ & $\begin{array}{l}\text { Mean } \\
\text { TM } \\
(\mathrm{AU})\end{array}$ & \multirow{2}{*}{$\begin{array}{l}\text { Rep. Comet } \\
\text { Image } \\
\text { Alkaline }\end{array}$} & \multirow{2}{*}{$\begin{array}{c}\text { Rep. Comet } \\
\text { Image } \\
\text { Neutral }\end{array}$} \\
\hline & & & \multicolumn{2}{|c|}{ Alkaline } & \multicolumn{2}{|c|}{ Neutral } & & \\
\hline VG-128 & Ever & Pos & Undef. & Undef. & 16.55 & 1.03 & 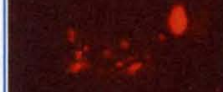 & $\cdot$ \\
\hline VG-129 & Ever & Pos & Undef. & Undef. & 45.83 & 2.45 & 72 & 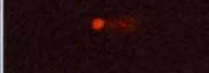 \\
\hline VG-130 & Never & Pos & Undef. & Undef. & 42.92 & 2.41 & & $\therefore$ \\
\hline VG-131 & Never & Pos & Undef. & Undef. & 29.49 & 1.65 & & $\because$ \\
\hline VG-132 & Ever & Pos & Undef. & Undef. & 20.29 & 1.08 & & : \\
\hline VG-133 & Never & Pos & Undef. & Undef. & 51.52 & 4.96 & NA & s \\
\hline VG-134 & Ever & Pos & Undef. & Undef. & 15.50 & 0.77 & NA & 8 \\
\hline VG-135 & NA & NA & Undef. & Undef. & Undef. & Undef. & NA & NA \\
\hline VG-136 & Ever & Pos & Undef. & Undef. & 12.87 & 0.23 & NA & - \\
\hline VG-137 & Ever & Pos & Undef. & Undef. & 28.18 & 3.97 & NA & 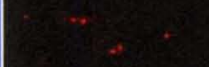 \\
\hline VG-138 & NA & NA & NA & NA & NA & NA & NA & NA \\
\hline VG-139 & Never & Pos & Undef. & Undef. & 54.71 & 2.71 & NA & $*$ \\
\hline VG-140 & Ever & Pos & Undef. & Undef. & 46.46 & 3.01 & NA & . \\
\hline
\end{tabular}




\begin{tabular}{|c|c|c|c|c|c|c|c|c|}
\hline \multirow[t]{2}{*}{ ID \# } & \multirow[t]{2}{*}{$\begin{array}{c}\text { SM } \\
\text { Status }\end{array}$} & \multirow[t]{2}{*}{$\begin{array}{l}\text { HPV } \\
\text { Status }\end{array}$} & $\begin{array}{c}\text { Mean } \\
\text { TL } \\
(\mu \mathrm{m})\end{array}$ & $\begin{array}{c}\text { Mean } \\
\text { TM } \\
\text { (AU) }\end{array}$ & $\begin{array}{c}\text { Mean } \\
\text { TL } \\
(\mu \mathrm{m})\end{array}$ & $\begin{array}{c}\text { Mean } \\
\text { TM } \\
\text { (AU) }\end{array}$ & \multirow{2}{*}{$\begin{array}{l}\text { Rep. Comet } \\
\text { Image } \\
\text { Alkaline }\end{array}$} & \multirow{2}{*}{$\begin{array}{c}\text { Rep. Comet } \\
\text { Image } \\
\text { Neutral }\end{array}$} \\
\hline & & & \multicolumn{2}{|c|}{ Alkaline } & \multicolumn{2}{|c|}{ Neutral } & & \\
\hline VG-141 & Ever & Pos & Undef. & Undef. & 13.09 & 0.31 & NA & \\
\hline VG-142 & Ever & Pos & Undef. & Undef. & 16.15 & 0.66 & NA & \\
\hline VG-143 & Never & Pos & Undef. & Undef. & 15.83 & 0.71 & NA & \\
\hline VG-144 & Ever & Pos & Undef. & Undef. & 17.69 & 0.64 & NA & \\
\hline VG-145 & Ever & Pos & Undef. & Undef. & 19.82 & 1.58 & NA & \\
\hline VG-146 & NA & NA & Undef. & Undef. & Undef. & Undef. & NA & \\
\hline VG-147 & Never & Pos & Undef. & Undef. & 39.95 & 1.77 & NA & \\
\hline VG-148 & Ever & Pos & Undef. & Undef. & 18.54 & 0.49 & NA & \\
\hline VG-149 & Ever & Pos & Undef. & Undef. & 20.11 & 1.27 & NA & \\
\hline VG-150 & Ever & Pos & Undef. & Undef. & 15.64 & 0.40 & NA & \\
\hline VG-151 & Ever & Pos & Undef. & Undef. & 17.85 & 0.95 & NA & \\
\hline VG-152 & Ever & Pos & Undef. & Undef. & 15.44 & 0.89 & NA & \\
\hline
\end{tabular}




\begin{tabular}{|c|c|c|c|c|c|c|c|c|}
\hline \multirow[t]{2}{*}{ ID \# } & \multirow[t]{2}{*}{$\begin{array}{c}\text { SM } \\
\text { Status }\end{array}$} & \multirow[t]{2}{*}{$\begin{array}{l}\text { HPV } \\
\text { Status }\end{array}$} & $\begin{array}{c}\text { Mean } \\
T L \\
(\mu \mathrm{m})\end{array}$ & $\begin{array}{c}\text { Mean } \\
\text { TM } \\
\text { (AU) }\end{array}$ & $\begin{array}{c}\text { Mean } \\
\text { TL } \\
(\mu \mathrm{m})\end{array}$ & $\begin{array}{c}\text { Mean } \\
\text { TM } \\
(\mathrm{AU})\end{array}$ & \multirow{2}{*}{$\begin{array}{c}\text { Rep. Comet } \\
\text { Image } \\
\text { Alkaline }\end{array}$} & \multirow{2}{*}{$\begin{array}{l}\text { Rep. Comet } \\
\text { Image } \\
\text { Neutral }\end{array}$} \\
\hline & & & \multicolumn{2}{|c|}{ Alkaline } & \multicolumn{2}{|c|}{ Neutral } & & \\
\hline VG-153 & Ever & Pos & Undef. & Undef. & 22.57 & 0.84 & NA & \\
\hline VG-153 & Ever & Pos & Undef. & Undef. & 22.57 & 0.84 & NA & \\
\hline VG-154 & Ever & Pos & Undef. & Undef. & 14.91 & 0.34 & NA & \\
\hline VG-155 & NA & NA & Undef. & Undef. & Undef. & Undef. & NA & \\
\hline VG-156 & Ever & Pos & Undef. & Undef. & 32.15 & 2.44 & NA & \\
\hline VG-157 & NA & NA & Undef. & Undef. & Undef. & Undef. & NA & \\
\hline VG-158 & Ever & Pos & Undef. & Undef. & 14.75 & 0.55 & NA & \\
\hline VG-159 & Ever & Pos & Undef. & Undef. & 24.31 & 1.75 & NA & \\
\hline VG-160 & NA & NA & Undef. & Undef. & Undef. & Undef. & NA & \\
\hline
\end{tabular}

TL: tail length

TM: tail moment

AU: arbitrary unit

NA: not available

SM: smoking 

[1] A. Jemal, R. Siegel, J. Xu, E. Ward, Cancer Statistics, 2010, CA Cancer J Clin, (2010).

[2] S.W. Wyatt, M. Lancaster, D. Bottorf,, F. Ross, History of tobacco use among Kentucky women diagnosed with invasive cervical cancer: 1997-1998, J Ky Med Assoc, 99 (2001) 537-539.

[3] M.J. Merino, Vaginal cancer: the role of infectious and environmental factors, Am J Obstet Gynecol, 165 (1991) 1255-1262.

[4] T.H. Duong, L.C. Flowers, Vulvo-vaginal cancers: risks, evaluation, prevention and early detection, Obstet Gynecol Clin North Am, 34 (2007) 783$802, x$.

[5] R. DeMay, The art and science of cytopathology, ASCP Press, 1995.

[6] A.P. Warwick, C.W. Redman, P.W. Jones, A.A. Fryer, J. Gilford, J. Alldersea, R.C. Strange, Progression of cervical intraepithelial neoplasia to cervical cancer: interactions of cytochrome P450 CYP2D6 EM and glutathione s-transferase GSTM1 null genotypes and cigarette smoking, Br J Cancer, 70 (1994) 704-708.

[7] W.A. McIndoe, M.R. McLean, R.W. Jones, P.R. Mullins, The invasive potential of carcinoma in situ of the cervix, Obstet Gynecol, 64 (1984) 451-458.

[8] J.T. Wharton, G. Tortolero-Luna, A.C. Linares, A. Malpica, V.V. Baker, E. Cook, E. Johnson, M. Follen Mitchell, Vaginal intraepithelial neoplasia and vaginal cancer, Obstet Gynecol Clin North Am, 23 (1996) 325-345.

[9] F. Dancuart, L. Delclos, J.T. Wharton, E.G. Silva, Primary squamous cell carcinoma of the vagina treated by radiotherapy: a failures analysis--the M. D. Anderson Hospital experience 1955-1982, Int J Radiat Oncol Biol Phys, 14 (1988) 745-749.

[10] A.L. Herbst, T.H. Green, Jr., H. Ulfelder, Primary carcinoma of the vagina. An analysis of 68 cases, Am J Obstet Gynecol, 106 (1970) 210-218.

[11] R. DeMay, Art and Science of Cytopathology 1996.

[12] M. Anderson, Systemic Pathology/Third Edition Churchill Livingston 1991. 
[13] J.D. Woodruff, Carcinoma in situ of the vagina, Clin Obstet Gynecol, 24 (1981) 485-501.

[14] P.E. Castle, Beyond human papillomavirus: the cervix, exogenous secondary factors, and the development of cervical precancer and cancer, J Low Genit Tract Dis, 8 (2004) 224-230.

[15] X. Castellsague, N. Munoz, Chapter 3: Cofactors in human papillomavirus carcinogenesis--role of parity, oral contraceptives, and tobacco smoking, J Natl Cancer Inst Monogr, (2003) 20-28.

[16] X. Castellsague, F.X. Bosch, N. Munoz, Environmental co-factors in HPV carcinogenesis, Virus Res, 89 (2002) 191-199.

[17] M.J. Khan, E.E. Partridge, S.S. Wang, M. Schiffman, Socioeconomic status and the risk of cervical intraepithelial neoplasia grade 3 among oncogenic human papillomavirus DNA-positive women with equivocal or mildly abnormal cytology, Cancer, 104 (2005) 61-70.

[18] H. zur Hausen, E.M. de Villiers, L. Gissmann, Papillomavirus infections and human genital cancer, Gynecol Oncol, 12 (1981) S124-128.

[19] A.T. Lorincz, R. Reid, A.B. Jenson, M.D. Greenberg, W. Lancaster, R.J. Kurman, Human papillomavirus infection of the cervix: relative risk associations of 15 common anogenital types, Obstet Gynecol, 79 (1992) 328-337.

[20] Y. Sun, J. Eluf-Neto, F.X. Bosch, N. Munoz, J.M. Walboomers, C.J. Meijer, K.V. Shah, B. Clayman, R.P. Viscidi, Serum antibodies to human papillomavirus 16 proteins in women from Brazil with invasive cervical carcinoma, Cancer Epidemiol Biomarkers Prev, 8 (1999) 935-940.

[21] M. Schiffman, P.E. Castle, Human papillomavirus: epidemiology and public health, Arch Pathol Lab Med, 127 (2003) 930-934.

[22] M.H. Schiffman, H.M. Bauer, R.N. Hoover, A.G. Glass, D.M. Cadell, B.B. Rush, D.R. Scott, M.E. Sherman, R.J. Kurman, S. Wacholder, et al., Epidemiologic evidence showing that human papillomavirus infection causes most cervical intraepithelial neoplasia, J Natl Cancer Inst, 85 (1993) 958-964.

[23] J.M. Walboomers, M.V. Jacobs, M.M. Manos, F.X. Bosch, J.A. Kummer, K.V. Shah, P.J. Snijders, J. Peto, C.J. Meijer, N. Munoz, Human papillomavirus is a necessary cause of invasive cervical cancer worldwide, J Pathol, 189 (1999) 1219.

[24] A. Duenas-Gonzalez, M. Lizano, M. Candelaria, L. Cetina, C. Arce, E. Cervera, Epigenetics of cervical cancer. An overview and therapeutic perspectives, Mol Cancer, 4 (2005) 38. 
[25] N. Munoz, F.X. Bosch, S. de Sanjose, R. Herrero, X. Castellsague, K.V. Shah, P.J. Snijders, C.J. Meijer, Epidemiologic classification of human papillomavirus types associated with cervical cancer, N Engl J Med, 348 (2003) 518-527.

[26] H. zur Hausen, Papillomaviruses causing cancer: evasion from host-cell control in early events in carcinogenesis, J Natl Cancer Inst, 92 (2000) 690-698.

[27] S. Motoyama, C.A. Ladines-Llave, S. Luis Villanueva, T. Maruo, The role of human papilloma virus in the molecular biology of cervical carcinogenesis, Kobe J Med Sci, 50 (2004) 9-19.

[28] F. Thierry, M.A. Benotmane, C. Demeret, M. Mori, S. Teissier, C. Desaintes, A genomic approach reveals a novel mitotic pathway in papillomavirus carcinogenesis, Cancer Res, 64 (2004) 895-903.

[29] K. Munger, P.M. Howley, Human papillomavinus immortalization and transformation functions, Virus Res, 89 (2002) 213-228.

[30] H. zur Hausen, Papillomaviruses and cancer: from basic studies to clinical application, Nat Rev Cancer, 2 (2002) 342-350.

[31] S. Duensing, K. Munger, Human papillomavirus type 16 E7 oncoprotein can induce abnormal centrosome duplication through a mechanism independent of inactivation of retinoblastoma protein family members, J Virol, 77 (2003) 1233112335.

[32] F.X. Bosch, T. Rohan, A. Schneider, I. Frazer, H. Pfister, X. Castellsague, S. de Sanjose, V. Moreno, L.M. Puig-Tintore, P.G. Smith, N. Munoz, H. zur Hausen, Papillomavirus research update: highlights of the Barcelona HPV 2000 international papillomavirus conference, J Clin Pathol, 54 (2001) 163-175.

[33] X. Liu, A. Clements, K. Zhao, R. Marmorstein, Structure of the human Papillomavirus E7 oncoprotein and its mechanism for inactivation of the retinoblastoma tumor suppressor, J Biol Chem, 281 (2006) 578-586.

[34] A.M. Kaufmann, C. Backsch, A. Schneider, M. Durst, HPV induced cervical carcinogenesis: molecular basis and vaccine development, Zentralbl Gynakol, 124 (2002) 511-524.

[35] P.E. Castle, S. Wacholder, M.E. Sherman, A.T. Lorincz, A.G. Glass, D.R. Scott, B.B. Rush, F. Demuth, M. Schiffman, Absolute risk of a subsequent abnormal pap among oncogenic human papillomavirus DNA-positive, cytologically negative women, Cancer, 95 (2002) 2145-2151. 
[36] S. Duensing, K. Munger, Centrosomes, genomic instability, and cervical carcinogenesis, Crit Rev Eukaryot Gene Expr, 13 (2003) 9-23.

[37] M.J. Kaiserman, W.S. Rickert, Carcinogens in tobacco smoke: benzo[a]pyrene from Canadian cigarettes and cigarette tobacco, Am J Public Health, 82 (1992) 1023-1026.

[38] IARC, IARC Monographs programme on the evaluation of the carcinogenic risk of chemicals to humans. Preamble, IARC Monogr Eval Carcinog Risk Chem Hum, 39 (1986) 13-32.

[39] S.C.M. Chen, Mainstream Smoke Chemical Analysis for 2R4F Kentucky Reference Cigarette, Contributions to Tobacco Research 20 (2003).

[40] O. Chambers, The Reference Cigarette (2001).

[41] W. Winkelstein, Jr., Smoking and cancer of the uterine cervix: hypothesis, Am J Epidemiol, 106 (1977) 257-259.

[42] D.M. Parkin, P. Pisani, A.D. Lopez, E. Masuyer, At least one in seven cases of cancer is caused by smoking. Global estimates for 1985, Int J Cancer, 59 (1994) 494-504.

[43] A.L. Coker, A.J. Rosenberg, M.F. McCann, B.S. Hulka, Active and passive cigarette smoke exposure and cervical intraepithelial neoplasia, Cancer Epidemiol Biomarkers Prev, 1 (1992) 349-356.

[44] P.E. Castle, S. Wacholder, A.T. Lorincz, D.R. Scott, M.E. Sherman, A.G. Glass, B.B. Rush, J.E. Schussler, M. Schiffman, A prospective study of highgrade cervical neoplasia risk among human papillomavirus-infected women, $J$ Natl Cancer Inst, 94 (2002) 1406-1414.

[45] H. Haverkos, M. Rohrer, W. Pickworth, The cause of invasive cervical cancer could be multifactorial, Biomed Pharmacother, 54 (2000) 54-59.

[46] H.W. Haverkos, G. Soon, S.L. Steckley, W. Pickworth, Cigarette smoking and cervical cancer: Part I: a meta-analysis, Biomed Pharmacother, 57 (2003) 6777.

[47] M.J. Arends, C.H. Buckley, M. Wells, Aetiology, pathogenesis, and pathology of cervical neoplasia, J Clin Pathol, 51 (1998) 96-103.

[48] K. McIntyre-Seltman, P.E. Castle, R. Guido, M. Schiffman, C.M. Wheeler, Smoking is a risk factor for cervical intraepithelial neoplasia grade 3 among oncogenic human papillomavirus DNA-positive women with equivocal or mildly abnormal cytology, Cancer Epidemiol Biomarkers Prev, 14 (2005) 1165-1170. 
[49] L. Gissmann, V. Diehl, H.J. Schultz-Coulon, H. zur Hausen, Molecular cloning and characterization of human papilloma virus DNA derived from a laryngeal papilloma, J Virol, 44 (1982) 393-400.

[50] G.Y. Ho, A.S. Kadish, R.D. Burk, J. Basu, P.R. Palan, M. Mikhail, S.L. Romney, HPV 16 and cigarette smoking as risk factors for high-grade cervical intra-epithelial neoplasia, Int J Cancer, 78 (1998) 281-285.

[51] Y. Nakao, X. Yang, M. Yokoyama, M.M. Pater, A. Pater, Malignant transformation of human ectocervical cells immortalized by HPV 18: in vitro model of carcinogenesis by cigarette smoke, Carcinogenesis, 17 (1996) 577-583.

[52] X. Yang, G. Jin, Y. Nakao, M. Rahimtula, M.M. Pater, A. Pater, Malignant transformation of HPV 16-immortalized human endocervical cells by cigarette smoke condensate and characterization of multistage carcinogenesis, Int J Cancer, 65 (1996) 338-344.

[53] D. Hellberg, S. Nilsson, N.J. Haley, D. Hoffman, E. Wynder, Smoking and cervical intraepithelial neoplasia: nicotine and cotinine in serum and cervical mucus in smokers and nonsmokers, Am J Obstet Gynecol, 158 (1988) 910-913.

[54] M.F. McCann, D.E. Irwin, L.A. Walton, B.S. Hulka, J.L. Morton, C.M. Axelrad, Nicotine and cotinine in the cervical mucus of smokers, passive smokers, and nonsmokers, Cancer Epidemiol Biomarkers Prev, 1 (1992) 125-129.

[55] B. Prokopczyk, J.E. Cox, D. Hoffmann, S.E. Waggoner, Identification of tobacco-specific carcinogen in the cervical mucus of smokers and nonsmokers, $J$ Natl Cancer Inst, 89 (1997) 868-873.

[56] B. Prokopczyk, N. Trushin, J. Leszczynska, S.E. Waggoner, K. El-Bayoumy, Human cervical tissue metabolizes the tobacco-specific nitrosamine, 4(methylnitrosamino)-1-(3-pyridyl)-1-butanone, via alpha-hydroxylation and carbonyl reduction pathways, Carcinogenesis, 22 (2001) 107-114.

[57] A.A. Melikian, P. Sun, B. Prokopczyk, K. El-Bayoumy, D. Hoffmann, X. Wang, S. Waggoner, Identification of benzo[a]pyrene metabolites in cervical mucus and DNA adducts in cervical tissues in humans by gas chromatographymass spectrometry, Cancer Lett, 146 (1999) 127-134.

[58] D.M. DeMarini, Genotoxicity of tobacco smoke and tobacco smoke condensate: a review, Mutat Res, 567 (2004) 447-474.

[59] T. Nakayama, M. Kaneko, M. Kodama, C. Nagata, Cigarette smoke induces DNA single-strand breaks in human cells, Nature, 314 (1985) 462-464. 
[60] S. Fielding, C. Short, K. Davies, N. Wald, B.A. Bridges, R. Waters, Studies on the ability of smoke from different types of cigarettes to induce DNA singlestrand breaks in cultured human cells, Mutat Res, 214 (1989) 147-151.

[61] Y. Yoshie, H. Ohshima, Synergistic induction of DNA strand breakage by cigarette tar and nitric oxide, Carcinogenesis, 18 (1997) 1359-1363.

[62] Q. Yang, M. Hergenhahn, A. Weninger, H. Bartsch, Cigarette smoke induces direct DNA damage in the human B-lymphoid cell line Raji, Carcinogenesis, 20 (1999) 1769-1775.

[63] L. Kjellberg, G. Hallmans, A.M. Ahren, R. Johansson, F. Bergman, G. Wadell, T. Angstrom, J. Dillner, Smoking, diet, pregnancy and oral contraceptive use as risk factors for cervical intra-epithelial neoplasia in relation to human papillomavirus infection, Br J Cancer, 82 (2000) 1332-1338.

[64] A. Szarewski, M.J. Jarvis, P. Sasieni, M. Anderson, R. Edwards, S.J. Steele, J. Guillebaud, J. Cuzick, Effect of smoking cessation on cervical lesion size, Lancet, 347 (1996) 941-943.

[65] J.B. McClure, E. Westbrook, S.J. Curry, D.W. Wetter, Proactive, motivationally enhanced smoking cessation counseling among women with elevated cervical cancer risk, Nicotine Tob Res, 7 (2005) 881-889.

[66] B.S. Madsen, H.L. Jensen, A.J. van den Brule, J. Wohlfahrt, M. Frisch, Risk factors for invasive squamous cell carcinoma of the vulva and vagina--populationbased case-control study in Denmark, Int J Cancer, 122 (2008) 2827-2834.

[67] J.R. Daling, M.M. Madeleine, S.M. Schwartz, K.A. Shera, J.J. Carter, B. McKnight, P.L. Porter, D.A. Galloway, J.K. McDougall, H. Tamimi, A population-based study of squamous cell vaginal cancer: HPV and cofactors, Gynecol Oncol, 84 (2002) 263-270.

[68] J.R. Daling, K.J. Sherman, T.G. Hislop, C. Maden, M.T. Mandelson, A.M. Beckmann, N.S. Weiss, Cigarette smoking and the risk of anogenital cancer, Am J Epidemiol, 135 (1992) 180-189.

[69] F. Levi, L. Randimbison, C. La Vecchia, G. Erler, V.C. Te, Multiple primary cancers to indicate associations between smoking and cancer incidence: Vaud and Neuchatel, Switzerland, 1974-1994, Int J Cancer, 76 (1998) 913-914.

[70] J.F. Sherman, S.L. Mount, M.F. Evans, J. Skelly, L. Simmons-Arnold, G.H. Eltabbakh, Smoking increases the risk of high-grade vaginal intraepithelial neoplasia in women with oncogenic human papillomavirus, Gynecol Oncol, 110 (2008) 396-401. 
[71] K. Hellman, C. Silfversward, B. Nilsson, A.C. Hellstrom, B. Frankendal, F. Pettersson, Primary carcinoma of the vagina: factors influencing the age at diagnosis. The Radiumhemmet series 1956-96, Int J Gynecol Cancer, 14 (2004) 491-501.

[72] L.A. Brinton, P.C. Nasca, K. Mallin, C. Schairer, J. Rosenthal, R. Rothenberg, E. Yordan, Jr., R.M. Richart, Case-control study of in situ and invasive carcinoma of the vagina, Gynecol Oncol, 38 (1990) 49-54.

[73] A.L. Jackson, L.A. Loeb, The contribution of endogenous sources of DNA damage to the multiple mutations in cancer, Mutation research, 477 (2001) 7-21.

[74] P.A. Cerutti, B.F. Trump, Inflammation and oxidative stress in carcinogenesis, Cancer Cells, 3 (1991) 1-7.

[75] S. Mena, A. Ortega, J.M. Estrela, Oxidative stress in environmental-induced carcinogenesis, Mutat Res, 674 (2009) 36-44.

[76] I. Dalle-Donne, R. Rossi, R. Colombo, D. Giustarini, A. Milzani, Biomarkers of oxidative damage in human disease, Clinical chemistry, 52 (2006) 601-623.

[77] M. Valko, D. Leibfritz, J. Moncol, M.T. Cronin, M. Mazur, J. Telser, Free radicals and antioxidants in normal physiological functions and human disease, The international journal of biochemistry \& cell biology, 39 (2007) 44-84.

[78] H. Wiseman, H. Kaur, B. Halliwell, DNA damage and cancer: measurement and mechanism, Cancer Lett, 93 (1995) 113-120.

[79] A. Javeri, X.X. Huang, F. Bernerd, R.S. Mason, G.M. Halliday, Human 8oxoguanine-DNA glycosylase 1 protein and gene are expressed more abundantly in the superficial than basal layer of human epidermis, DNA Repair (Amst), 7 (2008) 1542-1550.

[80] K.C. Cheng, D.S. Cahill, H. Kasai, S. Nishimura, L.A. Loeb, 8Hydroxyguanine, an abundant form of oxidative DNA damage, causes G----T and A---C substitutions, The Journal of biological chemistry, 267 (1992) 166-172.

[81] T.G. Rossman, E.I. Goncharova, Spontaneous mutagenesis in mammalian cells is caused mainly by oxidative events and can be blocked by antioxidants and metallothionein, Mutat Res, 402 (1998) 103-110.

[82] M.L. Wood, M. Dizdaroglu, E. Gajewski, J.M. Essigmann, Mechanistic studies of ionizing radiation and oxidative mutagenesis: genetic effects of a single 8-hydroxyguanine (7-hydro-8-oxoguanine) residue inserted at a unique site in a viral genome, Biochemistry, 29 (1990) 7024-7032. 
[83] J.T. Thaiparambil, M.V. Vadhanam, C. Srinivasan, C.G. Gairola, R.C. Gupta, Time-dependent formation of 8-oxo-deoxyguanosine in the lungs of mice exposed to cigarette smoke, Chem Res Toxicol, 20 (2007) 1737-1740.

[84] H. Kiyosawa, M. Suko, H. Okudaira, K. Murata, T. Miyamoto, M.H. Chung, H. Kasai, S. Nishimura, Cigarette smoking induces formation of 8hydroxydeoxyguanosine, one of the oxidative DNA damages in human peripheral leukocytes, Free Radic Res Commun, 11 (1990) 23-27.

[85] S. Loft, K. Vistisen, M. Ewertz, A. Tjonneland, K. Overvad, H.E. Poulsen, Oxidative DNA damage estimated by 8-hydroxydeoxyguanosine excretion in humans: influence of smoking, gender and body mass index, Carcinogenesis, 13 (1992) 2241-2247.

[86] S. Asami, T. Hirano, R. Yamaguchi, Y. Tomioka, H. Itoh, H. Kasai, Increase of a type of oxidative DNA damage, 8-hydroxyguanine, and its repair activity in human leukocytes by cigarette smoking, Cancer Res, 56 (1996) 2546-2549.

[87] M. Christmann, M.T. Tomicic, W.P. Roos, B. Kaina, Mechanisms of human DNA repair: an update, Toxicology, 193 (2003) 3-34.

[88] X. Wu, J. Gu, H.B. Grossman, C.I. Amos, C. Etzel, M. Huang, Q. Zhang, R.E. Millikan, S. Lerner, C.P. Dinney, M.R. Spitz, Bladder cancer predisposition: a multigenic approach to DNA-repair and cell-cycle-control genes, Am J Hum Genet, 78 (2006) 464-479.

[89] V.A. Bohr, DNA repair fine structure and its relations to genomic instability, Carcinogenesis, 16 (1995) 2885-2892.

[90] X. Wu, H. Zhao, R. Suk, D.C. Christiani, Genetic susceptibility to tobaccorelated cancer, Oncogene, 23 (2004) 6500-6523.

[91] E.C. Friedberg, How nucleotide excision repair protects against cancer, Nat Rev Cancer, 1 (2001) 22-33.

[92] E. Schwarz, U.K. Freese, L. Gissmann, W. Mayer, B. Roggenbuck, A. Stremlau, H. zur Hausen, Structure and transcription of human papillomavirus sequences in cervical carcinoma cells, Nature, 314 (1985) 111-114.

[93] K.H. Vousden, X. Lu, Live or let die: the cell's response to p53, Nat Rev Cancer, 2 (2002) 594-604.

[94] M. Hollstein, D. Sidransky, B. Vogelstein, C.C. Harris, p53 mutations in human cancers, Science, 253 (1991) 49-53. 
[95] N.B, Atkin, Solid tumor cytogenetics. Progress since 1979, Cancer Genet Cytogenet, 40 (1989) 3-12.

[96] B.A. Werness, A.J. Levine, P.M. Howley, Association of human papillomavirus types 16 and 18 E6 proteins with p53, Science, 248 (1990) 76-79.

[97] M. Scheffner, B.A. Werness, J.M. Huibregtse, A.J. Levine, P.M. Howley, The E6 oncoprotein encoded by human papillomavirus types 16 and 18 promotes the degradation of p53, Cell, 63 (1990) 1129-1136.

[98] K. Miwa, S. Miyamoto, H. Kato, T. Imamura, M. Nishida, Y. Yoshikawa, Y. Nagata, N. Wake, The role of p53 inactivation in human cervical cell carcinoma development, Br J Cancer, 71 (1995) 219-226.

[99] T. Crook, D. Wrede, K.H. Vousden, p53 point mutation in HPV negative human cervical carcinoma cell lines, Oncogene, 6 (1991) 873-875.

[100] D. Wrede, J.A. Tidy, T. Crook, D. Lane, K.H. Vousden, Expression of RB and p53 proteins in HPV-positive and HPV-negative cervical carcinoma cell lines, Mol Carcinog, 4 (1991) 171-175.

[101] D.P. Lane, Cancer. p53, guardian of the genome, Nature, 358 (1992) 15-16.

[102] S.P. Hussain, P. Amstad, P. He, A. Robles, S. Lupold, I. Kaneko, M. Ichimiya, S. Sengupta, L. Mechanic, S. Okamura, L.J. Hofseth, M. Moake, M. Nagashima, K.S. Forrester, C.C. Harris, p53-induced up-regulation of MnSOD and GPx but not catalase increases oxidative stress and apoptosis, Cancer Res, 64 (2004) 2350-2356.

[103] M. Tan, S. Li, M. Swaroop, K. Guan, L.W. Oberley, Y. Sun, Transcriptional activation of the human glutathione peroxidase promoter by $\mathrm{p} 53, \mathrm{~J}$ Biol Chem, 274 (1999) 12061-12066.

[104] A.V. Budanov, A.A. Sablina, E. Feinstein, E.V. Koonin, P.M. Chumakov, Regeneration of peroxiredoxins by p53-regulated sestrins, homologs of bacterial AhpD, Science, 304 (2004) 596-600.

[105] A.A. Sablina, A.V. Budanov, G.V. Iyinskaya, L.S. Agapova, J.E. Kravchenko, P.M. Chumakov, The antioxidant function of the p53 tumor suppressor, Nat Med, 11 (2005) 1306-1313.

[106] M. Scheffner, Ubiquitin, E6-AP, and their role in p53 inactivation, Pharmacol Ther, 78 (1998) 129-139.

[107] S. Hietanen, S. Lain, E. Krausz, C. Blattner, D.P. Lane, Activation of p53 in cervical carcinoma cells by small molecules, Proc Natl Acad Sci U S A, 97 (2000) 8501-8506. 
[108] K. Butz, L. Shahabeddin, C. Geisen, D. Spitkovsky, A. Ullmann, F. HoppeSeyler, Functional p53 protein in human papillomavirus-positive cancer cells, Oncogene, 10 (1995) 927-936.

[109] K. Butz, N. Whitaker, C. Denk, A. Ullmann, C. Geisen, F. Hoppe-Seyler, Induction of the p53-target gene GADD45 in HPV-positive cancer cells, Oncogene, 18 (1999) 2381-2386.

[110] R.L. Paquette, Y.Y. Lee, S.P. Wilczynski, A. Karmakar, M. Kizaki, C.W. Miller, H.P. Koeffler, Mutations of p53 and human papillomavirus infection in cervical carcinoma, Cancer, 72 (1993) 1272-1280.

[111] Global cancer facts and figures, in, 2010.

[112] A.L. Coker, C.P. DeSimone, K.S. Eggleston, C. Hopenhayn, J. Nee, T. Tucker, Smoking and survival among Kentucky women diagnosed with invasive cervical cancer: 1995-2005, Gynecol Oncol, 112 (2009) 365-369.

[113] J.M. Mundt, S.S. Hah, R.A. Sumbad, V. Schramm, P.T. Henderson, Incorporation of extracellular 8-oxodG into DNA and RNA requires purine nucleoside phosphorylase in MCF-7 cells, Nucleic Acids Res, 36 (2008) 228-236.

[114] American Cancer Society, Cervical Cancer. What are the risk factors for cervical cancer?, in, Atlanta, GA 2008.

[115] D. Hoffmann, I. Hoffmann, K. El-Bayoumy, The less harmful cigarette: a controversial issue. a tribute to Ernst L. Wynder, Chem Res Toxicol, 14 (2001) 767-790.

[116] S.S. Hecht, Tobacco carcinogens, their biomarkers and tobacco-induced cancer, Nat Rev Cancer, 3 (2003) 733-744.

[117] S.S. Hecht, Tobacco smoke carcinogens and lung cancer, J Natl Cancer Inst, 91 (1999) 1194-1210.

[118] M.J. Thun, S.J. Henley, E.E. Calle, Tobacco use and cancer: an epidemiologic perspective for geneticists, Oncogene, 21 (2002) 7307-7325.

[119] P. Leanderson, C. Tagesson, Cigarette smoke-induced DNA-damage: role of hydroquinone and catechol in the formation of the oxidative DNA-adduct, 8hydroxydeoxyguanosine, Chemico-biological interactions, 75 (1990) 71-81.

[120] P. Leanderson, C. Tagesson, Cigarette smoke-induced DNA damage in cultured human lung cells: role of hydroxyl radicals and endonuclease activation, Chemico-biological interactions, 81 (1992) 197-208. 
[121] T. Paz-Elizur, R. Ben-Yosef, D. Elinger, A. Vexler, M. Krupsky, A. Berrebi, A. Shani, E. Schechtman, L. Freedman, Z. Livneh, Reduced repair of the oxidative 8-oxoguanine DNA damage and risk of head and neck cancer, Cancer research, 66 (2006) 11683-11689.

[122] T. Kato, H. Nagasawa, C. Warner, R. Okayasu, J.S. Bedford, Cytotoxicity of cigarette smoke condensate is not due to DNA double strand breaks: Comparative studies using radiosensitive mutant and wild-type $\mathrm{CHO}$ cells, Int J Radiat Biol, 83 (2007) 583-591.

[123] A.P. Albino, X. Huang, E.D. Jorgensen, D. Gietl, F. Traganos, Z. Darzynkiewicz, Induction of DNA double-strand breaks in A549 and normal human pulmonary epithelial cells by cigarette smoke is mediated by free radicals, Int J Oncol, 28 (2006) 1491-1505.

[124] A. Sancar, L.A. Lindsey-Boltz, K. Unsal-Kacmaz, S. Linn, Molecular mechanisms of mammalian DNA repair and the DNA damage checkpoints, Annu Rev Biochem, 73 (2004) 39-85.

[125] V. Calini, C. Urani, M. Camatini, Comet assay evaluation of DNA singleand double-strand breaks induction and repair in C3H10T1/2 cells, Cell Biol Toxicol, 18 (2002) 369-379.

[126] F. Kassie, W. Parzefall, S. Knasmuller, Single cell gel electrophoresis assay: a new technique for human biomonitoring studies, Mutat Res, 463 (2000) 13-31.

[127] E. Rojas, M.C. Lopez, M. Valverde, Single cell gel electrophoresis assay: methodology and applications, J Chromatogr B Biomed Sci Appl, 722 (1999) 225-254.

[128] G. Chu, Double strand break repair, J Biol Chem, 272 (1997) 24097-24100.

[129] H. zur Hausen, Human genital cancer: synergism between two virus infections or synergism between a virus infection and initiating events?, Lancet, 2 (1982) 1370-1372.

[130] N.P. Singh, M.T. McCoy, R.R.'Tice, E.L. Schneider, A simple technique for quantitation of low levels of DNA damage in individual cells, Exp Cell Res, 175 (1988) 184-191.

[131] N.P. Singh, Microgels for estimation of DNA strand breaks, DNA protein crosslinks and apoptosis, Mutat Res, 455 (2000) 111-127.

[132] N.P. Singh, C.H. Muller, R.E. Berger, Effects of age on DNA double-strand breaks and apoptosis in human sperm, Fertil Steril, 80 (2003) 1420-1430. 
[133] F. Festa, T. Aglitti, G. Duranti, R. Ricordy, P. Perticone, R. Cozzi, Strong antioxidant activity of ellagic acid in mammalian cells in vitro revealed by the comet assay, Anticancer Res, 21 (2001) 3903-3908.

[134] L.T. Wu, C.C. Chu, J.G. Chung, C.H. Chen, L.S. Hsu, J.K. Liu, S.C. Chen, Effects of tannic acid and its related compounds on food mutagens or hydrogen peroxide-induced DNA strands breaks in human lymphocytes, Mutat Res, 556 (2004) 75-82.

[135] H.C. Pillsbury, C.C. Bright, Comparison of aliquot and complete sample procedure for the determination of nicotine in cigarette smoke, J Assoc Off Anal Chem, 55 (1972) 636-638.

[136] P.L. Olive, J.P. Banath, R.E. Durand, Heterogeneity in radiation-induced DNA damage and repair in tumor and normal cells measured using the "comet" assay, Radiat Res, 122 (1990) 86-94.

[137] A.R. Collins, The comet assay. Principles, applications, and limitations, Methods Mol Biol, 203 (2002) 163-177.

[138] I. Sinko, M. Morocz, J. Zadori, K. Kokavszky, I. Rasko, Effect of cigarette smoking on DNA damage of human cumulus cells analyzed by comet assay, Reprod Toxicol, 20 (2005) 65-71.

[139] G. Speit, T. Witton-Davies, W. Heepchantree, K. Trenz, H. Hoffmann, Investigations on the effect of cigarette smoking in the comet assay, Mutat Res, 542 (2003) 33-42.

[140] J.C. Willey, R.C. Grafstrom, C.E. Moser, Jr., C. Ozanne, K. Sundquvist, C.C. Harris, Biochemical and morphological effects of cigarette smoke condensate and its fractions on normal human bronchial epithelial cells in vitro, Cancer Res, 47 (1987) 2045-2049.

[141] R. Gopalakrishna, Z.H. Chen, U. Gundimeda, Tobacco smoke tumor promoters, catechol and hydroquinone, induce oxidative regulation of protein kinase $C$ and influence invasion and metastasis of lung carcinoma cells, Proc Natl Acad Sci U S A, 91 (1994) 12233-12237.

[142] C. Lambert, J. Li, K. Jonscher, T.C. Yang, P. Reigan, M. Quintana, J. Harvey, B.M. Freed, Acrolein inhibits cytokine gene expression by alkylating cysteine and arginine residues in the NF-kappaB1 DNA binding domain, J Biol Chem, 282 (2007) 19666-19675.

[143] K.W. Caldecott, Mammalian single-strand break repair: mechanisms and links with chromatin, DNA Repair (Amst), 6 (2007) 443-453. 
[144] S. Nocentini, Rejoining kinetics of DNA single- and double-strand breaks in normal and DNA ligase-deficient cells after exposure to ultraviolet $\mathrm{C}$ and gamma radiation: an evaluation of ligating activities involved in different DNA repair processes, Radiat Res, 151 (1999) 423-432.

[145] J. Pincheira, P. Carrera, K. Marcelain, C. De La Torre, Hepatocytes, rather than leukocytes reverse DNA damage in vivo induced by whole body gammairradiation of mice, as shown by the alkaline comet assay, Biol Res, 41 (2008) 217-225.

[146] T.J. Sohn, N.K. Kim, H.J. An, J.J. Ko, T.R. Hahn, D. Oh, S.G. Lee, R. Roy, K.Y. Cha, Y.K. Oh, Gene amplification and expression of the DNA repair enzyme, N-methylpurine-DNA glycosylase (MPG) in HPV-infected cervical neoplasias, Anticancer Res, 21 (2001) 2405-2411.

[147] B. Clarke, M. Gordon, M. Moodley, R. Naidoo, R. Chetty, Microsatellite analysis of early stage (Ia-IIb) uterine cervical squamous carcinoma, Int J Surg Pathol, 11 (2003) 253-260.

[148] N. Sizemore, H. Mukhtar, L.H. Couch, P.C. Howard, E.A. Rorke, Differential response of normal and HPV immortalized ectocervical epithelial cells to B[a]P, Carcinogenesis, 16 (1995) 2413-2418.

[149] S. Alam, M.J. Conway, H.S. Chen, C. Meyers, The cigarette smoke carcinogen benzo[a]pyrene enhances human papillomavirus synthesis, J Virol, 82 (2008) 1053-1058.

[150] Z. Feng, W. Hu, Y. Hu, M.S. Tang, Acrolein is a major cigarette-related lung cancer agent: Preferential binding at p53 mutational hotspots and inhibition of DNA repair, Proc Natl Acad Sci U S A, 103 (2006) 15404-15409.

[151] E. Moustacchi, DNA damage and repair: consequences on dose-responses, Mutat Res, 464 (2000) 35-40.

[152] R. Godschalk, J. Nair, F.J. van Schooten, A. Risch, P. Drings, K. Kayser, H. Dienemann, H. Bartsch, Comparison of multiple DNA adduct types in tumor adjacent human lung tissue: effect of cigarette smoking, Carcinogenesis, 23 (2002) 2081-2086.

[153] Y.L. Huang, C.Y. Chuang, F.C. Sung, C.Y. Chen, Thioredoxin overexpression modulates remodeling factors in stress responses to cigarette smoke, J Toxicol Environ Health A, 71 (2008) 1490-1498.

[154] T.L. Goncalves, F. Erthal, C.L. Corte, L.G. Muller, C.M. Piovezan, C.W. Nogueira, J.B. Rocha, Involvement of oxidative stress in the pre-malignant and malignant states of cervical cancer in women, Clin Biochem, 38 (2005) 10711075. 
[155] M. Das, D.R. Bickers, H. Mukhtar, Effect of ellagic acid on hepatic and pulmonary xenobiotic metabolism in mice: studies on the mechanism of its anticarcinogenic action, Carcinogenesis, 6 (1985) 1409-1413.

[156] A.R. Sudheer, S. Muthukumaran, N. Devipriya, V.P. Menon, Ellagic acid, a natural polyphenol protects rat peripheral blood lymphocytes against nicotineinduced cellular and DNA damage in vitro: with the comparison of $\mathrm{N}$ acetylcysteine, Toxicology, 230 (2007) 11-21.

[157] S. Chakraborty, M. Roy, R.K. Bhattacharya, Prevention and repair of DNA damage by selected phytochemicals as measured by single cell gel electrophoresis, J Environ Pathol Toxicol Oncol, 23 (2004) 215-226.

[158] S. Tsuda, N. Matsusaka, S. Ueno, N. Susa, Y.F. Sasaki, The influence of antioxidants on cigarette smoke-induced DNA single-strand breaks in mouse organs: a preliminary study with the alkaline single cell gel electrophoresis assay, Toxicol Sci, 54 (2000) 104-109.

[159] W.A. Smith, J.M. Arif, R.C. Gupta, Effect of cancer chemopreventive agents on microsome-mediated DNA adduction of the breast carcinogen dibenzo[a,1]pyrene, Mutat Res, 412 (1998) 307-314.

[160] W.A. Smith, J.W. Freeman, R.C. Gupta, Effect of chemopreventive agents on DNA adduction induced by the potent mammary carcinogen dibenzo[a,1]pyrene in the human breast cells MCF-7, Mutat Res, 480-481 (2001) 97-108.

[161] H.W. Haverkos, Multifactorial etiology of cervical cancer: a hypothesis, MedGenMed, 7 (2005) 57.

[162] W.A. Pryor, D.G. Prier, D.F. Church, Electron-spin resonance study of mainstream and sidestream cigarette smoke: nature of the free radicals in gasphase smoke and in cigarette tar, Environ Health Perspect, 47 (1983) 345-355.

[163] E.M. Park, Y.M. Park, Y.S. Gwak, Oxidative damage in tissues of rats exposed to cigarette smoke, Free Radic Biol Med, 25 (1998) 79-86.

[164] E.S. Copeland, A National Institutes of Health Workshop report. Free radicals in promotion--a chemical pathology study section workshop, Cancer Res, 43 (1983) 5631-5637.

[165] A. Valavanidis, T. Vlachogianni, K. Fiotakis, Tobacco smoke: involvement of reactive oxygen species and stable free radicals in mechanisms of oxidative damage, carcinogenesis and synergistic effects with other respirable particles, Int J Environ Res Public Health, 6 (2009) 445-462. 
[166] M. Scheffner, K. Munger, J.C. Byrne, P.M. Howley, The state of the p53 and retinoblastoma genes in human cervical carcinoma cell lines, Proc Natl Acad Sci U S A, 88 (1991) 5523-5527.

[167] H. Offer, R. Wolkowicz, D. Matas, S. Blumenstein, Z. Livneh, V. Rotter, Direct involvement of p53 in the base excision repair pathway of the DNA repair machinery, FEBS Lett, 450 (1999) 197-204.

[168] S. Prost, C.O. Bellamy, A.R. Clarke, A.H. Wyllie, D.J. Harrison, p53independent DNA repair and cell cycle arrest in embryonic stem cells, FEBS Lett, 425 (1998) 499-504.

[169] R.N. Fichorova, J.G. Rheinwald, D.J. Anderson, Generation of papillomavirus-immortalized cell lines from normal human ectocervical, endocervical, and vaginal epithelium that maintain expression of tissue-specific differentiation proteins, Biol Reprod, 57 (1997) 847-855.

[170] A. Moktar, S. Ravoori, M.V. Vadhanam, C.G. Gairola, R.C. Gupta, Cigarette smoke-induced DNA damage and repair detected by the comet assay in HPV-transformed cervical cells, Int J Oncol, 35 (2009) 1297-1304.

[171] S. Loft, H.E. Poulsen, Cancer risk and oxidative DNA damage in man, J Mol Med, 74 (1996) 297-312.

[172] M.J. Wilmer, A. de Graaf-Hess, H.J. Blom, H.B. Dijkman, L.A. Monnens, L.P. van den Heuvel, E.N. Levtchenko, Elevated oxidized glutathione in cystinotic proximal tubular epithelial cells, Biochem Biophys Res Commun, 337 (2005) 610-614.

[173] L. Wei, P.E. Gravitt, H. Song, A.M. Maldonado, M.A. Ozbun, Nitric oxide induces early viral transcription coincident with increased DNA damage and mutation rates in human papillomavirus-infected cells, Cancer research, 69 (2009) 4878-4884.

[174] R.E. Shackelford, W.K. Kaufmann, R.S. Paules, Oxidative stress and cell cycle checkpoint function, Free Radic Biol Med, 28 (2000) 1387-1404.

[175] X. Liu, H. Conner, T. Kobayashi, H. Kim, F. Wen, S. Abe, Q. Fang, X. Wang, M. Hashimoto, P. Bitterman, S.I. Rennard, Cigarette smoke extract induces DNA damage but not apoptosis in human bronchial epithelial cells, Am J Respir Cell Mol Biol, 33 (2005) 121-129.

[176] T.D. Kessis, R.J. Slebos, W.G. Nelson, M.B. Kastan, B.S. Plunkett, S.M. Han, A.T. Lorincz, L. Hedrick, K.R. Cho, Human papillomavirus 16 E6 expression disrupts the p53-mediated cellular response to DNA damage, Proc Natl Acad Sci U S A, 90 (1993) 3988-3992. 
[177] S. Srivastava, Y.A. Tong, K. Devadas, Z.Q. Zou, Y. Chen, K.F. Pirollo, E.H. Chang, The status of the p53 gene in human papilloma virus positive or negative cervical carcinoma cell lines, Carcinogenesis, 13 (1992) 1273-1275.

[178] J. Zhou, J. Ahn, S.H. Wilson, C. Prives, A role for p53 in base excision repair, EMBO J, 20 (2001) 914-923.

[179] J.M. Dypbukt, L. Atzori, C.C. Edman, R.C. Grafstrom, Thiol status and cytopathological effects of acrolein in normal and xeroderma pigmentosum skin fibroblasts, Carcinogenesis, 14 (1993) 975-980.

[180] D. Chakravarti, P.C. Mailander, E.L. Cavalieri, E.G. Rogan, Evidence that error-prone DNA repair converts dibenzo[a,l]pyrene-induced depurinating lesions into mutations: formation, clonal proliferation and regression of initiated cells carrying H-ras oncogene mutations in early preneoplasia, Mutat Res, 456 (2000) 17-32.

[181] F.H. Sillman, R.G. Fruchter, Y.S. Chen, L. Camilien, A. Sedlis, E. McTigue, Vaginal intraepithelial neoplasia: risk factors for persistence, recurrence, and invasion and its management, Am J Obstet Gynecol, 176 (1997) 93-99.

[182] M. Sugase, T. Matsukura, Distinct manifestations of human papillomaviruses in the vagina, Int J Cancer, 72 (1997) 412-415.

[183] G.Y. Ho, R. Bierman, L. Beardsley, C.J. Chang, R.D. Burk, Natural history of cervicovaginal papillomavirus infection in young women, $\mathrm{N}$ Engl J Med, 338 (1998) 423-428.

[184] J.W. Sellors, T.L. Karwalajtys, J. Kaczorowski, J.B. Mahony, A. Lytwyn, S. Chong, J. Sparrow, A. Lorincz, Incidence, clearance and predictors of human papillomavirus infection in women, CMAJ, 168 (2003) 421-425.

[185] S.S. Hecht, DNA adduct formation from tobacco-specific N-nitrosamines, Mutat Res, 424 (1999) 127-142.

[186] N.P. Singh, A rapid method for the preparation of single-cell suspensions from solid tissues, Cytometry, 31 (1998) 229-232.

[187] P. McCullagh, J.A. Nelder, Generalized linear models, Second Edition., Chapman and Hall, London 1989.

[188] R.C. Gupta, Munagala R., M.V. Vadhanam, B. Nagarajan, S. Ravoori, DNA adduct accumulation during the course of human cervical cancer development, and during and after radiotherapy, Toxicology Letters S08-02 (2009) S16-S36. 
[189] A. Schneider, M. Hotz, L. Gissmann, Increased prevalence of human papillomaviruses in the lower genital tract of pregnant women, Int J Cancer, 40 (1987) 198-201.

[190] C. Palle, S. Bangsboll, B. Andreasson, Cervical intraepithelial neoplasia in pregnancy, Acta Obstet Gynecol Scand, 79 (2000) 306-310.

[191] W.K. Chan, G. Klock, H.U. Bernard, Progesterone and glucocorticoid response elements occur in the long control regions of several human papillomaviruses involved in anogenital neoplasia, J Virol, 63 (1989) 3261-3269.

[192] R. Mittal, K. Tsutsumi, A. Pater, M.M. Pater, Human papillomavirus type 16 expression in cervical keratinocytes: role of progesterone and glucocorticoid hormones, Obstet Gynecol, 81 (1993) 5-12.

[193] M. Hampl, H. Sarajuuri, N. Wentzensen, H.G. Bender, V. Kueppers, Effect of human papillomavirus vaccines on vulvar, vaginal, and anal intraepithelial lesions and vulvar cancer, Obstet Gynecol, 108 (2006) 1361-1368.

[194] J.A. Dodge, G.H. Eltabbakh, S.L. Mount, R.P. Walker, A. Morgan, Clinical features and risk of recurrence among patients with vaginal intraepithelial neoplasia, Gynecol Oncol, 83 (2001) 363-369.

[195] D.M. Parkin, F. Bray, Chapter 2: The burden of HPV-related cancers, Vaccine, 24 Suppl 3 (2006) S3/11-25.

[196] P.E. Castle, M. Schiffman, A.G. Glass, B.B. Rush, D.R. Scott, S. Wacholder, A. Dunn, R.D. Burk, Human papillomavirus prevalence in women who have and have not undergone hysterectomies, J Infect Dis, 194 (2006) 17021705.

[197] M. Schiffman, R. Herrero, R. Desalle, A. Hildesheim, S. Wacholder, A.C. Rodriguez, M.C. Bratti, M.E. Sherman, J. Morales, D. Guillen, M. Alfaro, M. Hutchinson, T.C. Wright, D. Solomon, Z. Chen, J. Schussler, P.E. Castle, R.D. Burk, The carcinogenicity of human papillomavirus types reflects viral evolution, Virology, 337 (2005) 76-84.

[198] M. Stanley, Immune responses to human papillomavirus, Vaccine, 24 Suppl 1 (2006) S16-22.

[199] K. Middleton, W. Peh, S. Southern, H. Griffin, K. Sotlar, T. Nakahara, A. El-Sherif, L. Morris, R. Seth, M. Hibma, D. Jenkins, P. Lambert, N. Coleman, J. Doorbar, Organization of human papillomavirus productive cycle during neoplastic progression provides a basis for selection of diagnostic markers, J Virol, 77 (2003) 10186-10201. 
[200] H. Ikenberg, M. Runge, A. Goppinger, A. Pfleiderer, Human papillomavirus DNA in invasive carcinoma of the vagina, Obstet Gynecol, 76 (1990) 432-438.

[201] R.S. Ostrow, D.A. Manias, B.A. Clark, M. Fukushima, T. Okagaki, L.B. Twiggs, A.J. Faras, The analysis of carcinomas of the vagina for human papillomavirus DNA, Int J Gynecol Pathol, 7 (1988) 308-314.

[202] S. Duensing, K. Munger, Mechanisms of genomic instability in human cancer: insights from studies with human papillomavirus oncoproteins, Int J Cancer, 109 (2004) 157-162.

[203] I.D. Morris, S. llott, L. Dixon, D.R. Brison, The spectrum of DNA damage in human sperm assessed by single cell gel electrophoresis (Comet assay) and its relationship to fertilization and embryo development, Hum Reprod, 17 (2002) 990-998.

[204] G.L. Eddy, R.D. Marks, Jr., M.C. Miller, 3rd, P.B. Underwood, Jr., Primary invasive vaginal carcinoma, Am J Obstet Gynecol, 165 (1991) 292-296; discussion 296-298.

[205] R.G. Stock, A.S. Chen, J. Seski, A 30-year experience in the management of primary carcinoma of the vagina: analysis of prognostic factors and treatment modalities, Gynecol Oncol, 56 (1995) 45-52.

[206] M. Al-Kurdi, J.M. Monaghan, Thirty-two years experience in management of primary tumours of the vagina, Br J Obstet Gynaecol, 88 (1981) 1145-1150.

[207] D.L. Patrick, A. Cheadle, D.C. Thompson, P. Diehr, T. Koepsell, S. Kinne, The validity of self-reported smoking: a review and meta-analysis, Am J Public Health, 84 (1994) 1086-1093.

[208] American Cancer Society: Cervica Cancer. What are the risk factors for cervical cancer? Atlanta, GA in, 2008.

[209] B.N. Ames, J. McCann, E. Yamasaki, Methods for detecting carcinogens and mutagens with the Salmonella/mammalian-microsome mutagenicity test, Mútat Res, 31 (1975) 347-364.

[210] D. Anderson, T.W. Yu, B.J. Phillips, P. Schmezer, The effect of various antioxidants and other modifying agents on oxygen-radical-generated DNA damage in human lymphocytes in the COMET assay, Mutat Res, 307 (1994) 261271.

[211] W. Bocker, W. Rolf, T. Bauch, W.U. Muller, C. Streffer, Automated comet assay analysis, Cytometry, 35 (1999) 134-144. 
[212] A.R. Collins, S.J. Duthie, V.L. Dobson, Direct enzymic detection of endogenous oxidative base damage in human lymphocyte DNA, Carcinogenesis, 14 (1993) 1733-1735.

[213] C. Betti, R. Barale, B.L. Pool-Zobel, Comparative studies on cytotoxic and genotoxic effects of two organic mercury compounds in lymphocytes and gastric mucosa cells of Sprague-Dawley rats, Environ Mol Mutagen, 22 (1993) 172-180.

[214] V.W.C. Wong, Y.T. Szeto, A.R. Collins, I.F.F. Benzie, The comet assay: a biomonitoring tool for nutraceutical research, Current Topics in Nutraceutical Research 3(2005).

[215] S. Brendler-Schwaab, A. Hartmann, S. Pfuhler, G. Speit, The in vivo comet assay: use and status in genotoxicity testing, Mutagenesis, 20 (2005) 245-254. 


\section{APPENDIX}




\author{
ABBREVIATIONS \\ HPV: Human Papillomavirus \\ SSBs: Single-Strand Breaks \\ DSBs: Double-Strand Breaks \\ CSC: Cigarette Smoke Condensate \\ LSIL: Low-grade Squamous Intraepithelial Lesion \\ HSIL: High-grade Squamous Intraepithelial Lesion \\ T-ZONE: Transformation Zone \\ pRb: Retinoblastoma protein \\ PAHs: Polycyclic Aromatic Hydrocarbons \\ NNK: nitrosamine 4-(methylnitrosamino)-1-(3-pyridyl)-1-butanone \\ BP: benzo[a]pyrene \\ ROS: Reactive Oxygen Species \\ 8-oxodG: 8-oxo-7,8-dihydro-2'-deoxyguanosine \\ BER: Base Excision Repair \\ SCGE: Single Cell Gel Electrophoresis \\ TL: Tail Length \\ TM: Tail Moment
}




\title{
CURRICULUM VITAE
}

\author{
Afsoon Moktar \\ Department of Pharmacology and Toxicology \\ University of Louisville Health Sciences Center \\ Louisville, KY 40202 \\ Phone (502) 852-3684 \\ Emailafsoon1@aol.com
}

PERSONAL

Ph.D., Department of Pharmacology and Toxicology

University of Louisville, Louisville, KY: 2006-2010

MASTER OF SCIENCE IN PHARMACOLOGY AND TOXICOLOGY - University of Louisville, Louisville, KY

MASTER OF BUSINESS AdMINISTRATION - Bellarmine University, Louisville, KY

BACHELOR OF HEALTH SCIENCE, CYTOTECHNOLoGy - University of Louisville, Louisville, KY

BACHELOR OF SCIENCE IN NURSING - University of Tehran, Tehran, Iran

EMPLOYMENT HISTORY
UNIVERSITY OF LOUISVILLE — LOUISVILLE, KY
PRN CYTOTECHNOLOGIST, DEPARTMENT OF PATHOLOGY
BELLARMINE UNIVERSITY LOUISVILLE, KY
ASSISTANT PROFESSOR, CYTOTECHNOLOGY PROGRAM
INSTRUCTOR, CYTOTECHNOLOGY PROGRAM
MEDICAL LABORATORY CONSULTANTS — LOUISVILLE, KY
PRN CYTOTECHNOLOGIST
UNIVERSITY OF LOUISVILLE — LOUISVILLE, KY
INSTRUCTOR, CYTOTECHNOLOGY PROGRAM
JEFFERSON COUNTY PUBLIC SCHOOL SYSTEM — LOUISVILLE, KY
SUBSTITUTE TEACHER
SHAHID RAJAII CHILDREN'S HOSPITAL - KARA, IRAN
REGISTERED NURSE

American Society of Cytotechnolgy, 51st Annual National Scientific Meeting, Orlando, FL: Nov 2003

Kentuckiana Cytology Society, Louisville, KY: Oct 2003, Mar 2003, and Oct 2000

Professional Education and Training on SurePath Technology, Burlington, NC: Sep 2002

Kentucky Pathology Society State Meeting, Louisville, KY: Sep 2000

Annual Cytopathology Conference, Louisville, KY: Mar 1999

Nursing and Health Science Careers Fair Committee, Bellarmine University: Apr 2002 
Dean's List / Dean's Scholar, University of Louisville: 1995-1997

Volunteer Service Award, Baptist Home East Nursing Home: 1995-2002

Clinical Pathology Associates (CPA) Student Award: 1997

Outstanding Graduating Student in School of Allied Health Sciences: 1997

\section{BOARD CERTIFICATION}

Certified Cytotechnologist, CT (ASCP), American Society of Clinical Pathologists

Board of Registry: May 1997 \# 11782

\section{PROFESSIONAL AFFILIATIONS}

Member, American Association of Cancer Research: 2006-2007 and 2008-Present

Member, AED Pre-medical Honor Society: 1998-Present

Member, Colden Key National Honor Society: 1996-Present

Member, Phi Kappa Phi National Honor Society: 1996-Present

Newsletter Editor / Local Arrangement Chair, Kentuckiana Cytology Society: 2002-2004

Member, American Society for Cytopathology: 2002-2003

Member, American Society for Cytotechnology: 2001-2002

\section{PRESENTATIONS}

Annual Meeting Presentation, American Association of Cancer Research, Washington, DC: April, 2008, 2010

Research of Louisville, Louisville, KY: Oct 2008

James Graham Brown Cancer Center Retreat, Louisville KY: Nov 2008

Annual Meeting Presentation, American Association of Cancer Research, Los Angeles, CA: Apr 2007

American Society of Cytopathology, San Diego, CA: Nov 2005

Cytomorphology of Endocervical Adenocarcinoma, Kentuckiana Cytology Society, Louisville, KY: Oct 2000

\section{PUBLICATIONS}

\section{ARTICLES:}

Moktar A, Ravoori S., Vadhanam MV, Gairola GC, and Gupta RC Cigarette Smoke-Induced DNA Damage and Repair Detected by the Comet Assay in HPV-Transformed Cervical Cells; Int J Oncol. 2009 Dec; 35(6):1297-304

Moktar A, Singh R, Vadhanam MV, Ravoori S, Gairola GC, Lillard JW, and Gupta RC Cigarette smoke condensate-induced oxidative DNA damage and its removal in cervical cancer cell lines; Mutation Research. 2010 August, communicated.

Moktar A, Ravoori S, Vadhanam MV, Pan J, Rai SN, Jenson AB, Parker LP, Gupta RC The interplay of cigarette smoking and HPV infection in human vaginal abnormalities: an ex vivo study; Clinical Cancer Research. 2010 Sept., communicated.

\section{ABSTRACTS:}

Unverferth M, Moktar A. (2005) An Alternative Approach to Ten Percent Rescreen of Gynecologic Specimens as a Quality Control Method: Is $100 \%$ Prescreening a Solution?; ActaCytologica

Moktar A, Ravoori S., Vadhanam MV, Gairola GC, and Gupta RC (2007) Cigarette Smoke-Induced DNA Damage Detected by Comet Assay in HPV-Transformed Cervical Cells; Proc. Am. Assoc. Cancer Res., 48, Abst. \# 3478 
Moktar A, Parker LP, Gordinier ME, Metzinger DS, and Gupta RC (2008) DNA Strand Breaks in Human Vaginal Cells as Determined by Comet Assay; Proc. Am. Assoc. Cancer Res., 49, Abst. \# 583 p. 137

Moktar A, Singh R, Lillard JW, Vadhanam MV and Gupta RC (2008) Detection of 8-oxodG in Cigarette Smoke Condensate-Treated Human Ectocervical Cells by Image Based Flow Cytometry; Proc. Am. Assoc. Cancer Res., 49, Abst. \# 3141 p. 745

Ravoori S., Vadhanam MV, kausar H, Moktar A, Vuppalapati PK, Schultz D, Gupta RC (2008) Effect of Select Berries on Estrogen-Induced Mammary Tissue Proliferation; Proc. Am. Assoc. Cancer Res., 49, Abst. \# 3821 p. 905

Moktar A, Vadhanam MV, Singh R, Gairola CG, Lillard JW, and Gupta RC (2010) Cigarette Smoke Condensate-Induced Oxidative DNA Damage and its Removal in Cervical Cancer Cell Lines; Proc. Am. Assoc. Cancer Res 